\title{
THE ECONOMIC VALUE OF AIR-POLLUTION-RELATED HEALTH RISKS IN CHINA
}

\section{DISSERTATION}

\author{
Presented in Partial Fulfillment of the Requirements for \\ the Degree Doctor of Philosophy in the \\ Graduate School of The Ohio State University
}

\author{
By \\ Xiaoqi Guo, M.A. \\ $* * * * *$ \\ The Ohio State University \\ 2006
}

Dissertation Committee:

Approved by

Professor Timothy C. Haab, Adviser

Professor Alan Randall

Professor James K. Hammitt

Adviser

Professor Brian Roe

Graduate Program in Agricultural, Environmental and Development Economics 
Copyright by

Xiaoqi Guo

2006 


\begin{abstract}
This dissertation studies the economic valuation of air-pollution-related health risks in China, by applying two different valuation methods: the compensating wage differential method and the contingent valuation method. By using the compensating wage differential (CWD) method, the tradeoff between workers' wage and the on-the-job fatality risk workers bear in the labor market is estimated, with consideration of the market opportunities faced by workers in different regions. The result shows that a positive compensating wage differential for on-the-job fatality risk exists in China; and this wage differential convexly decreases with the local unemployment rate. The value of a statistical life (VSL) computed from the estimate varies from 12,000 to 120,000 US dollars, with different estimates of the fatality risk and regressions with and without the local unemployment rates considered.
\end{abstract}

By using the contingent valuation (CV) method, an individual interview survey is conducted to elicit resident's willingness-to-pay (WTP) for the health risk reductions of asthma and mortality. Binary choice WTP question is used in the in-person interview. The questionnaire is designed to test the hypothesis that the private provision and the public/government provision mechanisms of the health risk reductions have no 
significantly different effect to people's WTP. Higher WTP for the public/government provision is implied by the theories of altruism and warm glow.

Probit model is used to regress respondent's yes-no answers with the independent variables. The results show that, for the asthma risk reduction, the public/government provision mechanism has no significant effect to WTP, comparing to the private provision mechanism; for the mortality risk reduction, the public/government provision has a significantly negative effect to WTP. The possible reason for this negative effect is that respondents expected that the government was not very likely to provide the public health service to reduce the risk of mortality. Within-group analysis shows that the perceived effectiveness and trust are the major reasons of the stated preference of respondents on the provision mechanisms. This result rejects the hypothesis that the public/government provision would yield higher WTP because of altruistic or warm glow incentives.

In the CV study, the scope/scale effects of WTP to the magnitude of risk reduction and to the description of the severity of disease symptoms are also tested. For the asthma risk case, results suggest that the scope/scale effects are increasing with the income of respondents, which could be explained as that the respondents with higher income have better capability to understand the questionnaire in general as well as the small risk probability. For the mortality risk case, no significant scope/scale effect of WTP to the magnitude of risk reduction is found. A possible reason is that the magnitude of the mortality risk is even smaller, thus it is even more difficult for respondents to understand the probability of the mortality risk. Another possible reason is that respondents may have different perceived risk than the stated risk in the questionnaire. 
The estimated median value of a statistical case of asthma from the CV study is about 2400 US dollars, while the estimated median VSL is about 24,000 US dollars. Possible reasons of the discrepancy between the results generated by the CWD and the CV methods are discussed. Comparing these results to other studies, I suggest the interval of 20,000 to 60,000 US dollars as the VSL for researchers and policy makers.

The contribution of this dissertation is that it brings international experience and understanding to the undeveloped field of environmental health valuation in China; and ultimately it would strengthen the scientific basis of environmental decision-making in China. The empirical results of value of a statistical life and illness are very useful for research and policy-making in the fields of environment, public health and work safety. 
Dedicated to my parents 


\section{ACKNOWLEDGMENTS}

I thank my advisor, Timothy Haab, for his intellectual and administrative support throughout my doctoral program. I thank James Hammitt for his valuable guide throughout the whole procedure of the production of this dissertation. I thank Alan Randall for his help and expertise in seeing this dissertation completion.

I am grateful for the financial support provided by the Ohio Agricultural Research and Development. This research was conducted with collaboration of the China Project of the Harvard University Center for the Environment (HUCE) and Harvard Division of Engineering and Applied Sciences. It was also supported by grants to the Harvard China Project from the the V. Kann Rasmussen Foundation and the Henry Luce Foundation. The household survey was funded by China Project grants from the V. Kann Rasmussen Foundation, the Harvard University Asia Center, and the Volvo Research Foundations. The support of all of these funds is gratefully acknowledged. I also thank the Research Center for the Contemporary China of Peking University for their help on the questionnaire wording and the implementation of the survey. 
I thank Chris Nielsen for the tremendous amount of work he has done related to this research.

I also thank Rong Xu, Lu Xu, Qi Chen, Ruoyan Meng, my colleagues of AED Econ and China Project for their help in my life and study.

Lastly, I thank my parents who always believe me and support me. 


\section{VITA}

April, $1979 \ldots \ldots \ldots \ldots \ldots$. . . . . Born - Beijing, China

$2001 \ldots \ldots \ldots \ldots \ldots \ldots \ldots$. . . . . E . Economics, Peking University, China

$2002 \ldots \ldots \ldots \ldots \ldots \ldots$. . . . . . . Economics, The Ohio State University

2002-present . . . . . . . . . . . . . Graduate Associate, The Ohio State University

\section{FIELDS OF STUDY}

Major Field: Agricultural, Environmental and Development Economics

Areas of Specialization:

Environmental and Resource Economics 


\section{TABLE OF CONTENTS}

ABSTRACT

\section{CHAPTERS}

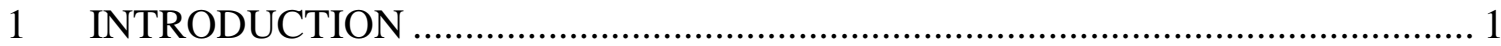

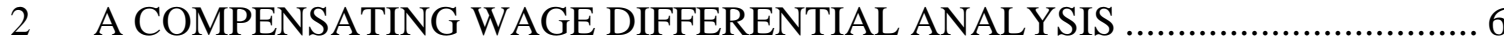

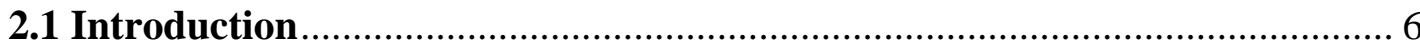

2.2 Theory and Model of the Wage Differential Method .................................. 8

2.3 The Assumption of Perfect Competitive Labor Market ............................ 11

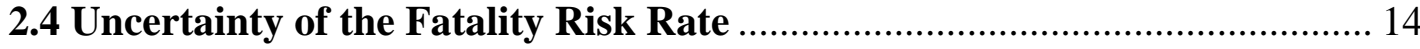

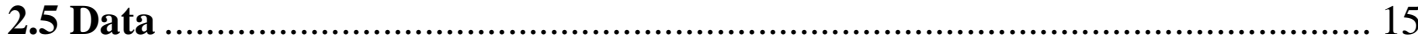

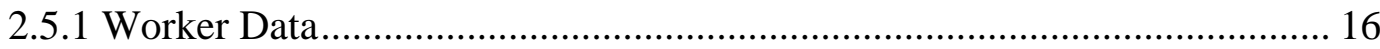

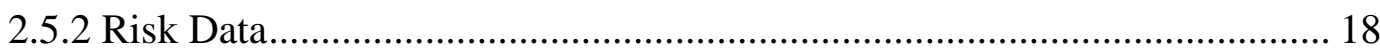

2.5.3 Local Unemployment Rate ........................................................................ 20

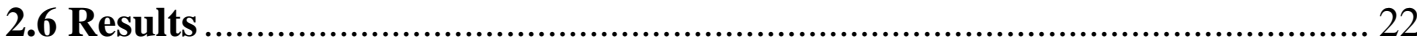

2.6.1 Regressions without Unemployment Interactions .................................. 23

2.6.2 CWD with Unemployment Interactions .................................................. 25

2.6.3 Regressions Using Alternative Risk Rates ................................................ 28

2.6.4 Estimating the Value of a Statistical Life ............................................... 28

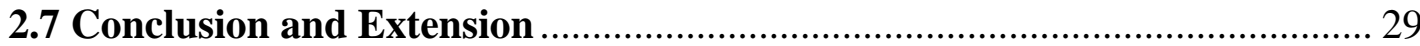

3 CONTINGENT VALUATON METHOD AND THE WILLINGNESS-TO-PAY

FOR HEALTH RISK REDUCTIONS IN CHINA …................................................. 45

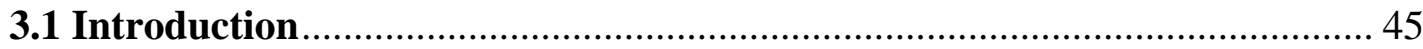

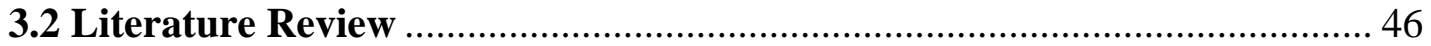

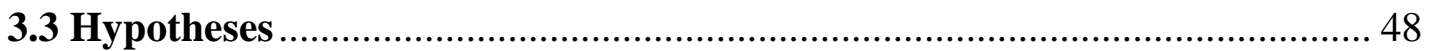

3.3.1 The Private and Public Provision Mechanisms of Health Risk Reduction.. 48

3.3.2 Scope/Scale Effect of the Contingent Valuation Method ............................ 58

3.3.3 Scope/Scale Sensitivity of Different Provision Mechanisms ....................... 68

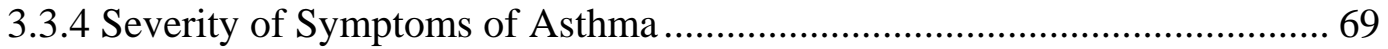

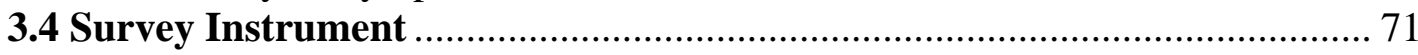




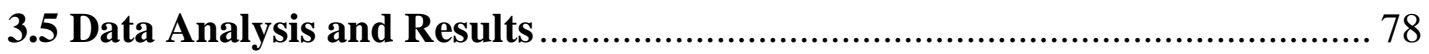

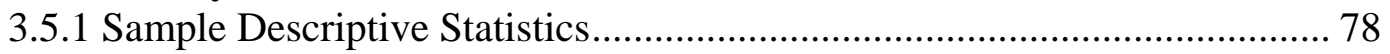

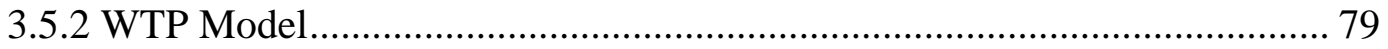

3.5.3 WTP to Reduce the Current Risk of Developing Asthma ........................... 81

3.5.4 WTP to Reduce the Risk of Mortality .................................................... 89

3.6 Analysis on Respondents Who Have Asthma or Chronic Bronchitis .......... 95

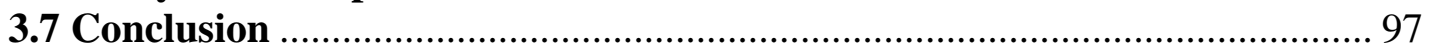

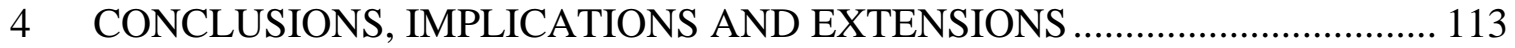

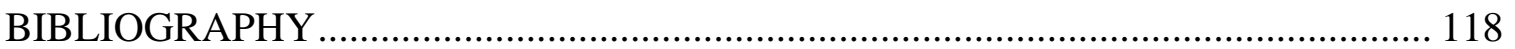




\section{LIST OF TABLES}

Table 2.1: Variable Definition and Statistics .............................................................. 32

Table 2.2: Work Place Fatality and Serious Injury Rate per 10,000 Workers by Sector in

China, 2000-2002 Average ............................................................................. 34

Table 2.3: Percentages of Workers in Each Sector in the Workers Sample..................... 35

Table 2.4: Percentages of Workers by Occupation and Sector....................................... 36

Table 2.5: Original and Recalculated Fatality Risks (Death per 10,000 Workers) .......... 36

Table 2.6: Regressions without the Interaction Terms of Risk and Unemployment Rate 37

Table 2.7: Regression Results with Unemployment Rate ........................................... 40

Table 2.8: Parameter Estimates Using Alternative Risk Estimates ................................ 43

Table 2.9: Parameter Estimates Using Alternative Risk Estimates ............................... 43

Table 2.10: VSL Estimates under Different Assumptions (US\$)................................... 44

Table 3.1: Description of Mild and Severe Symptoms of Asthma ................................. 99

Table 3.2: Sub-Sample Design of the Asthma WTP Question..................................... 100

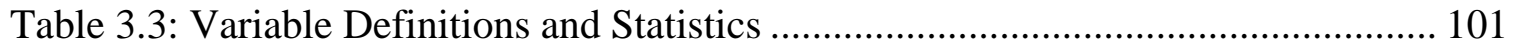

Table 3.4: Statistics of the Independent Variables in the Asthma WTP Model ............. 103

Table 3.5: Bid Vectors and Percentage of People Saying 'yes' to the Bid for Stated Risk

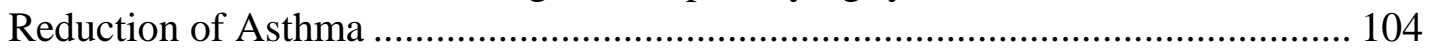

Table 3.6: Coefficient Estimates for Asthma............................................................. 104

Table 3.7: Coefficient Estimates for Asthma (Household Income > 30,000) ................. 105

Table 3.8: Coefficient Estimates for Asthma (Household Income >40,000) ................ 106

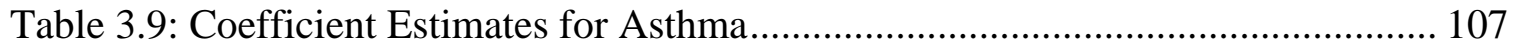

Table 3.10: Within-Group Regression Estimates for Asthma ..................................... 108

Table 3.11: Provision Preference for Asthma............................................................. 108

Table 3.12: Independent Variable Statistics for the Mortality Model ........................... 109

Table 3.13: Bid Vectors and Percentage of People Saying “yes” to the Bid for Stated Risk

Reduction of Mortality.................................................................................... 110

Table 3.14: Coefficient Estimates for Mortality ....................................................... 110

Table 3.15: Coefficient Estimates for Mortality ......................................................... 111

Table 3.16: Within-Group Regression Estimates for Mortality.................................. 112

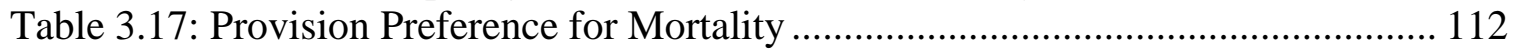

Table 4.1: Comparison of VSL and Per Capita Income ............................................ 117 


\section{LIST OF FIGURES}

Figure 2.1: Market process for determining compensating differentials....................... 10 


\section{CHAPTER 1}

\section{INTRODUCTION}

Environmental valuation is a series of techniques that economists use to assess the economic value of market and non-market goods, namely the state of the environment and natural resources. It is an application of the notion of efficient allocation of resources in economic theory to the field of environment and natural resources. Due to the scarcity of resources, it is necessary to judge whether an environmental improvement provides more benefit to the population than the alternative uses of the resources. Government agencies often apply benefit-cost analysis and related approaches in order to balance concerns about the cost of pollution control with the benefits of improved environmental quality. Environmental valuation is an important yet usually difficult part of environmental policy-making.

In the US, among the direct benefits of environmental regulations, the reduction of health risks such as mortality and respiratory diseases caused by air pollution is the most significant part. For example, the retrospective study of the Clean Air Act (CAA)

done by US Environmental Protection Agency (EPA) estimated that the mean of the total benefit for 1970-1990 from CAA was US\$ 22.2 trillion; among the benefits of improvement of human health, the reduced damage to agricultural crops and exposed 
materials, and the improvements to visibility, the benefit from improvements in human health counts more than $99 \%$ of the total benefits, and among all the human health improvements, the benefit from improvements in mortality and respiratory diseases accounts for more than $90 \%$ of this total benefits (Portney and Stavins, 2000).

In developing countries, many cities experience severe levels of air pollution with the rapid increase in fossil-fuel consumption for industrial, residential, and motor-vehicle use. Decision-makers in these countries are faced with the challenge of mitigating air pollution while supporting continued economic growth. In China, the demand of government agencies for valuation of environmental impacts is growing rapidly. The World Bank report 'Clear Water, Blue Skies’ (1997) estimated the health and productivity losses associated with urban air pollution as 'the single largest environmental cost in China'. Despite the pressing policy need, the peer-reviewed literature of environmental health valuation in China, with proper uncertainty analysis, currently consists of only a few published articles ${ }^{1}$. This dissertation aims to bring international experience and understanding to the undeveloped field of environmental valuation in China, ultimately to strengthen the scientific basis of environmental decision-making.

Environmental valuation is difficult because it often requires to value goods that are not traded in market, thus have no market values, such as mortality and other health risks. The goal of the non-market valuation is to elicit people's preferences for goods that are otherwise not valued in a market setting. In the US and other developed countries, two most widely used methods to value environmental health are the compensating wage

\footnotetext{
${ }^{1}$ These publications include Smil (1996), World Bank (1997), and Hammitt and Zhou (2006).
} 
differential (CWD) method and the contingent valuation (CV) method. The compensating wage differential method estimates the value of mortality and morbidity by investigating the trade-off between the equilibrium wage and the on-the-job fatality and injury risks in the labor market. It is an application of the hedonic pricing method in the labor market, which relates non-market goods to market goods whose prices are readily observable. The advantage of this method is that it studies the 'revealed market value' of health risks. The disadvantages of wage differential research are: (1) it assumes free labor market, which might be violated in the real world; (2) it depends on hard-to-find data, especially in developing countries. In contrast to the wage differential method, the contingent valuation method constructs a hypothetical market via a survey, asking people in carefully worded questions to directly state their willingness to pay (WTP) for reduction of the health risks. The advantage of the CV method is its flexibility. Unlike the wage differential method, which can only be used to estimate workers' preferences for existing jobs, one can survey any desired population (e.g., the elderly) and ask about existing or hypothetical interventions to reduce risk. A disadvantage is its hypothetical nature: people may behave differently in the hypothetical market than in a real market.

This dissertation estimates the values of air-pollution-related health risks in China by applying both the compensating wage differential method (chapter 2) and the contingent valuation method (chapter 3), with improvement of the application of the current environmental valuation methods. This dissertation contributes to the theoretical and empirical environmental health valuation literatures in developing countries. I estimate the monetary value of a statistical life and the value of a statistical case of asthma in China by using the wage differential method and the contingent valuation 
method. In the wage differential study part, I find that positive compensating wage differential for on-the-job fatality risk exists in China. An issue that often raises debate on the validity of the CWD method is its assumption of perfectly competitive labor market. If the labor market is not perfectly competitive, the compensating wage differential to risks may be weak or even absent. I tested this assumption empirically by introducing the local unemployment measurement into the CWD model. The empirical results show that the compensating wage differential to the on-the-job fatality risk decreases convexly with the increasing local unemployment. This evidence supports that the labor market in China is not perfectly competitive; in the area where unemployment is relatively low and thus job opportunities are more, workers earn a higher premium for per unit of the fatality risk.

In the CV study, an individual questionnaire survey is conducted in China to elicit people's WTP for risk reductions of asthma and mortality. Two important issues of the stated valuation are discussed: (1) the potential impact of provision mechanisms-private provision and public/government provision-to people’s WTP for health risk reduction. Since health care could often be either privately provided or publicly provided, it is important for researchers to know whether the provision mechanisms would affect people's WTP for the same health risk reduction. Some theories suggest that the public provision might intrigue respondents' altruistic or 'warm glow' incentive, thus yields higher stated WTP. (2) The scope/scale effects of the WTP to the magnitude of the health risk reduction and to the description of the severity of a disease are discussed and tested empirically. 
In Chapter 4, the results from the previous chapters are compared. Possible reasons of the discrepancy between the results of these two methods are discussed. This dissertation is one of the first studies, which compare the results of both revealed and stated valuation method in China. Limitation and directions of future research are also explored. 


\section{CHAPTER 2}

\section{A COMPENSATING WAGE DIFFERENTIAL ANALYSIS}

\subsection{Introduction}

By estimating the value associated with reduced mortality risk, often referred to as the value of a statistical life, economists provide policy makers with much needed input into environmental decisions. To estimate the value of mortality risk, the compensating wage differential (CWD) method is widely applied in developed countries. Due to intense data needs, and the inability to collect such data in developing and transitional economics, the compensating wage differential method is often set aside in favor of an easier, less data intensive method. For example, many researchers in developing countries compute the value of statistical life using the human capital method, which takes the value of life equal to the total wage income loss due to premature death ${ }^{2}$. However, the human capital method underestimates the value of life compared to the wage differential method. It does not take the value of an individual's unpaid housework and the values of many other activities of the individual into account. In this chapter, we are presented with a unique opportunity to perform perhaps the first compensating wage differential study in China, thus providing policy makers with a more accurate estimate of the value of life.

\footnotetext{
${ }^{2}$ For instance, see chapter 2, World Bank, 1997.
} 
In the CWD literature, Viscusi and Aldy (2003) summarize the estimated values of statistical life and injury from about ten countries. They also summarize the econometric methods and hurdles, data needs, the effects of income, union affiliation and age on the VSL, and the application of VSL in public policy decision-making.

For comparison to the current study, using data from 1982-1986 Taiwan labor surveys, Liu et al. (1997) found evidence of compensating wage differentials for industrial risk in Taiwan and estimate the VSL to be US\$413,000 (in 1990 dollars). Liu and Hammitt (1999) administered a survey on perceived occupational health risks for petrochemical workers in Taiwan and found that workers in risky jobs receive a compensating wage differential, ceteris paribus. The estimated VSL was approximately US\$624,000 in 1995 dollars. Siebert and Wei (1998) provided an estimate of wage compensation for fatal job risk in Hong Kong in 1991. They showed that there is a positive and significant compensating wage differential for job fatality risks for manual workers in Hong Kong. They estimated the VSL at about US\$1.4 million.

In this chapter, the economic value of mortality risk in China is estimated by applying the compensating wage differential method to an individual level labor market data set. To our knowledge, this is the first study attempting to investigate the relationship between wage and risk in China. In the process of studying the relationship between wages and risk in China, we relax the standard assumption of perfect competition in the labor market. Standard applications of compensating wage differential methods assume perfectly competitive labor market. However, this assumption is often violated in the real world. CWD theory does not predict whether positive CWD for risk would still exist, and how unemployment would affect CWD, in a labor market that is not 
perfectly competitive and has substantial unemployment. In this study, this question is empirically tested. By including a set of adjusted province level unemployment rates as a negative proxy of alternative job opportunities facing workers, we find that the marginal effect of the mortality risk on the log of wage is convexly decreasing with the unemployment rate. Workers in areas with high unemployment rate receive lower CWD for per unit of risk.

The uncertainty of the by-industry average fatality risk rate is considered in this study. A problem of using the industrial average risk rate is that different workers in the same industry face very different level of risks. Two approaches dealing with this problem are used. The first is the usual approach to this problem: using only workers at high risk as the sample for CWD estimation. The second approach is to assume that all the fatalities occur to one class (occupation category) of workers who are at high risk, and recalculate the by-industry fatality risk rates. By employing these two approaches, various estimates of the wage-risk trade-off are obtained.

\subsection{Theory and Model of the Wage Differential Method}

More than two hundred years ago, Adam Smith (1776) wrote in The Wealth of Nations that: "The wages of labor vary with the ease or hardship, the cleanliness or dirtiness, the honorableness or dishonorableness of the employment”. Rosen (1974) developed the theoretical framework of hedonic prices in pure competition. The compensating wage differential method is an application of the hedonic pricing theory in the labor market. In a perfectly competitive labor market, after disentangling the human capital factors and other wage-affecting factors, we would find that the higher job-related 
mortality and morbidity risks a worker bears, the higher his/her wage would be in equilibrium. To attract workers, the dangerous, dirty and hard jobs have to offer higher wages than the safe, clean and easy jobs.

Roesn's model is summarized graphically in Figure 2.1 (from Figure 1 of Viscusi and Aldy, 2003). In the space of wage and work-related risk, OC1 and OC2 are iso-profit curves for firm 1 and firm 2. These iso-profit curves have positive slope: to keep a given level of profit, the firm must pay workers less as the safety level rises, because the cost of worker increases with the safety level. EU1 and EU2 are the constant expected utility curves of worker 1 and worker 2 . Along these curves, the wage required is increasing when risk increases. For any given level of risk, workers prefer the wage-risk combination from the market offer curve with the highest wage level. The outer envelope of these offer curves is the market opportunities locus $w(p)$. Workers maximize their expected utility by choosing from potential wage-risk combinations along some market opportunities locus w(p). The tangency between the constant expected utility locus EU1 and firm 1's offer curve OC1 represents worker 1's optimal job risk choice.

Likewise, worker 2 maximizes expected utility at the tangency between EU2 and OC2. Researchers observe the actual market data of (p1, w1), (p2, w2) and the wage-risk combination choice of other workers on w(p). The compensating wage differential method attempts to estimate the wage-risk locus, w(p), which reflect the joint influence of supply and demand on the market equilibrium. 


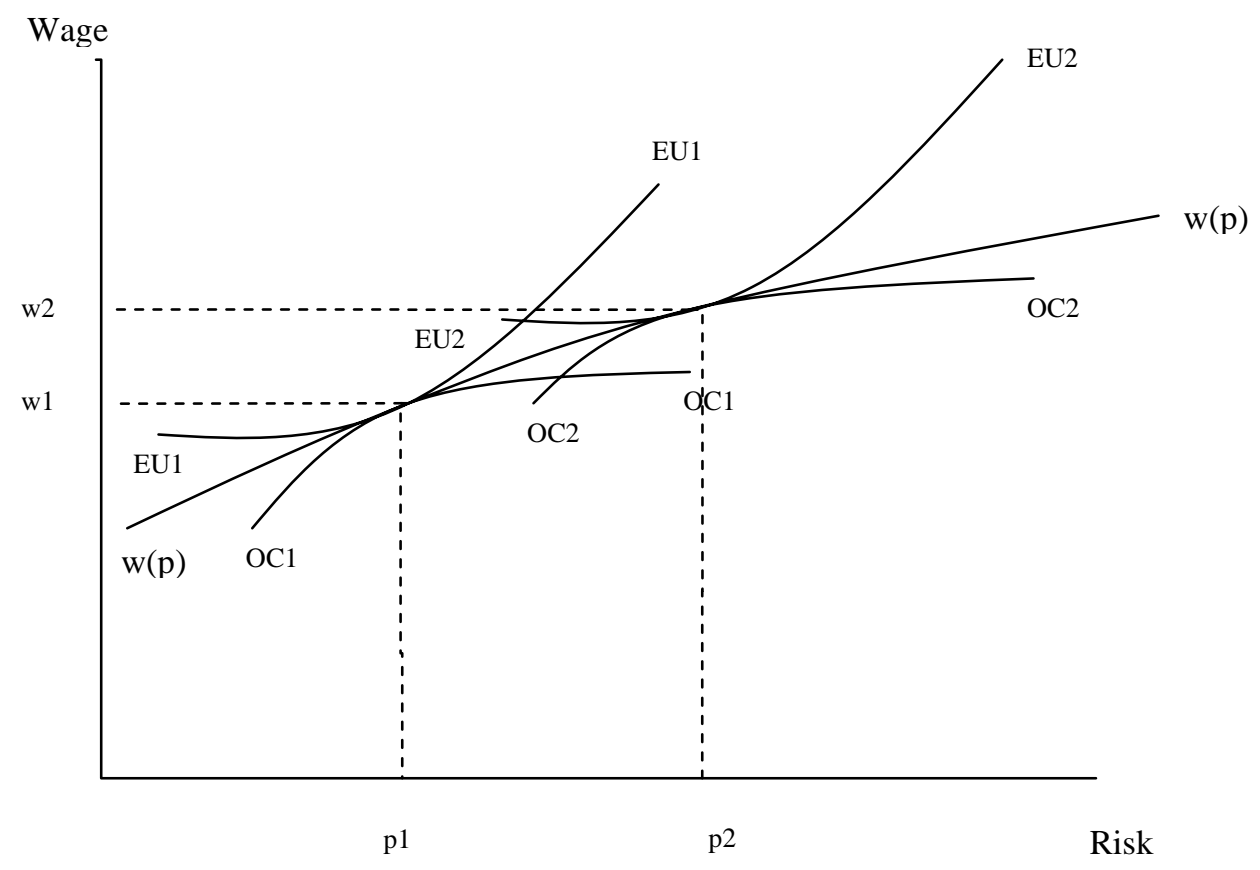

Figure 2.1: Market process for determining compensating differentials.

Most of the literature of the wage differential method focuses on valuing mortality risk by estimating compensating differentials for on-the-job risk exposure in a labor market. Consider a modified version of the wage-risk expression from Viscusi and Aldy (2003):

$g\left(w_{i}\right)=\alpha+H_{i}^{\prime} \beta_{1}+X_{i}{ }^{\prime} \beta_{2}+\gamma_{1} p_{i}+\gamma_{2} q_{i}+\gamma_{3} q_{i} W C_{i}+\varepsilon_{i} \quad(2.1)$,

where $w_{i}$ is the worker $i$ 's wage rate, $g\left(w_{i}\right)$ a linear or nonlinear transformation of $w_{i}, \alpha$ a constant term, $H$ a vector of individual characteristic variables of worker $i, X$ a vector of worker $i$ 's job characteristic variables, $p_{i}$ the fatality risk measure associated with worker i's job, $q_{i}$ the non-fatal injury risk measure associated with worker $i$ 's job, $w C_{i}$ the 
worker's compensation for a job injury usually paid by the employer of worker $i$, and $\varepsilon_{i}$ the random error term including unmeasured factors influencing worker $i$ 's wage rate. Interaction terms between fatality risk and individual's characteristics could also enter the equation. $w_{i}$ or the natural log of $w_{i}$ are often used as the dependent variable in wage differential models. The VSL is equal to the rate of substitution between wage and risk $d w / d p$.

\subsection{The Assumption of Perfect Competitive Labor Market}

Perfect competition in the labor market may not exist in the real world. Perfect competition requires free market entry of workers and employers, perfect mobility of workers and perfect information for both workers and employers. When the perfectly competitive labor market assumption is not satisfied, Rosen’s theory does not predict whether positive CWD would still exist and whether the magnitude of CWD per unit of risk would change. Specifically, if workers are not perfectly mobile and unemployment due to surplus of labor supply occurs, the shape of the iso-profit curves and the constant utility curves in Figure1 might change, which may change both the intercept and the curvature of w(p). Unfortunately, theory does not predict how w(p) would change. Some researchers believe that the magnitude of CWD would decrease. Purse (2004) criticized the perfect mobility assumption ${ }^{3}$ : 'if workers do not have freedom to change jobs when faced with unacceptable risks arising from their work, the presumed imperative paced on employers by the market to compensate them is correspondingly reduced... In the real world, workers are not at complete liberty to change jobs whenever

\footnotetext{
${ }^{3}$ For other works criticizing the compensating wage differential method, refer to Dorman (1996).
} 
they feel inclined to do so'. He also pointed out that 'when confronted with a higher level of unemployment, workers, especially those with low education and few marketable skills, may be much less likely to quit their job, irrespective of whether it is hazardous or not'. If Purse's argument is true, the market trade-off between wage and risk w(p) would become flatter or even has a zero or negative slope under limited labor mobility and high unemployment.

Little empirical evidence exists on the relationship between risk and wages with imperfect labor markets. Viscusi and Aldy (2003) reviewed ten U.S. labor market VSL studies on union and non-union workers. Nine of them found union workers received greater compensating differentials for mortality risk than non-union workers. Viscusi (1980) demonstrated theoretically that in a firm with monopsonistic power, the provision of work safety would be lower than the social optimal level, and union bargaining on behalf of work quality preference of the average worker may promote social efficiency. His empirical study used the interaction terms of a dummy variable of worker's union status and on-the-job subjective and objective fatal and non-fatal risk measures as independent variables in the wage equation. He found significant and positive coefficients of the risk variables and these interaction terms (Viscusi's Table 2). Another explanation of the different CWDs of union and non-union workers is that union workers have advantages of obtaining information about their on-the-job risks than non-union workers (Viscusi, 1979; Olson, 1981; Dillingham and Smith, 1984). These suggest that the estimated CWD received by the union workers should be a more consistent estimate to compute the VSL, whereas CWD received by the non-union workers is downward 
biased. Several studies even found that non-union workers received no compensation or negative CWD for risks (for example, Viscusi, 1980 and Dorsey, 1983).

Viscusi (2003) looked at the racial differences in the labor market VSL. He ran the CWD regressions using separate samples of black and white workers. His empirical findings resulted the conclusion that black workers face a different offer curve, which is lower and flatter (but still positive) than the offer curve of white workers. Viscusi stated that it appears unlikely that the difference can be traced to differences in risk-related productivity of black workers and white workers, other explanations such as structurally different labor market opportunities by race (e.g. discrimination) are more likely explanations; though the author did not explore these possible explanations.

In this chapter, we look at the relationship between unemployment under limited labor mobility and the CWD. In China, before and at the beginning of the economic transition (before 1990s), labor mobility was very low. The residential registration (hukou) system made moving from one city to another or from rural area to urban area very difficult. Since the economic transition, the registration system has been discarded gradually. During 1990s, labor mobility increased but the effect of the registration system still existed.

Many estimates suggest that the urban unemployment rates increased from the early 1990s to 2002 (e.g. Giles et al., 2005). At the same time, the social assistance system of China was still under construction. Considering the historical effect of the registration system on labor mobility, the high unemployment rate and the lack of social assistance system during this period of time, we may expect that workers faced with high job-related hazard might not have been able to quit their jobs freely. If this is true, the 
compensating wage differential for on-the-job fatality and injury risks may be very weak or even absent.

When labor is not perfectly mobile, local unemployment rates can be used as a negative proxy for working opportunities faced by a worker. Considering that the unemployment rate might have a negative impact on the compensating wage differential, we include regional unemployment measurement into the wage model to test if this impact exists. It is expected that the log of wages will decrease with the regional unemployment rate. More importantly, the interaction term of the fatality risk and the unemployment rate is included as an independent variable; the hypothesis that the coefficient of this interaction term is zero is tested.

\subsection{Uncertainty of the Fatality Risk Rate}

Due to limited data, as with many other CWD studies, industrial average risk rates are assigned to each worker in the regression. A concern about using the industrial average risk rate is that different workers in the same industry face very different risks. Thus, assigning the industrial average risk to workers may yield bias. For instance, a collier faces much higher risk than an accountant working in the same coal mining operation. For the 'low risk workers', the industrial average risk cannot represent the relative danger they face across industries. On the other hand, the industrial average risk may be able to provide a proper ranking of risk for the 'high risk workers', although the magnitude of the industrial average risk may be smaller than the magnitude of the average risk for the 'high risk workers'. The usual approach is to delete workers who are probably at low risk. In the worker data we use, there are 7 occupational categories: 
owner of private or individual enterprise, head or division head of institution, professional or technical worker, office worker, skilled worker, unskilled worker and other. In many industries, the owners, heads, professional workers, office workers face lower risks than the skilled and unskilled workers do; the skilled workers may face lower risks than the unskilled workers do. Thus, we use the sub-samples of unskilled workers and skilled workers separately and combined to run the wage differential regressions to test if different estimates of the risk coefficient would be obtained from these subsamples.

Another method is to assume that essentially all the fatalities occur to one class of workers (e.g., unskilled workers, or unskilled workers plus skilled workers), and then recalculate the estimated risk as equal to the number of fatalities divided by the number of workers within this class (in each sector). This is equivalent to dividing the originally estimated risk by the ratio of employment within the occupation in that sector to the total employment. Thus, we compute three sets of industrial fatality risk rates: the original fatality risks for each sector in the worker survey data (DR1), the recalculated fatality risks assuming that all the fatalities occur to the unskilled and skilled workers (DR2) and assuming that all the fatalities occur to the unskilled workers (DR3). All three risk rates are used in regressions.

\subsection{Data}

To apply the wage differential model, data of a sample of individual workers including each worker's characteristics variables, his/her wage from work, and his/her job characteristics variables are needed. Also, the fatality risk and nonfatal injury risk 
rates associated with each worker's occupation or industry are needed. Both the individual worker data and the risk rate data are rare in China. Fortunately, we managed to obtain the data needed for this study, although the data has limitations.

\subsubsection{Worker Data}

The individual worker data set used is from the Chinese Household Income Project conducted by Riskin, Zhao and Li (2000) in 1995 in China ${ }^{4}$. The universe of this survey is the resident population of the People's Republic of China. The data collection consists of two distinct samples of the urban and rural populations of the People's Republic of China, which were selected from significantly larger samples drawn by the State Statistical Bureau. The urban individual data set of this survey was used for this study. The survey sampled 21,698 members in 11 provinces of China. In this survey, individual urban respondents reported on their economic status within the household, Communist Party membership, gender, age, nature of employment, income, and relationship to the household head. For this study, the most important variables are the human capital variables, each individual's occupation and wage, the sector (industry) that the individual is working in, and the characteristics of the individual's job. We delete the respondents who are unemployed throughout 1995 or some of the time in 1995 . We also delete the respondents with less than 1000 yuan (US\$125) annual wage in 1995 (about $1 \%$ of the respondents) to avoid extreme cases. The cleaned data set has about 10,000

\footnotetext{
${ }^{4}$ Acknowledgement of this study: The Chinese Household Income Project is a joint research effort sponsored by the Institute of Economics, Chinese Academy of Social Sciences, the Asian Development Bank and the Ford Foundation. Additional support was provided by the East Asian Institute, Columbia University.
} 
working and earning income individuals. Statistics of important variables are reported in Table 2.1.

As stated before, in this individual worker data set, there are six occupational categories: owner of private or individual enterprise, head or division head of institution, professional or technical worker, office worker, skilled worker, unskilled worker and other. To investigate the workers with occupations possibly related to high on-the-job risks, the statistics of the sub-sample of skilled and unskilled workers are also presented in Table 2.1. It can be seen that skilled and unskilled workers on average earn less annual wage than the whole sample. Skilled and unskilled workers also tend to have worse working environment than the whole sample: the means of the variables of UNDERGW (dummy variable equal to 1 if the worker is working underground or under water), TEMPER (dummy variable equal to 1 if the worker is working in high temperature), TOXIC (dummy variable equal to 1 if the worker is working in toxic environment) and SATISF (satisfaction of work environment: from 1-very satisfied to 5-very dissatisfied) show larger percentages of the skilled and the unskilled workers working underground or under water, working in high temperature, toxic environment, and smaller percentages satisfied with their working environment.

One problem of this data set is that it contains formal urban residents with registration (hukou) only, but not migrants. A large part of the migrants (especially those called 'peasant workers') are relatively young and lower educated. They often take the low-paid and unattractive jobs such as construction worker, maid, and waiter. This part of the migrants may be willing to accept risky jobs for less compensation than the formal urban residents because they have fewer job choices than the formal residents do. There 
is very few survey data with migrants included since most of the individual surveys done in China used the registration list as a sampling device.

\subsubsection{Risk Data}

There is no job-related risk data reported in this survey data set. The publicly reported job-related risk data by authority in China are the 'numbers of work-related deaths and serious injuries of staff and workers' in each sector (industry), which can be found in China’s Work Safety Yearbook from 2000 to $2002^{5}$. Thus, for each year from 2000 to 2002, we compute the by-sector work-related mortality risk rate by dividing the number of work-related death of staff and workers by the total number of staff and workers in each sector. The by-sector average fatality rates and serious injury rates from 2000 to 2002 are reported in Table 2.2.

As reported in Table 2.2, the weighted cross-sector average fatality rate was 1.188 per 10,000 workers from 2000 to 2002 in China, while it was 1.04 per 10,000 from 1992 to 1998 in Hong Kong ${ }^{6}$, 2.72 from 1982 to 1985 and 1.40 per 10,000 from 1994 to 1997 in Taiwan ${ }^{7}$.

In China, the work-related accidents of fatality and injuries are supposed to be reported from employers to the local administration of work safety, and then to the state administration of work safety. However, some employers may conceal the accidents to avoid punishment from government. The statistics reported by the authority are often under the suspicion of understating the true risks.

\footnotetext{
${ }^{5}$ The data before 2000 are not published.

${ }^{6}$ Hong Kong data is computed from the data reported in China Labor Statistical Yearbook (2003).

${ }^{7}$ The Taiwan data is from the study of Liu, Hammitt and Liu (1997).
} 
From Table 2.2, it is seen that the 'mining and quarrying' sector has the largest fatality rate, the second largest is the 'others' sector, and the third largest is the 'construction' sector. Although the magnitude of the rates may be inaccurate, the ranking of dangerous sectors is reasonable, since fatality rates of other countries and areas show similar patterns. For instance, the ranking of industry fatality rate in U.S. (averaged from 1992-1995) from high to low is 'Mining', ‘Agriculture, Forestry and Fisheries’, 'Construction', 'Transportation and Utilities', 'Manufacturing', 'Whole Sale Trade’, 'Retail Trade’, 'Services’ and ‘Finance, Insurance and Real Estate’ (Viscusi and Aldy, 2003). The by-industry fatality rate of Hong Kong from 1994 to 2000 shows that 'Mining', 'Construction', and 'Transportation, Storage and Communications' are the top three most dangerous industries from high to low (China Labor Statistical Yearbook, 2003).

As discussed above, we match the by-sector average mortality risk rate to each individual in the survey data by the sector that the individual is working in. A problem is that there is a time gap between the risk data (2000-2002) and the worker data (1995). The only available risk data are from 2000-2002; and we used the 1995 worker data set because it contains a very complete set of human capital variables and job characteristic variables of the workers. Therefore, we decided to match the 2000-2002 average fatality risk rate to the 1995 worker data, with the assumption that the fatality risk rate in 1995 is the same as the average of 2000-2002.

In the 1995 worker survey data, respondents were divided into 13 industry sectors instead of the 16 sectors as the risk data does, although most of these two lists of sector division are exactly the same. However, it is not clear how to transfer the 16 sectors in 
the risk data to the 13 sectors in the worker data. For example, in the risk data set, there are sectors of 'Agriculture, Hunting, Forestry and Fishing' 'Mining and Quarrying' and 'Geological Prospecting and Water Conservancy'; while in the worker data, these 3 sectors are presented as 2 sectors of 'agricultural, forestry, animal husbandry, fishing or water conservancy' and 'mining and geological survey and prospecting'. The transformation is done in what we believe to be a reasonable way (see Table 2.3). Other possible ways of transformation are also tested; the results and conclusion are not affected. The percentages of workers in each of the 13 sectors in the sample and how the risk rates of the 16 sectors in Table 2.2 are matched to the 13 sectors are reported in Table 2.3. The sample average and standard deviation of the fatality risk (DR1) are reported in Table 2.1.

As stated in section 2.4, we compute another two sets of fatality risk rates assuming all the fatality occurs to specific occupation categories, which is equivalent to dividing the originally estimated risk by the ratio of employment within the occupation in that sector to the total employment. The ratio of employment within each occupation category to the total employment by each industry is computed by using the worker data set, and reported in Table 2.4. The original fatality risks for each sector in the worker survey data (DR1) and the recalculated fatality risks assuming that all the fatalities occur to the unskilled and skilled workers (DR2) and assuming that all the fatalities occur to the unskilled workers (DR3) are reported in Table 2.5.

\subsubsection{Local Unemployment Rate}

A set of adjusted province level unemployment rates is also used in the model. As stated in Giles et al. (2005), the official unemployment rates of China (the so-called 
'urban registered unemployment rates') count only those individuals who register for unemployment benefits with local governments, and are not based on representative sample surveys. Thus, the official unemployment rate is widely believed to significantly understate the true unemployment rate: these figures overlook millions of workers who were laid off with no expectation of reemployment, who lost jobs but did not register with local governments, and who involuntarily retired early, among others. On the other hand, substantial numbers of officially registered unemployed workers may actually be working part- or full-time or may no longer be looking for work (i.e. out of the labor force).

The National Bureau of Statistics (NBS) of China reported the official national unemployment rate as only 0.029 in 1995 . Giles et al. (2005) estimated the 'true' rate of unemployment in China from 1996 to 2001 by analyzing data from an unemployment survey conducted in five large Chinese cities in 2002 that applied internationally standard definitions of unemployment ${ }^{8}$, and by combining their results with other unemployment measurements across time and space. They reported an estimated unemployment rate among urban permanent residents (excluding migrants) of 0.061 in January of 1996. However, Giles et al. could not estimate the unemployment rate of every province of China. Assuming that the ratio of real unemployment rate of each province to its official estimate is the same across provinces and equal to the ratio of the estimate of Giles et al. to the official national estimate, we inflate the official province level unemployment rates in 1995 (from China Statistical Yearbook, 2003) by the ratio of Giles's estimate (0.061)

\footnotetext{
${ }^{8}$ The general definition of unemployment is that the worker is not working, able to work, and looking for work during defined reference periods. Please see Giles et al. (2005) for the exact definition of unemployment they used to estimate the unemployment rates.
} 
to the official national rate $(0.029)$, which is 2.103 . Then we match the adjusted province unemployment rates to each worker by the province he/she works in. The sample average of this unemployment rate variable (UNEM) is 0.057 as reported in Table 2.1.

\subsection{Results}

The estimated semi-log wage differential model results are reported in the first column (Model I) of Table 2.4. For completeness, we tried the fatality rate and serious injury rate as independent variables both separately and together in the regressions. The estimated coefficient of the serious injury rate was never significant. This may be due to the poor accuracy of the reported number of serious injury numbers in each industry. Therefore, we exclude the injury rate and use the fatality rate only. Considering that there might be correlation among the error terms of the employed workers, we run a Heckman two-step model by using the data of both currently employed and unemployed workers. The estimated coefficient of the inverse Mill's ratio term was not significant, and the estimated coefficient of the fatality risk was very close to the semi-log model estimate. Therefore, only the results of the semi-log model are reported.

To demonstrate the effect of the unemployment rate to the price of risk, we report the regression results of the models without the interaction terms of the unemployment rate and the mortality risk in Table 2.6 (using DR1 as the fatality rate); the regression results of the models with the interaction terms considered are reported in Table 2.7 (again, using DR1 as the fatality rate). Different samples of workers are used for regressions, as noted as Model I-VI in Table 2.6 and 2.7. Regression results using DR2 
and DR3 are also done and reported in Table 2.8 and 2.9, corresponding to Table 2.6 and 2.7.

\subsubsection{Regressions without Unemployment Interactions}

In all the regressions, estimated coefficients of different models demonstrate similar effects of human capital variables and job characteristic variables. As an example, consider the first column (Model I) of Table 2.6. Among all the sampled workers, working experience has positive but diminishing effect on the log of wage. One more year of education yields $1.9 \%$ higher annual wages. Male workers earn about $6.3 \%$ more than female workers. Currently married workers earn about 9.8\% more than currently unmarried workers. Communist party members earn about 3.2\% more. The coefficients of TEMPER, TOXIC and UNDERGW are positive, meaning that worse working environment yields higher wage. On the other hand, the coefficient of SATISF is negative, showing that workers who are more satisfied with their working environment earn higher wage. INTENSIVE has a positive coefficient, meaning workers who think their average work is more intensive earn higher wage. DAY has a negative coefficient, probably because the job requires longer working days per week is often low-paid labor job (for example, the unskilled workers have a larger mean of DAY). The estimated coefficients of PROF, HEAD and UNSKILLED show that professional workers and technical workers earn about $7.7 \%$ more, heads of institutions earn about $6.2 \%$ more, while unskilled workers earn about 6.8\% less. Positive coefficients of SEC2, SEC5 and SEC11 show that workers in the sector of industry earn 2.0\% more, workers in the sector of transportation, communications, posts and telecommunications earn about $9.6 \%$ more, workers in the sector of finance and insurance earn about 21.0\% more. INDIVIDUAL, 
SINOFOR, FOREIGN and COLLECTIVE are variables indicating the ownership of workplace. It can be seen that workers in the individually owned enterprises earn 34\% more, workers in the sino-foreign joint venture enterprises earn $21.7 \%$ more, workers in the foreign owned workplaces earn $82.4 \%$ more, whereas workers in the urban collective enterprises earn $13.7 \%$ less. HEAPUB and HEASELF are variables indicating what forms of health protection the workers have in 1995. It can be seen that workers with public health service provided by the state or the work unit earn $9.7 \%$ more, while workers entirely self-financing their health protection earn $16.3 \%$ less. This means that higher paid jobs also provide better medical insurance to their employees. Variable LOSE is a dummy and equal to one if the respondent reports that his workplace lose money in 1995. Workers in the losing money workplaces earn $17.4 \%$ less. The variables JIANGSU and GUANGDONG are regional dummy variables as the provinces where the households of respondents locate in Jiangsu and Guangdong provinces, where workers in Jiangsu and Guangdong earn $19.9 \%$ more and $66.5 \%$ more respectively, than workers in other provinces. Workers in the provinces with higher unemployment rate earn fewer wages: when the unemployment rate increases by $1 \%$, the wage decreases by $2.481 \%$.

In Table 2.6, we can see from the first column (Model I), there is a significant relationship between the workers' by-industry fatality risk and their wage rates ${ }^{9}$. The estimated coefficient of the fatality risk is 0.0056 (with significance at 4\%). In the second column (Model II), we include both DR and the interaction term DR $\times$ UNSKILLED, which is the multiplication of the fatality risk and the dummy variable for the unskilled workers. The estimated coefficient of this interaction term is 0.014 with significance at

\footnotetext{
${ }^{9}$ Note that the sector dummy variables (SEC2, SEC5 and SEC11) are used to control in part for the possibility of systematic between-industry (or sector) wage differences that are unrelated to risk (Leigh, 1995).
} 
5\%, whereas DR is positive but not significant. The estimated coefficients of DR and $\mathrm{DR} \times$ UNSKILLED with the sample of the skilled and the unskilled workers of Model III and IV in Table 2.6 have a similar pattern. Using the sample with the unskilled workers only (Model V), we find that the estimated coefficient of risk is 0.016 with $2 \%$ level significance. When we use the skilled workers only (Model VII), the estimated coefficient of risk is insignificant.

From these results, it can be seen that the correlation between wage and risk is larger and more significant for the unskilled workers sub-sample, while for the skilled workers group, no significant relationship can be found. This finding does not mean that positive correlation between wage and risk does not exist for the skilled workers, but to find the relationship, finer and more accurate risk data is needed. The absence of the correlation between wage and risk for the skilled workers could lower the magnitude and the significance of the risk coefficient in the pooled sample cases (Model I and III). Thus, the estimated risk coefficient from the pooled samples might be biased, and the unskilled workers sub-sample estimate might be more consistent. An estimated coefficient of 0.016 for the mortality risk means that one more death per 10,000 workers yields a 1.6\% increase of the worker's wage.

\subsubsection{CWD with Unemployment Interactions}

Next, in order to test if the unemployment rate has an effect on the trade-off between risk and wage, two interaction terms were added as independent variables: the mortality risk by the unemployment rate $(\mathrm{DR} \times \mathrm{UNEM})$ and the mortality risk by the 
unemployment rate squared ${ }^{10}(\mathrm{DR} \times \mathrm{UNEM} 2)$. Reported in Table 2.7, these two interaction terms are significant in Model I, II and III, where DR $\times$ UNEM has a positive coefficient, and $\mathrm{DR} \times \mathrm{UNEM} 2$ has a negative one. The interaction terms are not significant in Model IV, V or VI. A possible reason is that the adjusted unemployment rates used cannot capture the true unemployment rates of the unskilled and skilled workers in different regions very well. Table 2.7 shows very similar results of the estimated coefficients of the common independent variables except for the risk variable in Model I, III and V. For example, the estimated coefficient of DR of Model I in Table 2.7 is 0.055 , compared to 0.0056 in Model I of Table 2.6. Also in this column, the estimated coefficient of $\mathrm{DR} \times \mathrm{UNEM}$ is (-1.371) with significance at $1 \%$, while $\mathrm{DR} \times \mathrm{UNEM} 2$ is 8.434 and significant at $1 \%$. This suggests that when the unemployment rate ranges from 0 to 0.081 , the marginal effect of risk to the log of wage is convexly decreasing with the unemployment rate. Coefficients of these two interaction terms in all the other models in Table 2.7 show the same signs, although the magnitudes and significance are different. These empirical results suggest that the market wage-risk opportunity curve w(p) in Figure 2.1 shifts downward (the estimated coefficient of UNEM is negative) and becomes flatter when the unemployment rate increases in a reasonable interval.

The downward shift of $w(p)$ may be explained by a surplus of labor resulting in higher unemployment rate and reduced price of labor. Purse's argument could explain the flatter w(p): when the mobility of workers is low, and the unemployment is high, workers would have to stay at jobs without full compensation for the risks they bear. Therefore,

\footnotetext{
${ }^{10}$ Note that the unemployment rate itself is included as an independent variable in all of the regressions run. Its estimated coefficient is negative and significant in every regression. 
workers in the areas with high unemployment averagely receive lower compensation for per unit of risk than workers working in the areas with low unemployment. Another possible explanation concerns the assumption that workers have perfect information on job-related risks. Suppose the surplus of labor supply is caused by an influx of new job seekers, such as migrants ${ }^{11}$ and new graduates. These new job seekers have relatively less information about the risk and other characteristics of certain jobs than experienced workers, thus they are likely to under-estimate the risks and accept the risky jobs with less compensation than the experienced workers. Therefore, entering of new job seekers, which raises the unemployment rate, may also reduce the average market CWD for risks. Both of these explanations are possible causes of the negative association between CWD and unemployment in China.

In the sample used for the regressions, the mean of the unemployment rate for the unskilled workers sample is 0.054 . Computing the marginal effect of DR to the log of wage using the results from Model V in Table 2.7, we will get 0.062$1.632 \times 0.054+11.490 \times 0.054 \times 0.054$, which is 0.0073 . If we use the national unemployment rate 0.061 , the estimated marginal effect is 0.0052 . When the unemployment is zero, the marginal effect is 0.062 . We can see that the unemployment rate has a great impact on the marginal effect of the mortality risk to the log of wage. From these results, we may not be able to conclude that, generally, VSL would vary with the unemployment level, but at least we should consider the possible effect of

\footnotetext{
${ }^{11}$ Although the unemployment rate of migrants in China is estimated much lower than the unemployment rate of the formal urban residents (see Giles et al., 2005), it is possible that the entering of migrants raises the unemployment rate of the formal urban residents, because of the increased competence from the migrants.
} 
unemployment to VSL, and to include it into the regression when appropriate unemployment measurement is available.

\subsubsection{Regressions Using Alternative Risk Rates}

Regressions using DR2 and DR3, instead of DR1 are also done. The parameter estimates of the fatality risk and the interaction terms of DR with other variables are reported in Table 2.8 and 2.9, corresponding to the results in Table 2.6 and 2.7. All the other independent variables have very similar estimated coefficients and significance as the corresponding models in Table 2.6 and 2.7, thus are not reported. Table 2.8 and 2.9 show parameter estimates with much smaller magnitude than those in Table 2.6 and 2.7, because the magnitude of the fatality risk is greater.

\subsubsection{Estimating the Value of a Statistical Life}

To compute the value of a statistical life, we multiply the estimated marginal effect of DR to the log of wage by the annual average wage of workers and the magnitude of the risk rate $(10,000)$. If we apply the DR coefficient 0.016 (Model V in Table 2.6) and the average annual wage of all the sampled workers 5973 yuan, the estimated VSL is 955,680 yuan or US\$119,460 ${ }^{12}$. If we apply the marginal effect of 0.0052 (Model V in Table 2.7, with the estimated 1995 national unemployment rate), the resulted value of a statistical life is 310,596 yuan or US\$38,825. If we apply the marginal effect of 0.062 (Model V in Table 2.7), as the unemployment rate is zero, the VSL would be 3,703,260 yuan, or US\$462,908.

\footnotetext{
${ }^{12}$ The exchange rate of US dollar to yuan used is $1: 8$.
} 
Similarly, if we use the estimates of Model V in Table 2.8, which is 0.0029, the VSL is 173,217 yuan or US\$21,652. When we use the estimates of Model V in Table 2.9, and the national unemployment rate, the marginal effect is 0.0016 and the VSL is 95,387 yuan, or US\$11,923; by assuming the unemployment rate is zero, the VSL is estimated as 657,030 yuan or US\$82,129.

All the estimates of VSL are summarized in Table 2.10. It is difficult, though, to answer which one of these estimates is more consistent. If the unemployment rates used in the model are close to China's true unemployment rates by province, we would suggest using the results of the models with the unemployment rate included. When accurate unemployment rates are not available, the estimated VSL from Model V in Table 2.6 and 2.8 are usable ${ }^{13}$.

\subsection{Conclusion and Extension}

In Table 2.6-2.9, 13 out of 18 models have results show that higher fatality risk of sector of workers yields significantly higher wage rate, which suggests that the compensating wage differential for the work-related fatality risk exists in China. The

\footnotetext{
${ }^{13}$ The estimates above are calculated from the 1995 average wage rate. Under assumptions: (1) the unemployment rates of all the provinces in China did not change, or changed by the same proportion from 1995 to 2002; (2) people's preference to risk does not change over this period, the VSL of 2002 could be estimated using the result of 1995. To obtain the estimates for 2002, the real wage increase from 1995 and the elasticity of VSL to income is needed. Computed from the price indices reported in China's Statistical Yearbook (2003), the consumer price level in 2002 was 109.22\% of the price level in 1995. The national nominal annual wage in 1995 was 5500 yuan; while it is 12,422 yuan in 2002 (China Statistical Yearbook, 2003). Thus, the real urban wage of 2002 was increased by 107\% relative to the 1995 wage. Since wagerisk studies employ a measure of income as the dependent variable, an individual study cannot estimate the effect of income on the premium for bearing mortality risk. The income elasticity of VSL concluded from studies in U.S. and other high-income countries is about 0.5 (Viscusi and Aldy, 2003). Hammitt et al. (2002) estimated the income elasticity of VSL in Taiwan based on a series of wage-differential estimates over 16 years. Their resulted income elasticity of VSL was 2 to 3. Applying 0.5 (2.0) to the estimate yields the 2002 VSL equal to $153.50 \%$ (314\%) of the 1995 estimates, inflating to 2002 yuan by multiplying $109.22 \%$ yields $167.65 \%$ (342.26\%). Thus, multiplying the 1995 estimates in Table 10 by $167.65 \%$ or $342.2 \%$, the estimates of VSL in 2002 varies from 0.02 million dollars to 0.4 million dollars.
} 
trade-off between wage and risk estimated is often higher in the models with the sample of the unskilled workers than the models with sample of workers (except the results in Table 2.9). This suggests that the by-industry rank of the fatality risk estimated might be more consistent with the real risk for the unskilled workers.

Workers in province with high unemployment risk have averagely low wage income. The marginal effect of the mortality risk to wage is convexly decreasing with the adjusted province level unemployment rate in a proper range of the unemployment rate. The negative association between the unemployment rate and the wage-risk trade-off is consistent with our expectation: workers in province with high unemployment risk face fewer job opportunities in the labor market, when the labor market is not perfectly competitive; these workers thus have to accept lower wage compensation for one unit of risk than workers facing more job opportunities. Entering of new job seekers with little information about job risks may also decrease the CWD in the labor market.

The VSL in 1995 has been estimated by using these regression results; the VSL estimate varies from US\$12,000 to US\$120,000 based on different risk estimates and income elasticity assumption. It is difficult though to pin down a more accurate interval in this interval with current available data and information. In Chapter 4, this result will be compared with the result from Chapter 3. 
For future studies, more detailed and accurate risk rates (e.g., occupational risk rates by sector) are needed to test the consistency and accuracy of these estimates. The unknown accuracy of the adjusted unemployment rate is also a limitation of this study. Directions of future research are (1) to do surveys to workers in order to get more accurate wage and perceived risk data; (2) to conduct more theoretical and empirical studies on the relationship between imperfectly competitive labor market and compensating wage differentials. 


\begin{tabular}{|c|c|c|c|c|}
\hline \multirow{2}{*}{ Variables } & \multirow{2}{*}{ Label } & \multicolumn{3}{|c|}{$\begin{array}{c}\text { Mean } \\
\text { (Standard Error) }\end{array}$} \\
\hline & & $\begin{array}{l}\text { Whole } \\
\text { Sample }\end{array}$ & $\begin{array}{c}\text { Skilled } \\
\text { Workers }\end{array}$ & $\begin{array}{l}\text { Unskilled } \\
\text { Workers } \\
\end{array}$ \\
\hline ANNUALW & Annual Wage (yuan) & $\begin{array}{c}5973.78 \\
(3323.19)\end{array}$ & $\begin{array}{l}5655.67 \\
(2950.57)\end{array}$ & $\begin{array}{c}4876.95 \\
(2740.73)\end{array}$ \\
\hline AGE & Age & $\begin{array}{l}38.68 \\
(9.41)\end{array}$ & $\begin{array}{l}37.24 \\
(9.13)\end{array}$ & $\begin{array}{l}36.46 \\
(8.77)\end{array}$ \\
\hline GENDER & 1 if male, 0 if female & $\begin{array}{c}0.53 \\
(0.50)\end{array}$ & $\begin{array}{c}0.62 \\
(0.49)\end{array}$ & $\begin{array}{c}0.38 \\
(0.49)\end{array}$ \\
\hline MARRIAGE & 1 if currently married; 0 otherwise & $\begin{array}{c}0.88 \\
(0.32)\end{array}$ & $\begin{array}{c}0.83 \\
(0.37)\end{array}$ & $\begin{array}{c}0.85 \\
(0.36)\end{array}$ \\
\hline PARTY & $\begin{array}{l}1 \text { if communist party member, } 0 \\
\text { otherwise }\end{array}$ & $\begin{array}{l}0.26 \\
(0.44)\end{array}$ & $\begin{array}{c}0.12 \\
(0.32)\end{array}$ & $\begin{array}{l}0.072 \\
(0.26)\end{array}$ \\
\hline EDUY & $\begin{array}{l}\text { Number of years of education } \\
\text { received }\end{array}$ & $\begin{array}{l}10.88 \\
(2.90)\end{array}$ & $\begin{array}{l}9.67 \\
(2.36)\end{array}$ & $\begin{array}{c}9.00 \\
(2.19)\end{array}$ \\
\hline EXP & $\begin{array}{l}\text { Number of years of working } \\
\text { experience }\end{array}$ & $\begin{array}{l}19.58 \\
(9.51)\end{array}$ & $\begin{array}{l}18.74 \\
(9.26)\end{array}$ & $\begin{array}{l}16.91 \\
(8.66)\end{array}$ \\
\hline UNDERGW & $\begin{array}{l}1 \text { if working environment is under } \\
\text { ground or under water, } 0 \\
\text { otherwise }\end{array}$ & $\begin{array}{l}0.0037 \\
(0.06)\end{array}$ & $\begin{array}{l}0.0077 \\
(0.09)\end{array}$ & $\begin{array}{l}0.011 \\
(0.10)\end{array}$ \\
\hline TEMPER & $\begin{array}{l}1 \text { if work under high or low } \\
\text { temperature, } 0 \text { otherwise }\end{array}$ & $\begin{array}{c}0.047 \\
(0.211)\end{array}$ & $\begin{array}{c}0.12 \\
(0.33)\end{array}$ & $\begin{array}{l}0.072 \\
(0.26)\end{array}$ \\
\hline TOXIC & $\begin{array}{l}1 \text { if the worker works in a toxic } \\
\text { environment or other dangerous } \\
\text { situation; } 0 \text { otherwise }\end{array}$ & $\begin{array}{c}0.065 \\
(0.246)\end{array}$ & $\begin{array}{c}0.17 \\
(0.38)\end{array}$ & $\begin{array}{l}0.068 \\
(0.25)\end{array}$ \\
\hline DAY & $\begin{array}{l}\text { Average number of work days per } \\
\text { week in } 1995\end{array}$ & $\begin{array}{c}5.45 \\
(0.61)\end{array}$ & $\begin{array}{c}5.54 \\
(0.62)\end{array}$ & $\begin{array}{c}5.63 \\
(0.68)\end{array}$ \\
\hline INTENSIVE & $\begin{array}{l}\text { Intensiveness of work: } 1 \text {, not } \\
\text { intensive; } 2 \text { moderate; } 3 \text { very } \\
\text { intensive }\end{array}$ & $\begin{array}{c}2.04 \\
(0.43)\end{array}$ & $\begin{array}{l}2.14 \\
(0.45)\end{array}$ & $\begin{array}{c}2.04 \\
(0.42)\end{array}$ \\
\hline SATISF & $\begin{array}{l}\text { Satisfaction of work environment: } \\
\text { from 1-very satisfied to 5-very } \\
\text { dissatisfied }\end{array}$ & $\begin{array}{c}2.67 \\
(0.84)\end{array}$ & $\begin{array}{c}2.90 \\
(0.82)\end{array}$ & $\begin{array}{c}2.89 \\
(0.81)\end{array}$ \\
\hline OWNER & $\begin{array}{l}1 \text { if the worker is owner or } \\
\text { manager of private or individual } \\
\text { enterprise; } 0 \text { otherwise }\end{array}$ & $\begin{array}{l}0.0064 \\
(0.080)\end{array}$ & N.A. & N.A. \\
\hline HEAD & $\begin{array}{l}1 \text { if the worker is head of } \\
\text { institution }\end{array}$ & $\begin{array}{c}0.12 \\
(0.33)\end{array}$ & N.A. & N.A. \\
\hline
\end{tabular}

Continued

Table 2.1: Variable Definition and Statistics 
Table 2.1 Continued

\begin{tabular}{|c|c|c|c|c|}
\hline PROF & $\begin{array}{l}1 \text { if the worker is professional or } \\
\text { technical worker }\end{array}$ & $\begin{array}{c}0.24 \\
(0.41)\end{array}$ & N.A. & N.A. \\
\hline OFFICE & 1 if the worker is office worker & $\begin{array}{c}0.22 \\
(0.41)\end{array}$ & N.A. & N.A. \\
\hline SKILLED & 1 if the worker is skilled worker & $\begin{array}{c}0.21 \\
(0.41)\end{array}$ & N.A. & N.A. \\
\hline UNSKILLED & 1 if the worker is unskilled worker & $\begin{array}{c}0.15 \\
(0.36)\end{array}$ & N.A. & N.A. \\
\hline PERMANENT & 1 if the worker is permanent worker & $\begin{array}{c}0.79 \\
(0.41)\end{array}$ & $\begin{array}{c}0.67 \\
(0.47)\end{array}$ & $\begin{array}{c}0.63 \\
(0.48)\end{array}$ \\
\hline LONGTERM & $\begin{array}{l}1 \text { if the worker is long-term contract } \\
\text { worker }\end{array}$ & $\begin{array}{c}0.18 \\
(0.39)\end{array}$ & $\begin{array}{c}0.30 \\
(0.46)\end{array}$ & $\begin{array}{c}0.32 \\
(0.46)\end{array}$ \\
\hline TEMPORARY & 1 if the worker is temporary worker & $\begin{array}{l}0.022 \\
(0.15)\end{array}$ & $\begin{array}{l}0.024 \\
(0.15)\end{array}$ & $\begin{array}{l}0.055 \\
(0.23)\end{array}$ \\
\hline PUBLIC & $\begin{array}{l}1 \text { if workplace is state-owned or local } \\
\text { publicly-owned, } 0 \text { otherwise }\end{array}$ & $\begin{array}{c}0.84 \\
(0.37)\end{array}$ & $\begin{array}{c}0.81 \\
(0.39)\end{array}$ & $\begin{array}{c}0.70 \\
(0.46)\end{array}$ \\
\hline INDIVIDUAL & $\begin{array}{l}1 \text { if workplace is self-employed } \\
\text { business/individual enterprise, } 0 \\
\text { otherwise }\end{array}$ & $\begin{array}{c}0.001 \\
(0.033)\end{array}$ & 0 & 0 \\
\hline COLLECTIVE & $\begin{array}{l}1 \text { if workplace is urban collective, } 0 \\
\text { otherwise }\end{array}$ & $\begin{array}{c}0.14 \\
(0.35)\end{array}$ & $\begin{array}{c}0.17 \\
(0.37)\end{array}$ & $\begin{array}{c}0.28 \\
(0.45)\end{array}$ \\
\hline SINOFOR & $\begin{array}{l}1 \text { if workplace is sino-foreign joint } \\
\text { venture, } 0 \text { otherwise }\end{array}$ & $\begin{array}{l}0.011 \\
(0.11)\end{array}$ & $\begin{array}{l}0.019 \\
(0.14)\end{array}$ & $\begin{array}{l}0.013 \\
(0.11)\end{array}$ \\
\hline FOREIGN & $\begin{array}{l}1 \text { if workplace is foreign owned, } 0 \\
\text { otherwise }\end{array}$ & $\begin{array}{c}0.001 \\
(0.033)\end{array}$ & $\begin{array}{l}0.0005 \\
(0.022)\end{array}$ & $\begin{array}{l}0.0027 \\
(0.052)\end{array}$ \\
\hline HEAPUB & $\begin{array}{l}1 \text { if public health service provided by } \\
\text { the state of the working unit is } \\
\text { received by workers; } 0 \text { otherwise }\end{array}$ & $\begin{array}{c}0.69 \\
(0.46)\end{array}$ & $\begin{array}{c}0.71 \\
(0.45)\end{array}$ & $\begin{array}{c}0.58 \\
(0.49)\end{array}$ \\
\hline HEASELF & $\begin{array}{l}1 \text { if health protection of workers is } \\
\text { entirely self-employed; } 0 \text { otherwise }\end{array}$ & $\begin{array}{c}0.13 \\
(0.33)\end{array}$ & $\begin{array}{c}0.12 \\
(0.32)\end{array}$ & $\begin{array}{c}0.20 \\
(0.40)\end{array}$ \\
\hline LOSE & $\begin{array}{l}1 \text { if the worker reports that his } \\
\text { working place is losing money; } 0 \\
\text { otherwise }\end{array}$ & $\begin{array}{c}0.20 \\
(0.40)\end{array}$ & $\begin{array}{c}0.29 \\
(0.45)\end{array}$ & $\begin{array}{c}0.25 \\
(0.44)\end{array}$ \\
\hline UNEM & Adjusted urban unemployment rate & $\begin{array}{c}0.057 \\
(0.023)\end{array}$ & $\begin{array}{c}0.056 \\
(0.024)\end{array}$ & $\begin{array}{c}0.054 \\
(0.020)\end{array}$ \\
\hline DR & $\begin{array}{l}\text { Sector fatality rate per } 10,000 \\
\text { workers }\end{array}$ & $\begin{array}{c}0.61 \\
(1.51)\end{array}$ & $\begin{array}{c}0.78 \\
(1.35)\end{array}$ & $\begin{array}{c}0.76 \\
(1.57)\end{array}$ \\
\hline $\mathbf{N}$ & Number of Observations & 10165 & 2100 & 1524 \\
\hline
\end{tabular}




\begin{tabular}{|c|c|c|c|}
\hline & Sector & $\begin{array}{l}\text { Fatality } \\
\text { Rate }\end{array}$ & $\begin{array}{c}\text { Serious } \\
\text { Injury } \\
\text { Rate } \\
\end{array}$ \\
\hline 1 & Agriculture, Hunting, Forestry and Fishing & 0.213 & 0.150 \\
\hline 2 & Mining and Quarrying & 13.815 & 1.154 \\
\hline 3 & Manufacturing & 0.721 & 0.691 \\
\hline 4 & $\begin{array}{l}\text { Production and Supply of Electricity, Gas and } \\
\text { Water }\end{array}$ & 0.868 & 0.261 \\
\hline 5 & Construction & 2.234 & 0.643 \\
\hline 6 & Geological Prospecting and Water Conservancy & 0.389 & 0.153 \\
\hline 7 & Transport, Storage, Post and Telecommunication & 0.336 & 0.317 \\
\hline 8 & $\begin{array}{l}\text { Wholesale and Retail Trade and Catering } \\
\text { Services }\end{array}$ & 0.225 & 0.074 \\
\hline 9 & Finance and Insurance & 0.006 & 0.003 \\
\hline 10 & Real Estate Trade & 0.267 & 0.110 \\
\hline 11 & Social Services & 0.355 & 0.130 \\
\hline 12 & Health Care, Sporting and Social Welfare & 0.010 & 0.008 \\
\hline 13 & $\begin{array}{l}\text { Education, Culture and Arts, Radio, Film and } \\
\text { Television }\end{array}$ & 0.016 & 0.008 \\
\hline 14 & Scientific Research and Poly-technical Services & 0.083 & 0.063 \\
\hline 15 & $\begin{array}{l}\text { Government Agencies, Party Agencies and Social } \\
\text { Organizations }\end{array}$ & 0.015 & 0.005 \\
\hline \multirow[t]{2}{*}{16} & Others & 3.365 & 2.127 \\
\hline & Total & 1.188 & 0.365 \\
\hline
\end{tabular}

Table 2.2: Work Place Fatality and Serious Injury Rate per 10,000 Workers by Sector in China, 2000-2002 Average 


\begin{tabular}{|c|c|c|c|}
\hline $\begin{array}{l}\text { Dummy } \\
\text { Variable }\end{array}$ & Sector & Percentage & $\begin{array}{c}\text { Matched } \\
\text { risk rates } \\
\text { of } 16 \\
\text { Sectors in } \\
\text { Table } 2.2 \\
\end{array}$ \\
\hline SEC1 & $\begin{array}{l}\text { Agricultural, forestry, animal husbandry, } \\
\text { fishing or water conservancy }\end{array}$ & $1.65 \%$ & Sector 1 \\
\hline SEC2 & Industry & $40.00 \%$ & Sector 3 \\
\hline SEC3 & $\begin{array}{l}\text { Mining and Geological Survey and } \\
\text { Prospecting }\end{array}$ & $1.14 \%$ & Sector 2 \\
\hline SEC4 & Construction & $3.01 \%$ & Sector 5 \\
\hline SEC5 & $\begin{array}{l}\text { Transportation, Communications, Posts and } \\
\text { Telecommunications }\end{array}$ & $5.10 \%$ & Sector 7 \\
\hline SEC6 & $\begin{array}{l}\text { Commerce and Trade, Restaurants and } \\
\text { Catering, Materials Supply, Marketing, and } \\
\text { Warehousing }\end{array}$ & $14.15 \%$ & Sector 8 \\
\hline SEC7 & $\begin{array}{l}\text { Real Estate, Public Utilities, Personal and } \\
\text { Consulting Services }\end{array}$ & $3.81 \%$ & $\begin{array}{l}\text { Weighted } \\
\text { average of } \\
\text { Sector } 10 \\
\text { and } 11\end{array}$ \\
\hline SEC8 & $\begin{array}{l}\text { Health, Physical Cultural and Social } \\
\text { Welfare }\end{array}$ & $4.92 \%$ & Sector 12 \\
\hline SEC9 & Education, Cultural, Arts and Broadcasting & $8.05 \%$ & Sector 13 \\
\hline SEC10 & Scientific Research and Technical Services & $2.59 \%$ & Sector 14 \\
\hline SEC11 & Finance, Insurance & $2.13 \%$ & Sector 9 \\
\hline SEC12 & $\begin{array}{l}\text { Government and Party Organs, Social } \\
\text { Organizations }\end{array}$ & $12.91 \%$ & Sector 15 \\
\hline SEC13 & Others & $0.66 \%$ & Sector 16 \\
\hline
\end{tabular}

Table 2.3: Percentages of Workers in Each Sector in the Workers Sample 


\begin{tabular}{c|c|c|c|c|c|c|c}
\hline \multirow{2}{*}{ Sector } & \multirow{2}{*}{$\mathbf{N}$} & \multicolumn{6}{|c|}{ Percentage of each occupation (\%) } \\
\cline { 3 - 8 } & & Owner & Professional & Head & Office & Skilled & Unskilled \\
\hline $\mathbf{1}$ & 165 & 1.21 & 32.12 & 18.79 & 20.61 & 13.94 & 12.12 \\
$\mathbf{2}$ & 3956 & 0.58 & 17.69 & 7.13 & 13.14 & 36.83 & 22.30 \\
$\mathbf{3}$ & 112 & 1.79 & 31.25 & 10.71 & 16.07 & 17.86 & 17.86 \\
$\mathbf{4}$ & 296 & 0.34 & 27.03 & 8.45 & 17.57 & 29.05 & 14.19 \\
$\mathbf{5}$ & 513 & 0.58 & 19.49 & 11.50 & 22.42 & 27.68 & 14.42 \\
$\mathbf{6}$ & 1394 & 0.65 & 11.98 & 11.69 & 29.34 & 10.40 & 22.31 \\
$\mathbf{7}$ & 372 & 0.54 & 16.40 & 11.56 & 26.88 & 16.67 & 18.82 \\
$\mathbf{8}$ & 490 & 0 & 59.39 & 8.98 & 15.51 & 8.16 & 4.90 \\
$\mathbf{9}$ & 806 & 0.37 & 57.20 & 12.66 & 16.25 & 4.59 & 3.97 \\
$\mathbf{1 0}$ & 261 & 1.15 & 59.39 & 15.71 & 9.58 & 10.73 & 2.30 \\
$\mathbf{1 1}$ & 211 & 0.95 & 26.54 & 14.22 & 50.24 & 4.27 & 1.90 \\
$\mathbf{1 2}$ & 1295 & 1.00 & 16.22 & 30.58 & 44.40 & 3.86 & 2.24 \\
$\mathbf{1 3}$ & 65 & 1.54 & 20.00 & 16.92 & 29.23 & 7.69 & 15.38 \\
\hline
\end{tabular}

Table 2.4: Percentages of Workers by Occupation and Sector

\begin{tabular}{c|c|c|c}
\hline Sector & DR1 & DR2 & DR3 \\
\hline $\mathbf{1}$ & 0.213 & 0.923 & 1.743 \\
$\mathbf{2}$ & 0.721 & 3.125 & 3.233 \\
$\mathbf{3}$ & 13.815 & 59.883 & 77.352 \\
$\mathbf{4}$ & 2.234 & 9.686 & 15.747 \\
$\mathbf{5}$ & 0.336 & 1.457 & 2.331 \\
$\mathbf{6}$ & 0.225 & 0.977 & 1.010 \\
$\mathbf{7}$ & 0.393 & 1.471 & 1.803 \\
$\mathbf{8}$ & 0.0104 & 0.045 & 0.213 \\
$\mathbf{9}$ & 0.0156 & 0.068 & 0.394 \\
$\mathbf{1 0}$ & 0.0835 & 0.362 & 3.629 \\
$\mathbf{1 1}$ & 0.00570 & 0.025 & 0.300 \\
$\mathbf{1 2}$ & 0.0150 & 0.065 & 0.668 \\
$\mathbf{1 3}$ & 3.365 & 14.586 & 21.879 \\
\hline
\end{tabular}

Table 2.5: Original and Recalculated Fatality Risks (Death per 10,000 Workers) 


\begin{tabular}{|c|c|c|c|c|c|c|}
\hline \multirow{3}{*}{$\begin{array}{l}\text { Independent } \\
\text { Variables }\end{array}$} & \multicolumn{6}{|c|}{$\begin{array}{c}\text { Estimated Coefficients } \\
\text { (t-value) }\end{array}$} \\
\hline & \multicolumn{2}{|c|}{ All Workers Sample } & \multicolumn{2}{|c|}{$\begin{array}{l}\text { Skilled and Unskilled } \\
\text { Workers Sample }\end{array}$} & \multirow{2}{*}{$\begin{array}{c}\begin{array}{c}\text { Unskilled } \\
\text { Workers } \\
\text { Sample }\end{array} \\
\text { Model V }\end{array}$} & \multirow{2}{*}{$\begin{array}{c}\begin{array}{c}\text { Skilled } \\
\text { Workers } \\
\text { Sample }\end{array} \\
\text { Model VI }\end{array}$} \\
\hline & Model I & Model II & Model III & Model IV & & \\
\hline Intercept & $\begin{array}{l}8.07 * * * \\
(160.15)\end{array}$ & $\begin{array}{l}8.07 * * * \\
(160.17)\end{array}$ & $\begin{array}{c}8.24 * * * \\
(92.89)\end{array}$ & $\begin{array}{c}8.25 * * * \\
(92.93)\end{array}$ & $\begin{array}{c}8.13^{* * *} \\
(58.40)\end{array}$ & $\begin{array}{c}8.29 * * * \\
(73.43)\end{array}$ \\
\hline EXP & $\begin{array}{c}0.030 * * * \\
(15.42)\end{array}$ & $\begin{array}{c}0.030 * * * \\
(15.39)\end{array}$ & $\begin{array}{c}0.030 * * * \\
(8.59)\end{array}$ & $\begin{array}{c}0.030 * * * \\
(8.55)\end{array}$ & $\begin{array}{c}0.035^{* * *} \\
(6.12)\end{array}$ & $\begin{array}{l}0.025^{* * *} \\
\quad(5.45)\end{array}$ \\
\hline EXP_Squared & $\begin{array}{l}-0.00038 \\
(-8.60) * * *\end{array}$ & $\begin{array}{c}-0.00038 \\
(-8.57) * * *\end{array}$ & $\begin{array}{c}-0.00038 \\
(-4.41) * * *\end{array}$ & $\begin{array}{c}-0.00037 \\
(-4.37) * * *\end{array}$ & $\begin{array}{c}-0.00046 \\
(-3.15) * * *\end{array}$ & $\begin{array}{c}-0.00028 \\
(-2.65) \\
* * *\end{array}$ \\
\hline EDUY & $\begin{array}{c}0.019 * * * \\
(11.34)\end{array}$ & $\begin{array}{c}0.019 * * * \\
(11.37)\end{array}$ & $\begin{array}{c}0.015^{* * * *} \\
(4.60)\end{array}$ & $\begin{array}{c}0.015^{* * *} \\
(4.63)\end{array}$ & $\begin{array}{c}0.012 * * \\
(2.18)\end{array}$ & $\begin{array}{c}0.017 * * * \\
(4.32)\end{array}$ \\
\hline GENDER & $\begin{array}{c}0.063 * * * \\
(7.57)\end{array}$ & $\begin{array}{c}0.063^{* * *} \\
(7.55)\end{array}$ & $\begin{array}{c}0.085 * * * \\
(5.84)\end{array}$ & $\begin{array}{c}0.085^{* * *} \\
(5.84)\end{array}$ & $\begin{array}{c}0.083 * * * \\
(3.55)\end{array}$ & $\begin{array}{c}0.086^{* * *} \\
(4.61)\end{array}$ \\
\hline MARRIAGE & $\begin{array}{c}0.098 * * * \\
(5.95)\end{array}$ & $\begin{array}{c}0.099 * * * \\
(5.97)\end{array}$ & $\begin{array}{c}0.090 * * * \\
(3.40)\end{array}$ & $\begin{array}{c}0.091^{* * * *} \\
(3.45)\end{array}$ & $\begin{array}{l}0.031 \\
(0.77)\end{array}$ & $\begin{array}{c}0.15^{* * *} \\
(4.31)\end{array}$ \\
\hline PARTY & $\begin{array}{c}0.032 * * * \\
(3.13)\end{array}$ & $\begin{array}{c}0.032 * * * \\
(3.11)\end{array}$ & $\begin{array}{c}0.063 * * * \\
(2.66)\end{array}$ & $\begin{array}{c}0.063 * * * \\
(2.64)\end{array}$ & $\begin{array}{l}0.077^{*} \\
(1.74)\end{array}$ & $\begin{array}{c}0.056^{* *} \\
(2.04)\end{array}$ \\
\hline UNDERGW & $\begin{array}{c}0.27 * * * \\
(4.12)\end{array}$ & $\begin{array}{c}0.26 * * * \\
(3.84)\end{array}$ & $\begin{array}{c}0.29 * * * \\
(4.04)\end{array}$ & $\begin{array}{c}0.28^{* * * *} \\
(3.82)\end{array}$ & $\begin{array}{c}0.30 * * * \\
(2.69)\end{array}$ & $\begin{array}{c}0.28^{* * *} \\
(2.83)\end{array}$ \\
\hline TEMPER & $\begin{array}{c}0.077^{* * *} \\
(3.76)\end{array}$ & $\begin{array}{c}0.078^{* * *} \\
(3.80)\end{array}$ & $\begin{array}{c}0.056^{* *} \\
(2.25)\end{array}$ & $\begin{array}{c}0.057^{* *} \\
(2.29)\end{array}$ & $\begin{array}{l}0.045 \\
(0.98)\end{array}$ & $\begin{array}{c}0.059^{* *} \\
(2.03)\end{array}$ \\
\hline TOXIC & $\begin{array}{c}0.092^{* * *} \\
(5.18)\end{array}$ & $\begin{array}{c}0.092^{* * *} \\
(5.18)\end{array}$ & $\begin{array}{c}0.095 * * * \\
(4.15)\end{array}$ & $\begin{array}{c}0.095 * * * \\
(4.16)\end{array}$ & $\begin{array}{l}0.064 \\
(1.36)\end{array}$ & $\begin{array}{c}0.096 * * * \\
(3.73)\end{array}$ \\
\hline
\end{tabular}

Continued

Table 2.6: Regressions without the Interaction Terms of Risk and Unemployment Rate 
Table 2.6 Continued

\begin{tabular}{|c|c|c|c|c|c|c|}
\hline SATISF & $\begin{array}{c}-0.027 * * * \\
(-5.25)\end{array}$ & $\begin{array}{c}-0.026 * * * \\
(-5.24)\end{array}$ & $\begin{array}{c}-0.038 * * * \\
(-4.31)\end{array}$ & $\begin{array}{c}-0.038 * * * \\
(-4.32) \\
\end{array}$ & $\begin{array}{c}-0.035^{* *} \\
(-2.45)\end{array}$ & $\begin{array}{c}-0.038 * * * \\
(-3.35)\end{array}$ \\
\hline INTENSIVE & $\begin{array}{c}0.064 * * * \\
(6.60)\end{array}$ & $\begin{array}{c}0.063 * * * \\
(6.57)\end{array}$ & $\begin{array}{c}0.053^{* * *} \\
(3.11)\end{array}$ & $\begin{array}{c}0.052^{* * *} \\
(3.10)\end{array}$ & $\begin{array}{l}0.012 \\
(0.41)\end{array}$ & $\begin{array}{c}0.080^{* * *} \\
(3.80)\end{array}$ \\
\hline DAY & $\begin{array}{c}-0.051^{* * *} \\
(-7.50)\end{array}$ & $\begin{array}{c}-0.051^{* * *} \\
(-7.47)\end{array}$ & $\begin{array}{c}-0.063^{* * *} \\
(-5.75)\end{array}$ & $\begin{array}{c}-0.063^{* * *} \\
(-5.76)\end{array}$ & $\begin{array}{c}-0.050 * * * \\
(-2.99)\end{array}$ & $\begin{array}{c}-0.074 * * * \\
(-5.05)\end{array}$ \\
\hline PROF & $\begin{array}{c}0.077 * * * \\
(7.12)\end{array}$ & $\begin{array}{c}0.077^{* * *} \\
(7.12)\end{array}$ & N.A. & N.A. & N.A. & N.A. \\
\hline HEAD & $\begin{array}{c}0.062 * * * \\
(4.35)\end{array}$ & $\begin{array}{c}0.062 * * * \\
(4.34)\end{array}$ & N.A. & N.A. & N.A. & N.A. \\
\hline UNSKILLED & $\begin{array}{c}-0.068 * * * \\
(-5.66)\end{array}$ & $\begin{array}{c}-0.078 * * * \\
(-6.00)\end{array}$ & $\begin{array}{c}-0.072^{* * *} \\
(-4.84)\end{array}$ & $\begin{array}{c}-0.086 * * * \\
(-5.18)\end{array}$ & N.A. & N.A. \\
\hline SEC2 & $\begin{array}{c}0.020^{* *} \\
(2.26)\end{array}$ & $\begin{array}{c}0.021^{* *} \\
(2.34)\end{array}$ & $\begin{array}{l}0.025 \\
(1.60)\end{array}$ & $\begin{array}{l}0.024 \\
(1.56)\end{array}$ & $\begin{array}{c}0.079 * * * \\
(3.31)\end{array}$ & $\begin{array}{l}-0.020 \\
(-0.93)\end{array}$ \\
\hline SEC5 & $\begin{array}{c}0.096 * * * \\
(5.27)\end{array}$ & $\begin{array}{c}0.097 * * * \\
(5.30)\end{array}$ & $\begin{array}{c}0.10 * * * \\
(3.22)\end{array}$ & $\begin{array}{c}0.098 * * * \\
(3.16)\end{array}$ & $\begin{array}{c}0.128 * * \\
(2.38)\end{array}$ & $\begin{array}{l}0.067 * \\
(1.74)\end{array}$ \\
\hline SEC11 & $\begin{array}{c}0.21^{* * *} \\
(7.57)\end{array}$ & $\begin{array}{c}0.209 * * * \\
(7.53)\end{array}$ & $\begin{array}{c}0.27 * * \\
(2.41)\end{array}$ & $\begin{array}{c}0.266^{* *} \\
(2.38)\end{array}$ & $\begin{array}{c}0.403^{*} \\
(1.92)\end{array}$ & $\begin{array}{l}0.174 \\
(1.34)\end{array}$ \\
\hline COLLECTIVE & $\begin{array}{c}-0.14 * * * \\
(-11.40)\end{array}$ & $\begin{array}{c}-0.14 * * * \\
(-11.40)\end{array}$ & $\begin{array}{c}-0.14 * * * \\
(-7.71)\end{array}$ & $\begin{array}{c}-0.135 * * * \\
(-7.72)\end{array}$ & $\begin{array}{c}-0.109 * * * \\
(-4.22)\end{array}$ & $\begin{array}{c}-0.164 * * * \\
(-6.78)\end{array}$ \\
\hline INDIVIDUAL & $\begin{array}{c}0.34^{* *} \\
(2.51)\end{array}$ & $\begin{array}{c}0.341^{* * * *} \\
(2.52)\end{array}$ & $\begin{array}{c}1.06 * * * \\
(3.75)\end{array}$ & $\begin{array}{c}1.058 * * * \\
(3.74)\end{array}$ & N.A. & N.A. \\
\hline SINOFOR & $\begin{array}{c}0.22 * * * \\
(5.85)\end{array}$ & $\begin{array}{c}0.217 * * * \\
(5.86)\end{array}$ & $\begin{array}{c}0.21^{* * *} \\
(3.90)\end{array}$ & $\begin{array}{c}0.211^{* * *} \\
(3.90)\end{array}$ & $\begin{array}{l}0.150 \\
(1.52)\end{array}$ & $\begin{array}{c}0.238 * * * \\
(3.73)\end{array}$ \\
\hline FORIEGN & $\begin{array}{c}0.82 * * * \\
(7.11) \\
\end{array}$ & $\begin{array}{c}0.825^{* * *} \\
(7.13)\end{array}$ & $\begin{array}{c}0.52 * * * \\
(2.89)\end{array}$ & $\begin{array}{c}0.520 * * * \\
(2.90)\end{array}$ & $\begin{array}{c}0.470 * * \\
(2.23)\end{array}$ & $\begin{array}{l}0.638^{*} \\
(1.65)\end{array}$ \\
\hline HEAPUB & $\begin{array}{c}0.097 * * * \\
(9.07)\end{array}$ & $\begin{array}{c}0.097 * * * \\
(9.06)\end{array}$ & $\begin{array}{c}0.094^{* * *} \\
(5.23)\end{array}$ & $\begin{array}{c}0.093^{* * *} \\
(5.23)\end{array}$ & $\begin{array}{c}0.122 * * * \\
(4.35)\end{array}$ & $\begin{array}{c}0.065^{* * *} \\
(2.79)\end{array}$ \\
\hline HEASELF & $\begin{array}{c}-0.16 * * * \\
(-10.97)\end{array}$ & $\begin{array}{c}-0.163 * * * \\
(-10.96)\end{array}$ & $\begin{array}{c}-0.16 * * * \\
(-6.60)\end{array}$ & $\begin{array}{c}-0.158 * * * \\
(-6.59)\end{array}$ & $\begin{array}{c}-0.149 * * * \\
(-4.32)\end{array}$ & $\begin{array}{c}-0.065 * * * \\
(-4.77)\end{array}$ \\
\hline LOSE & $\begin{array}{c}-0.17 * * * \\
(-16.80)\end{array}$ & $\begin{array}{c}-0.17 * * * \\
(-16.75)\end{array}$ & $\begin{array}{c}-0.17 * * * \\
(-11.12)\end{array}$ & $\begin{array}{c}-0.17 * * * \\
(-11.05)\end{array}$ & $\begin{array}{c}-0.17 * * * \\
(-6.52)\end{array}$ & $\begin{array}{c}-0.18 * * * \\
(-9.20)\end{array}$ \\
\hline
\end{tabular}

Continued 
Table 2.6 Continued

\begin{tabular}{|c|c|c|c|c|c|c|}
\hline JIANGSU & $\begin{array}{c}0.19 * * * \\
(14.96)\end{array}$ & $\begin{array}{c}0.20 * * * \\
(14.94)\end{array}$ & $\begin{array}{c}0.20 * * * \\
(9.34)\end{array}$ & $\begin{array}{c}0.20 * * * \\
(9.30)\end{array}$ & $\begin{array}{c}0.27 * * * \\
(7.56)\end{array}$ & $\begin{array}{c}0.16^{* * *} \\
(5.77)\end{array}$ \\
\hline GUANGDONG & $\begin{array}{c}0.66^{* * *} \\
(46.25)\end{array}$ & $\begin{array}{c}0.66^{* * *} \\
(46.25)\end{array}$ & $\begin{array}{c}0.61^{* * *} \\
(23.49)\end{array}$ & $\begin{array}{c}0.61^{* * *} \\
(23.49)\end{array}$ & $\begin{array}{c}0.59 * * * \\
(15.89)\end{array}$ & $\begin{array}{c}0.61^{* * *} \\
(16.69)\end{array}$ \\
\hline UNEM & $\begin{array}{c}-2.48 * * * \\
(-13.85)\end{array}$ & $\begin{array}{c}-2.47 * * * \\
(-13.80)\end{array}$ & $\begin{array}{c}-2.67 * * * \\
(-8.41)\end{array}$ & $\begin{array}{c}-2.66 * * * \\
(-8.36)\end{array}$ & $\begin{array}{c}-2.56 * * * \\
(-4.53)\end{array}$ & $\begin{array}{c}-2.62^{* * *} \\
(-6.88)\end{array}$ \\
\hline DR & $\begin{array}{c}0.0056^{* *} \\
(2.09)\end{array}$ & $\begin{array}{l}0.0031 \\
(1.05)\end{array}$ & $\begin{array}{c}0.0070 \\
(1.48)\end{array}$ & $\begin{array}{c}-0.0019 \\
(-0.28)\end{array}$ & $\begin{array}{c}0.016 * * \\
(2.33)\end{array}$ & $\begin{array}{c}-0.0040 \\
(-0.61)\end{array}$ \\
\hline DR $\times$ UNSKILL & - & $\begin{array}{c}0.014^{* *} \\
(2.03)\end{array}$ & - & $\begin{array}{l}0.018^{*} \\
(1.89)\end{array}$ & N.A. & N.A. \\
\hline R-square & 0.44 & 0.45 & 0.42 & 0.42 & 0.41 & 0.41 \\
\hline $\mathbf{N}$ & 9468 & 9468 & 3452 & 3452 & 1462 & 1987 \\
\hline
\end{tabular}

'N.A.' in a cell means the corresponding independent variable cannot be included in the model because it does not vary across observations.

'__ ' in a cell means that the variable is not included in the regression.

* indicates significance at $10 \%$ level; ** indicates significance at $5 \%$ level; *** indicates significance at $1 \%$ level. 


\begin{tabular}{|c|c|c|c|c|c|c|}
\hline \multirow{3}{*}{$\begin{array}{l}\text { Independent } \\
\text { Variables }\end{array}$} & \multicolumn{6}{|c|}{$\begin{array}{c}\text { Estimated Coefficients } \\
\text { (t-value) }\end{array}$} \\
\hline & \multicolumn{2}{|c|}{ All Workers Sample } & \multicolumn{2}{|c|}{$\begin{array}{l}\text { Skilled and Unskilled } \\
\text { Workers Sample }\end{array}$} & \multirow{2}{*}{$\begin{array}{l}\begin{array}{l}\text { Unskilled } \\
\text { Workers } \\
\text { Sample }\end{array} \\
\text { Model V } \\
\end{array}$} & \multirow{2}{*}{$\begin{array}{l}\begin{array}{l}\text { Skilled } \\
\text { Workers } \\
\text { Sample }\end{array} \\
\text { Model VI }\end{array}$} \\
\hline & Model I & Model II & Model III & Model IV & & \\
\hline Intercept & $\begin{array}{l}8.05^{* * *} \\
(159.26)\end{array}$ & $\begin{array}{l}8.05^{* * *} \\
(159.23)\end{array}$ & $\begin{array}{l}8.22 * * * \\
(91.90)\end{array}$ & $\begin{array}{l}8.23 * * * \\
(91.59)\end{array}$ & $\begin{array}{l}8.11 * * * \\
(57.74)\end{array}$ & $\begin{array}{l}8.26 * * * \\
(72.35)\end{array}$ \\
\hline EXP & $\begin{array}{l}0.030 * * * \\
(15.47)\end{array}$ & $\begin{array}{l}0.030 * * * \\
(15.44)\end{array}$ & $\begin{array}{l}0.030 * * * \\
(8.62)\end{array}$ & $\begin{array}{l}0.030 * * * \\
(8.58)\end{array}$ & $\begin{array}{l}0.034^{* * *} \\
(6.11)\end{array}$ & $\begin{array}{l}0.025^{* * *} \\
(5.50)\end{array}$ \\
\hline EXP2 & $\begin{array}{l}-0.00038 \\
(-8.65) * * *\end{array}$ & $\begin{array}{l}-0.00038 \\
(-8.62) * * *\end{array}$ & $\begin{array}{l}-0.00038 \\
(-4.44) * * *\end{array}$ & $\begin{array}{l}-0.00038 \\
(-4.40) * * *\end{array}$ & $\begin{array}{l}-0.00046 \\
(-3.12) * * *\end{array}$ & $\begin{array}{l}-0.00029 \\
(-2.71) \\
* * *\end{array}$ \\
\hline EDUY & $\begin{array}{l}0.019 * * * \\
(11.39)\end{array}$ & $\begin{array}{l}0.019 * * * \\
(11.41)\end{array}$ & $\begin{array}{l}0.015 * * * \\
(4.62)\end{array}$ & $\begin{array}{l}0.015^{* * * *} \\
(4.63)\end{array}$ & $\begin{array}{l}0.012 * * \\
(2.14)\end{array}$ & $\begin{array}{l}0.017 * * * \\
(4.34)\end{array}$ \\
\hline GENDER & $\begin{array}{l}0.063^{* * *} \\
(7.49)\end{array}$ & $\begin{array}{l}0.063^{* * *} \\
(7.49)\end{array}$ & $\begin{array}{l}0.085^{* * *} \\
(5.84)\end{array}$ & $\begin{array}{l}0.085^{* * *} \\
(5.84)\end{array}$ & $\begin{array}{l}0.084^{* * *} \\
(3.58)\end{array}$ & $\begin{array}{l}0.086 * * * \\
(4.61)\end{array}$ \\
\hline MARRIAGE & $\begin{array}{l}0.098 * * * \\
(5.94)\end{array}$ & $\begin{array}{l}0.098 * * * \\
(5.96)\end{array}$ & $\begin{array}{l}0.089 * * * \\
(3.39)\end{array}$ & $\begin{array}{l}0.090 * * * \\
(3.42)\end{array}$ & $\begin{array}{l}0.030 \\
(0.74)\end{array}$ & $\begin{array}{l}0.15^{* * *} \\
(4.30)\end{array}$ \\
\hline PARTY & $\begin{array}{l}0.032 * * * \\
(3.11)\end{array}$ & $\begin{array}{l}0.032 * * * \\
(3.10)\end{array}$ & $\begin{array}{l}0.063 * * * \\
(2.64)\end{array}$ & $\begin{array}{l}0.062 * * * \\
(2.63)\end{array}$ & $\begin{array}{l}0.075^{*} \\
(1.69)\end{array}$ & $\begin{array}{l}0.058 * * \\
(2.08)\end{array}$ \\
\hline UNDERGW & $\begin{array}{l}0.26 * * * \\
(3.94)\end{array}$ & $\begin{array}{l}0.25^{* * *} \\
(3.80)\end{array}$ & $\begin{array}{l}0.28 * * * \\
(3.90)\end{array}$ & $\begin{array}{l}0.28 * * * \\
(3.78)\end{array}$ & $\begin{array}{l}0.30 * * * \\
(2.68)\end{array}$ & $\begin{array}{l}0.28 * * * \\
(2.83)\end{array}$ \\
\hline TEMPER & $\begin{array}{l}0.079 * * * \\
(3.82)\end{array}$ & $\begin{array}{l}0.079 * * * \\
(3.84)\end{array}$ & $\begin{array}{l}0.057 * * \\
(2.31)\end{array}$ & $\begin{array}{l}0.058 * * \\
(2.32)\end{array}$ & $\begin{array}{l}0.045 \\
(0.98)\end{array}$ & $\begin{array}{l}0.059 * * \\
(2.03)\end{array}$ \\
\hline TOXIC & $\begin{array}{l}0.093 * * * \\
(5.25)\end{array}$ & $\begin{array}{l}0.093 * * * \\
(5.24)\end{array}$ & $\begin{array}{l}0.097 * * * \\
(4.22)\end{array}$ & $\begin{array}{l}0.096^{* * * *} \\
(4.21)\end{array}$ & $\begin{array}{l}0.069 \\
(1.46)\end{array}$ & $\begin{array}{l}0.097 * * * \\
(3.76)\end{array}$ \\
\hline SATISF & $\begin{array}{l}-0.027 * * * \\
(-5.27)\end{array}$ & $\begin{array}{l}-0.027 * * * \\
(-5.27)\end{array}$ & $\begin{array}{l}-0.038 * * * \\
(-4.32)\end{array}$ & $\begin{array}{l}-0.038 * * * \\
(-4.32)\end{array}$ & $\begin{array}{l}-0.036 * * \\
(-2.46)\end{array}$ & $\begin{array}{l}-0.038 * * * \\
(-3.36)\end{array}$ \\
\hline INTENSIVE & $\begin{array}{l}0.063^{* * * *} \\
(6.50)\end{array}$ & $\begin{array}{l}0.063^{* * *} \\
(6.49)\end{array}$ & $\begin{array}{l}0.051^{* * *} \\
(3.05)\end{array}$ & $\begin{array}{l}0.052 * * * \\
(3.05)\end{array}$ & $\begin{array}{l}0.0090 \\
(0.32)\end{array}$ & $\begin{array}{l}0.080 * * * \\
(3.82)\end{array}$ \\
\hline
\end{tabular}

Continued

Table 2.7: Regression Results with Unemployment Rate 
Table 2.7 Continued

\begin{tabular}{|c|c|c|c|c|c|c|}
\hline DAY & $\begin{array}{l}-0.050 * * * \\
(-7.40)\end{array}$ & $\begin{array}{l}-0.050^{* * *} \\
(-7.39)\end{array}$ & $\begin{array}{l}-0.062 * * * \\
(-5.64)\end{array}$ & $\begin{array}{l}-0.063^{* * *} \\
(-5.66)\end{array}$ & $\begin{array}{l}-0.048^{* * *} \\
(-2.84)\end{array}$ & $\begin{array}{l}-0.074 * * * \\
(-5.06)\end{array}$ \\
\hline PROF & $\begin{array}{l}0.077^{* * *} \\
(7.17)\end{array}$ & $\begin{array}{l}0.077 * * * \\
(7.16)\end{array}$ & N.A. & N.A. & N.A. & N.A. \\
\hline HEAD & $\begin{array}{l}0.062^{* * *} \\
(4.37)\end{array}$ & $\begin{array}{l}0.062 * * * \\
(4.36)\end{array}$ & N.A. & N.A. & N.A. & N.A. \\
\hline UNSKILLED & $\begin{array}{l}-0.069 * * * \\
(-5.77)\end{array}$ & $\begin{array}{l}-0.075^{* * *} \\
(-5.71)\end{array}$ & $\begin{array}{l}-0.073 * * * \\
(-4.87)\end{array}$ & $\begin{array}{l}-0.082 * * * \\
(-4.85)\end{array}$ & N.A. & N.A. \\
\hline SEC2 & $\begin{array}{l}0.020 * * \\
(2.18)\end{array}$ & $\begin{array}{l}0.020 * * \\
(2.24)\end{array}$ & $\begin{array}{l}0.025 \\
(1.61)\end{array}$ & $\begin{array}{l}0.025 \\
(1.58)\end{array}$ & $\begin{array}{l}0.081^{* * *} \\
(3.37)\end{array}$ & $\begin{array}{l}-0.021 \\
(0.99)\end{array}$ \\
\hline SEC5 & $\begin{array}{l}0.096^{* * *} \\
(5.29)\end{array}$ & $\begin{array}{l}0.097 * * * \\
(5.30)\end{array}$ & $\begin{array}{l}0.10^{* * *} \\
(3.25)\end{array}$ & $\begin{array}{l}0.010 * * * \\
(3.20)\end{array}$ & $\begin{array}{l}0.128^{* *} \\
(2.38)\end{array}$ & $\begin{array}{l}0.068^{*} \\
(1.78)\end{array}$ \\
\hline SEC11 & $\begin{array}{l}0.21^{* * *} \\
(7.59)\end{array}$ & $\begin{array}{l}0.21^{* * *} \\
(7.57)\end{array}$ & $\begin{array}{l}0.27^{* *} \\
(2.42)\end{array}$ & $\begin{array}{l}0.27^{* *} \\
(2.39)\end{array}$ & $\begin{array}{l}0.40^{*} \\
(1.91)\end{array}$ & $\begin{array}{l}0.18 \\
(1.37)\end{array}$ \\
\hline COLLECTIVE & $\begin{array}{l}-0.14^{* * *} \\
(-11.38)\end{array}$ & $\begin{array}{l}-0.14 * * * \\
(-11.37)\end{array}$ & $\begin{array}{l}-0.14 * * * \\
(-7.68)\end{array}$ & $\begin{array}{l}-0.14^{* * *} \\
(-7.68)\end{array}$ & $\begin{array}{l}-0.11^{* * * *} \\
(-4.17)\end{array}$ & $\begin{array}{l}-0.16^{* * * *} \\
(-6.77)\end{array}$ \\
\hline INDIVIDUAL & $\begin{array}{l}0.34 * * \\
(2.51)\end{array}$ & $\begin{array}{l}0.34 * * * \\
(2.51)\end{array}$ & $\begin{array}{l}1.06^{* * *} \\
(3.75)\end{array}$ & $\begin{array}{l}1.06^{* * *} \\
(3.74)\end{array}$ & N.A. & N.A. \\
\hline SINOFOR & $\begin{array}{l}0.22 * * * \\
(5.87)\end{array}$ & $\begin{array}{l}0.22 * * * \\
(5.88)\end{array}$ & $\begin{array}{l}0.21^{* * *} \\
(3.92)\end{array}$ & $\begin{array}{l}0.21 * * * \\
(3.91)\end{array}$ & $\begin{array}{l}0.15 \\
(1.53)\end{array}$ & $\begin{array}{l}0.24^{* * *} \\
(3.73)\end{array}$ \\
\hline FORIEGN & $\begin{array}{l}0.80 * * * \\
(6.93)\end{array}$ & $\begin{array}{l}0.81^{* * *} \\
(6.95)\end{array}$ & $\begin{array}{l}0.52^{* * *} \\
(2.90)\end{array}$ & $\begin{array}{l}0.52^{* * *} \\
(2.90)\end{array}$ & $\begin{array}{l}0.47 * * \\
(2.23)\end{array}$ & $\begin{array}{l}0.64^{*} \\
(1.65)\end{array}$ \\
\hline HEAPUB & $\begin{array}{l}0.097 * * * \\
(9.07)\end{array}$ & $\begin{array}{l}0.097 * * * \\
(9.06)\end{array}$ & $\begin{array}{l}0.093^{* * *} \\
(5.19)\end{array}$ & $\begin{array}{l}0.093^{* * *} \\
(5.20)\end{array}$ & $\begin{array}{l}0.12^{* * *} \\
(4.29)\end{array}$ & $\begin{array}{l}0.065^{* * * *} \\
(2.79)\end{array}$ \\
\hline HEASELF & $\begin{array}{l}-0.16^{* * *} \\
(-10.93)\end{array}$ & $\begin{array}{l}-0.16^{* * *} \\
(-10.93)\end{array}$ & $\begin{array}{l}-0.16^{* * *} \\
(-6.64)\end{array}$ & $\begin{array}{l}-0.16 * * * \\
(-6.62)\end{array}$ & $\begin{array}{l}-0.15^{* * *} \\
(-4.39)\end{array}$ & $\begin{array}{l}-0.16^{* * *} \\
(-4.74)\end{array}$ \\
\hline LOSE & $\begin{array}{l}-0.17 * * * \\
(-16.77)\end{array}$ & $\begin{array}{l}-0.17 * * * \\
(-16.74)\end{array}$ & $\begin{array}{l}-0.17 * * * \\
(-11.09) \\
\end{array}$ & $\begin{array}{l}-0.17 * * * \\
(-11.05)\end{array}$ & $\begin{array}{l}-0.17 * * * \\
(-6.48)\end{array}$ & $\begin{array}{l}-0.18 \\
(-9.18)\end{array}$ \\
\hline JIANGSU & $\begin{array}{l}0.20 * * * \\
(15.04)\end{array}$ & $\begin{array}{l}0.20 * * * \\
(15.02)\end{array}$ & $\begin{array}{l}0.20 * * * \\
(9.43)\end{array}$ & $\begin{array}{l}0.20 * * * \\
(9.38)\end{array}$ & $\begin{array}{l}0.28 * * * \\
(7.62)\end{array}$ & $\begin{array}{l}0.16^{* * *} \\
(5.83)\end{array}$ \\
\hline GUANGDONG & $\begin{array}{l}0.67 * * * \\
(46.38)\end{array}$ & $\begin{array}{l}0.67 * * * \\
(46.35)\end{array}$ & $\begin{array}{l}0.61 * * * \\
(23.57)\end{array}$ & $\begin{array}{l}0.6 * * * \\
(23.53)\end{array}$ & $\begin{array}{l}0.60^{* * * *} \\
(15.95)\end{array}$ & $\begin{array}{l}0.61^{* * *} \\
(16.70)\end{array}$ \\
\hline UNEM & $\begin{array}{l}-2.29 * * * \\
(-11.84)\end{array}$ & $\begin{array}{l}-2.31^{* * *} \\
(-11.89)\end{array}$ & $\begin{array}{l}-2.36^{* * *} \\
(-6.57)\end{array}$ & $\begin{array}{l}-2.43^{* * *} \\
(-6.67)\end{array}$ & $\begin{array}{l}-2.34 * * * \\
(-3.69)\end{array}$ & $\begin{array}{l}-2.24^{* * *} \\
(-4.95)\end{array}$ \\
\hline
\end{tabular}

Continued 
Table 2.7 Continued

\begin{tabular}{|c|c|c|c|c|c|c|}
\hline DR*UNEM & $\begin{array}{l}-1.37 * * * \\
(-3.29)\end{array}$ & $\begin{array}{l}-1.24 * * * \\
(-2.87)\end{array}$ & $\begin{array}{l}-1.42^{* *} \\
(-1.99)\end{array}$ & $\begin{array}{l}-0.11 \\
(-1.46) \\
\end{array}$ & $\begin{array}{l}-1.63 \\
(-1.37)\end{array}$ & $\begin{array}{l}-0.97 \\
(-0.98)\end{array}$ \\
\hline DR*UNEM2 & $\begin{array}{l}8.43^{* * *} \\
(2.99)\end{array}$ & $\begin{array}{l}7.74 * * * \\
(2.67)\end{array}$ & $\begin{array}{l}8.58 * \\
(1.75)\end{array}$ & $\begin{array}{l}6.82 \\
(1.33)\end{array}$ & $\begin{array}{l}11.49 \\
(1.43)\end{array}$ & $\begin{array}{l}3.80 \\
(0.57)\end{array}$ \\
\hline DR & $\begin{array}{l}0.055^{* * *} \\
(3.68)\end{array}$ & $\begin{array}{l}0.048^{* * *} \\
(3.01)\end{array}$ & $\begin{array}{l}0.056 * * \\
(2.35)\end{array}$ & $\begin{array}{l}0.039 \\
(1.39)\end{array}$ & $\begin{array}{l}0.062^{*} \\
(1.70)\end{array}$ & $\begin{array}{l}0.043 \\
(1.17)\end{array}$ \\
\hline DR $\times$ UNSKILL & - & $\begin{array}{l}0.008 \\
(1.09)\end{array}$ & - & $\begin{array}{l}0.012 \\
(1.16)\end{array}$ & N.A. & N.A. \\
\hline R-square & 0.45 & 0.45 & 0.42 & 0.42 & 0.42 & 0.41 \\
\hline $\mathbf{N}$ & 9468 & 9468 & 3452 & 3452 & 1462 & 1987 \\
\hline
\end{tabular}

Same notations as in Table 2.6. 


\begin{tabular}{c|c|c|c|c}
\hline \multicolumn{2}{c|}{ Skilled and Unskilled Workers } & \multicolumn{2}{c}{ Unskilled Workers } \\
\hline & Model III & Model IV & & Model V \\
\hline DR2 & 0.00016 & -0.00044 & DR3 & $0.0029 * *$ \\
& $(1.48)$ & $(-0.28)$ & & $(2.36)$ \\
DR2 $\times$ & - & $0.0041^{*}$ & DR3 $\times$ & N.A. \\
UNSKILL & & $(1.89)$ & UNSKILL & \\
\hline
\end{tabular}

$*$ and $* *$ indicate significance at $10 \%$ and $5 \%$ levels respectively.

Table 2.8: Parameter Estimates Using Alternative Risk Estimates without Unemployment

\begin{tabular}{c|c|c|c|c}
\hline \multicolumn{2}{c|}{ Skilled and Unskilled Workers } & Unskilled Workers \\
\hline & Model III & Model IV & & Model V \\
\hline DR2 & $0.013^{* *}$ & 0.0090 & DR3 & 0.011 \\
& $(2.35)$ & $(1.39)$ & & $(1.62)$ \\
DR2 $\times$ & & 0.0027 & DR3 $\times$ & N.A. \\
UNSKILL & & $(1.16)$ & UNSKILL & \\
DR2 $\times$ & $-0.327 * *$ & -0.256 & DR3 $\times$ & -0.272 \\
UNEM & $(-1.99)$ & $(-1.46)$ & UNEM & $(-1.30)$ \\
DR2 $\times$ & $1.979 *$ & 1.574 & DR3 $\times$ & 1.932 \\
UNEM2 & $(1.75)$ & $(1.33)$ & UNEM2 & $(1.36)$ \\
\hline * and ** indicate significance at 10\% and 5\% levels respectively.
\end{tabular}

Table 2.9: Parameter Estimates Using Alternative Risk Estimates with Unemployment 


\begin{tabular}{|c|c|c|c|c|}
\hline \multirow[t]{2}{*}{ Estimated VSL } & \multicolumn{2}{|c|}{$\begin{array}{l}\text { Model without the } \\
\text { interaction of the } \\
\text { unemployment rate }\end{array}$} & \multicolumn{2}{|c|}{$\begin{array}{c}\text { Model with the } \\
\text { interaction of the } \\
\text { unemployment rate } \\
\text { Unemployment rate = } \\
0.061\end{array}$} \\
\hline & DR1 & DR3 & DR1 & DR3 \\
\hline 1995 & 119,460 & 21,652 & 38,825 & 11,923 \\
\hline
\end{tabular}

Table 2.10: VSL Estimates under Different Assumptions (US\$) 


\section{CHAPTER 3}

\section{CONTINGENT VALUATON METHOD AND THE WILLINGNESS-TO-PAY FOR HEALTH RISK REDUCTIONS IN CHINA}

\subsection{Introduction}

The Contingent Valuation (CV) method uses survey questions to ask respondents to directly value the good or service of interest in a hypothetical market. The CV method is very flexible as researchers can construct a hypothetical market with a desired provision structure and payment vehicle for a wide range of public or private goods. The goods that have been valued by the CV method include environmental amenities, resources, new private commodities and health risks. The limitation of the CV method is the hypothetical nature of the CV survey; people's stated preferences may deviate from their true preferences because of the hypothetical scenario.

Despite its apparent simplicity, CV requires the researcher to make multiple decisions to ensure valid and reliable responses from survey subjects. Because it is a hypothetical method for valuing goods and services that cannot be valued in a traditional market setting, the derived values cannot be validated externally. As such, the burden turns to the researcher to make survey design decisions to ensure the internal validity of the derived values. 
In this chapter, a CV survey study conducted in China to elicit people's WTP for health risk reductions of asthma and mortality is reported. Two important issues of the stated valuation method are discussed: (1) the potential impact of the provision mechanisms of the good to be valued-private provision mechanism and public provision mechanism-to people's WTP. Since health care could be either privately provided or publicly provided, it is important for researchers to know whether the provision mechanisms would affect people's WTP for the same health risk reduction; (2) the scope/scale effects of the CV survey are discussed and tested empirically. At last, the value of a statistical life (VSL) and the value of a statistical case of asthma are estimated.

\subsection{Literature Review}

The Contingent Valuation method was first proposed by Ciriacy-Wantrup in 1947 to reveal preferences on externalities. He also suggested the cooperation of economists and psychologists in the design and implementation of CV surveys. In 1984, the US EPA held a conference that brought together practitioners of $\mathrm{CV}$, other economists and psychologists to assess the state-of-art of the CV method (Cummings et al., 1986). In 1989, Mitchell and Carson published their book "Using surveys to value public goods: the Contingent Valuation method”, which included elements from economics, psychology and political science; it became a standard reference on CV. In 1992, the Exxon Valdez oil spill study (Carson et al., 2003) propelled CV into the mainstream. Although there is still debate on the validity of the CV method, CV is more and more accepted by both economists and policy makers as a valid and efficient way to value nonmarket goods. 
Jones-Lee et al. (1985) used a UK national sample CV survey to study the value of transport safety. Jones-Lee et al. tried to measure people’s WTP for both privately provided safety improvement, like safer coach trip with lower probability of fatal accidents, new safety features of car to reduce probability of fatal accidents, and publicly provided safety improvement like a government road improvement project to reduce probability of fatal accidents with different payment rules. However, there was a flaw in their public project question design (pp58, footnote 1). The question did not specify whether the payment collection would be once or repeated annually. This made the result from this question questionable. Open-ended question format was used. From their results, an estimated value of a statistical life was about $£ 800,000$. They also sorted their results into categories of supporting credibility of the CV method, casting doubt on credibility and neutral to credibility.

Tolley et al. (1994) reviewed applications of the CV method to health symptoms related to air pollution. Loehman et al. (1979) used a mail questionnaire to ask Florida residents their WTP to reduce symptoms associated with sulfur oxides including shortness of breath, chest pain, coughing, sneezing, head congestion, etc. Respondents were asked to value various days of symptom relief. Rowe and Chestnut (1984) estimated the value of a reduction in asthma symptoms, using personal interviews of a group of individuals suffering asthma. They found a mean bid for a 50\% reduction (19 days in average) in bad asthma days of $\$ 401$ per year, with a standard deviation of $\$ 85$. Viscusi et al. (1991) estimated the value of reductions in the risk of chronic bronchitis using a sample from the general population. To communicate the chronic disease effects to potential sufferers, they used an interactive personal-computer program. They found that 
the mean WTP for one statistical case of chronic bronchitis is about $\$ 883,000$, with a standard error of $\$ 114,000$. Similar to Viscusi et al., my study also value health risk reduction based on a sample from the general population.

Hammitt and Zhou (2006) valued colds, chronic bronchitis and mortality related to air pollution in China using a three-location CV survey for the general population. They asked people's WTP for risk reductions of getting the health effects. They estimated that the value of a statistical case of cold ranged between $\$ 3$ and $\$ 6$, the value of a statistical case of chronic bronchitis ranged between $\$ 500$ and $\$ 1,000$, and the value per statistical life ranged between $\$ 4200$ and $\$ 16,900$. This study is known as the first wellorganized and peer-reviewed CV study on health effects in China. Our study is based on Hammitt and Zhou by using similar WTP question for health risk reduction.

\subsection{Hypotheses}

\subsubsection{The Private and Public Provision Mechanisms of Health Risk Reduction}

Health risk reduction could be either privately provided as a market good or publicly provided as a government public project/service. In the literature of health risks valuation, CV surveys have asked people’s WTP for medicines, treatments, private water line filter installment, automobile safety equipment and other goods aiming to reduce health risks. Health risks can also be valued as public goods in CV surveys, such as medicines to treat infectious diseases, and government projects to reduce health risks. In the real world, health care is an important part of the public provision of private goods in both developed and developing countries. An interesting and important question thus is whether the different provision mechanisms would affect people's valuation of health 
risk reduction differently. This question is important because the difference of valuation may result different cost-benefit analysis conclusion and thus result different policy implication. Some theories such as the altruism theory and Andreoni's warm-glow theory suggest that public and private provision mechanisms may result different valuation of people for the same good. However, very few empirical studies have been done to test whether the difference exists. If this difference exists empirically, researchers must be cautious when they use CV survey to reveal people's WTP for certain goods. If the good can be either privately or publicly provided, researchers must make a decision on which provision should be used for the WTP question in the survey. If the difference is not significant, it suggests that the theories predicting the difference may be not consistent with the empiric. In this chapter, I test empirically whether there are different effects between the private and the public provision mechanisms to people's WTP responses to the same health risk reduction in the CV survey.

\section{Public and Quasi-Public Goods}

Public provision of health risk reduction can be viewed as a public or quasi-public good. If the public provision is a public good, for example, an outdoor air pollution reduction project, it has the properties of non-rivalry and non-excludability. Nonexcludability means that it is either impossible, or at least very costly to prevent consumption of the good by those who fail to pay for it once it is supplied; non-rivalry means that one individual's consumption of the good does not interfere with any other individual's ability to consume it. Due to these two properties, the utility maximizing choice of an economic agent who maximizes his utility on the amounts of consumptions of private goods and public goods is to free ride: he could pay less than a public good is 
worth to him in the expectation that others will pay enough to provide it nevertheless (Mitchell and Carson, 1989). The free riding expectation of people's strategic response is based on the assumption that each person maximizes utility, while taking both the price of the public good and the quantities bought by all other individuals as given. Under this assumption, the utility-maximizing amount of public good a person should purchase is zero given a price of the public good. This implies that if the supply of public goods is left to the market, there will be undersupply. As to the stated preference methods to reveal public goods' values, Paul Samuelson in his 1954 paper stated: "It is in the selfish interest of each person to give false signals, to pretend to have less interest in a given collective activity than he really has.” If the public provision is a quasi-public good, which is an erstwhile public good that has had payment and exclusion mechanisms attached to it by a central authority structure, people would have less incentive to free ride because of the attached payment and exclusion mechanism. However, when the mechanism is hypothetical as in a CV survey, the incentive to free-ride of respondents may still exist depending on the perception of the respondents: if respondents believe that the provision of the public good will not be contingent on their stated WTP amounts and they will actually have to pay their stated WTP, the free riding effect suggests that respondents will understate their true WTP. On the other hand, if respondents believe that the provision of the public good will be contingent on their stated WTP amounts and they will not actually have to pay their stated WTP, then they have the incentive to overstate their WTP. This effect is called "over-pledging".

Taking the free riding assumption as true, some researchers try to make special designs in a preference revealing procedure to make it incentive compatible, i.e., it is the 
individual's self-interest to reveal his true preference. Clarke (1971), Groves (1973), Grove and Loeb (1975), and Groves and Ledyard (1977) proposed one class of incentive compatible demand revelation devices (ICDRDs) with the property that under the reasonable assumptions about preferences, it is the selfish interest of the consumer to report his true WTP. Gibbard (1973) and Satterwaite (1975) found requirements for a non-manipulable voting mechanism. Indeed, derived from Gibbard and Satterwaite, binary choice question is the only response format that is potentially incentive compatible (Carson et al., 2000). Becher, DeGroot and Marschak (1964) proposed an incentive compatible elicitation procedure now commonly employed in value elicitation experiments. Applied to the CV methodology, incentive compatible devices relate to the WTP/WTA question format, payment rule and other designs of WTP/WTA question. As to valuing public or quasi-public goods, Hoehn and Randall (1987) illustrated that 'in a policy referendum model with individual parametric costs, truth-telling is the individual optimal strategy'. The NOAA Blue Ribbon Panel report also favors the referendum format because 'it is realistic: referenda on the provision of public goods are not uncommon in real life. And, there is no strategic reason for the respondent to do other than answer truthfully... (Arrow et al., pg 21).' Based on Green et al. (1998) and Carson et al. (2000), Guo and Haab (2003) illustrated the necessary and sufficient conditions for the referendum format and open-ended format WTP questions to be incentive compatible. They showed that contrary to the prejudice that the open-ended format WTP question cannot be incentive compatible, under some conditions, the open-ended question format can be designed as a variation of the Becker-Degroot-Marschak (1964) utility elicitation procedure, so that to be incentive compatible indeed. However, except the referendum 
format, various incentive compatible devices are generally too complex to be implemented in field.

\section{Altruism and Warm-Glow}

Some researchers doubt the assumption of self-interest and have found that experiments and real-life evidence are inconsistent with this assumption. Marwell and Ames (1979, 1980, and 1981) implement an experiment with a setting very closely corresponding to the conventional model of public good purchasing and consumption, and thus provides a direct test of the hypothesis that individuals act according to parametric instrumental rationality. The experimental result was that subjects contribute less to the collective activity than would be necessary for Pareto efficiency, but much more than was implied by the selfish assumption. Other experimental results against selfishness assumption include Smith (1980), Isaac and Walker (1988), and many others. In real life, voluntary contributions to charities and political organizations are evidence against the selfishness assumption (for example, see Schiff, 1990).

In order to explain this evidence, alternative theories have been proposed. One stream of the theories is the theory of altruism. In economics, altruism means that people gain welfare from utility of others or consumption undertaken by others. An example of empirical studies to investigate the existence of altruistic preferences is Hudson and Jones (1995). They presented respondents with alternative policies and then asked them which policy they favored, which policy they thought would be in their self-interest, and which policy they considered to be in the public interest. They found the public interest answer was about twice as highly correlated with the favored policy as the self-interest answer. Andreoni and Miller (2002) implemented experiments and categorized subjects' utility 
into three forms of utility functions-selfish, Leontief and perfect substitutes, where the last two types are altruistic utility functions: both subject's self payoff and other people's payoff enter the utility function. They found that about $47.2 \%$ of the subjects behaved strong or weak selfish, about $30.4 \%$ of the subjects behaved consistently with strong or weak Leontief preferences, and about $22.4 \%$ behaved consistently with strong or week perfect substitutes preferences ${ }^{14}$. From these results, they concluded, first, that it is indeed possible to capture altruistic choices with quasi-concave utility functions for individuals, implying that altruistic choices are consistent with the axioms of revealed preference; secondly, individuals are heterogeneous with a range from selfish preferences to altruistic preferences, and there is not one notion of fairness or inequality-aversion that all people follow. Theoretical studies on altruism include different models of altruism (for example, see Johansson (1997)) and the implications of altruism to CV study (Quiggin, 1998), to optimal taxes on externality (Johansson, 1997) and to cost-benefit analysis (McConnell, 1997).

Another theory to explain the absence of free-riding is Andreoni's 'warm glow' theory $(1988,1990)$. The key point of the 'warm glow' theory is that the amount of an individual's voluntary contribution to a public good enters his utility function twice, once as part of the total amount of the public good to be consumed, and again as a private good. This special form of utility function is arranged to capture the author's explanation to voluntary contribution: it is motivated by the desire for the 'warm glow' of believing that one has done a good deed.

\footnotetext{
14 'Strong' here means that, in the experiment, the individual allocates the token exactly as the selfish, Leontief or the perfect substitute utility function predicts. 'Weak' means that the allocation of the individual has the minimal distance to the choices from one of the three utility functions predicted.
} 


\section{Empirical Study on CV and Provision Mechanism}

Implied by the altruism theory and the 'warm glow' theory, people might have different valuations for the same good when it is provided as a private good and when it is provided as a public good or quasi-public good; specifically, the public provision may induce higher WTP than the private provision would. Lower WTP to the public provision may also be resulted, if free-riding is not excluded. In the health care case, the private provision offers the reduction of health risk as a private good to the individual himself, whereas the public provision offers the reduction of health risk to everybody impacted by the public health policy. An individual who has altruistic or 'warm glow' incentive thus might be willing to pay more for the publicly provided health risk reduction than the privately provided same risk reduction.

This prediction of different valuation has been seldom tested empirically by experiments or surveys. Crenson (1971) compared community political support for air pollution programs in the 1960s and found that political parties in communities characterized by a 'private-regarding ethos' tended to ignore pollution issues, whereas in communities where a 'public-regarding ethos' prevailed, such issues were likely to reach an agenda. Mitchell and Carson (1986) observed that, in a pretest of their drinking water risks study, the same respondents gave lower amounts when asked how much they would pay to have a pollution control device installed and maintained in their homes by the city water company than when asked how much they would pay in higher water bills to have the town's water plant install and maintain new equipment that would achieve the same risk reduction, but for everyone in the community. These respondents valued the latter program more because they perceived that it protected others besides themselves. Jones- 
Lee et al. (1985) implemented a national CV survey on the value of different morbidity risks. They ask people's WTP on reduction of the risk of car accident by traveling with a safer coach firm, by purchasing additional safety features for private car, and by paying for a public project of road improvement. They found the resulted VSL from the first two questions are much larger than the VSL computed from the last WTP question. However, as they indicated, their public project question introduced unintended ambiguities by failing to clarify the period of validity of the project and the type people's payment (once for all, or repeated annually). Another flaw of this study is that all of these three questions use open-ended formats instead of binary choice format, which might introduce incentive incompatibility.

Perceived Effectiveness of the Provision Mechanisms of Health Risk Reduction

Besides the theories that imply people’s possibly different responses to public and private goods or provision mechanisms, the perceived effectiveness of each provision mechanism is also a very important factor. Respondents may perceive that either the private provision is more effective than the public provision of the health risk reduction, or the public provision is more effective. This perception may be caused by respondents trust or distrust to the private provider-hospitals and the public provider-municipal government. Respondents thus may have higher WTP to the provision mechanism with higher perceived effectiveness.

To sum up the potential causes of different WTP to the same good with private and public provision mechanisms, if a great proportion of the respondents have altruistic or 'warm glow' incentive, the public provision may induce a higher mean/median WTP than the private provision mechanism; if a great proportion of the respondents believe 
that the private (public) provision of the health risk reduction is more effective or trustful, we would observe a higher mean/median WTP to the private (public) provided health risk reduction.

Hypothesis Test

To empirically test the possible different valuation to different provision mechanisms, I design a questionnaire to compare the WTP of people for the health risks reduction with both private provision and public provision mechanisms. Through this comparison, my objectives are (1) to test whether the difference between the WTP of these two provision mechanisms exists, (2) to study the factors affecting people's valuation including altruism, warm-glow, and perceived effectiveness. The hypothesis to test is:

Hypothesis 1: private or public provision mechanism of health risk reduction has no significant differential effect on people's WTP.

To test this hypothesis, in the CV survey, the sample is randomly divided into four sub-samples. For each sub-sample, respondents were told about two same treatments, which would reduce health risks of asthma and mortality respectively. For the first subsample, these treatments are described as private goods that respondents can pay to participate in hospitals. Respondents were asked whether they would be willing to pay certain prices for these treatments. For the second sub-sample, respondents were told that the municipal government was planning to organize all residents to participate in these treatments and collect a one-time fee from every resident if the majority of the residents support this program and agree to pay. Respondents were then asked whether they would be willing to pay this fee for this program. For the third sub-sample, respondents were 
asked the WTP question first with the private provision mechanism and then with the public provision mechanism. For the fourth sub-sample, the order of the WTP questions was reversed to control for the possible ordering effect. The WTP questions are in binary choice/referendum format to rule out free riding. Pooling the responses to the first questions of the third and fourth sub-samples with the first and second sub-samples constructs a between-group test, while comparing each individual's valuation in the third and fourth sub-samples constructs a within-group test. The expected/median WTP of the public provision version might be greater than, equal to or less than the expected/median WTP of the private provision version. The null hypothesis is that there is no significant difference between them. If this is not rejected, it implies that people's preferences on health risks are stable; altruistic motivation, warm glow or other factors do not have significant impacts on people's valuation. Thus, researchers may choose to value health risks either as publicly provided or privately provided. It also implies that the altruism or the 'warm glow' theories may not be consistent with people's behavior, at least in this case. If Hypothesis 1 is rejected, and the WTP of the public provision is greater than the WTP of the private provision, it implies that altruistic motive, warm glow or perceived higher effectiveness of the public provision has a great impact to people's valuation. If the expected/median WTP of the private provision is greater than the WTP of the public provision, higher perceived effectiveness of the private provision may be the reason. In these cases, researchers need to be careful when they decide whether to value health risks as private goods or public goods, because it may make a large difference of the resulted total amount of valuation, thus change the result of cost-benefit analysis. Debriefing question about the perceived efficiency of the public provision is asked in the end of the 
survey. Answers to this question are used to test if perceived or expected efficiency affects WTP. In the questionnaire for the third and fourth sub-samples, I also ask each respondent which provision mechanisms they prefer if the cost is the same and why. From the answers to this debriefing question, we may see if altruistic motive, warm glow or perceived effectiveness is a major concern when people decide their WTP answers.

\subsubsection{Scope/Scale Effect of the Contingent Valuation Method}

Insensitivity of the CV WTP result to the scope or scale of the good to be valued is a problem faced by CV economists. There are several different explanations on the cause of the insensitivity of $\mathrm{CV}$ valuation for public goods. A unique possible cause of the scope/scale insensitivity of CV on health risks is the misunderstanding of probability. Public Good/Political Market

Scope/Scale effect was a key issue in the debate on validity of the CV method and is still a very important and fundamental problem in the current theory and practice. Opponents of CV claim that insensitive scope/scale effect of CV estimates contradict economic theory, thus CV is not a valid preference elicitation method; while proponents view no contradiction between CV results and the economics theory. Scope/scale effect is that the WTP from CV survey varies with changes in the scale or scope of the item being valued (Hanemann, 1994). For example, a heavily cited study by both opponents and proponents of CV is the study of Desvousges (1993), which obtained roughly the same WTPs for saving 2000, 20,000 and 200,000 birds. Evidence on the other side also exists. Carson (1997) reviewed 35 CV studies since 1984, where 31 of them reject the scope insensitivity hypothesis. Another term “embedding effect” (Kahneman and Knetsch, 1992) is also commonly used. By Diamond and Hausman's definition, embedding effect is the 
tendency of WTP responses to be highly similar across different surveys, even where theory suggests that responses be very different. Hanemann (1994) pointed out that "embedding effect” includes three distinct notions: 'scope effect', if the object of preference is thought to be the scope or scale of goods, 'sequencing effect', if each good is seen as a separate argument in the utility function, and 'sub-additivity effect' in both utility structures.

With regard to the scope effect, researchers have quite different opinions about how much WTP should vary with scope or scale, and what classic microeconomic theory tells us about it. Diamond (1996) started with a model of utility $I+U(b)$, where $I$ is income to spend on private goods (assuming no income effect) and $U(b)$ is the (sub)utility from the existence of $b$ birds. He also assumed that $U(b)$ is concave in $b$. He studied two scenarios of WTPs'. First, there are $z$ birds, $x$ of them are at risk, and respondent is asked for WTP in order to save $y$ out of $x$ birds at risk. In this scenario, $W T P(y)$ is concave in $y$, i.e., it would increase less than proportion to $y$. The second scenario is that there are $z$ birds, $y$ of them are at risk, the respondent is asked for WTP in order to save all $y$ birds at risk. In this case, $W T P(y)$ is convex in $y$, and it would increase more than proportion to $y$. The author also generalized these results to include income effect and reached that there should be no sizable difference between WTP and WTA if there is no large income effect or a large WTP.

Hanemann (1994) pointed out that Diamond's model assumes that people only care about the ultimate number of birds, but have no preference on the numbers of birds initially alive, at risk or saved. A major part of CV studies are to value non-use (passive 
use, bequest, existence) value of environment instead of use value. For use value, people may care only the quantity and quality of the goods they consume. However it is possible that the structure of utility for non-use value (passive value, bequest value) is different from the structure of use value. Smith and Osborne (1996) suggested a CES utility function to environmental resource with the form $V(I, b)=I+\alpha\left[B^{s}-b^{s}\right]^{1 / s}$, where $I$ is income, $B$ is population number of birds, $b$ is the number of birds lost without policy intervention. It is easy to check that the utility is concave in $(-b)$ when $s$ is less than one (Cornes, 1993). In this case, the ratio of the WTP to save two different amounts of birds varies with the magnitude of s, i.e., the elasticity of substitution between the current population of birds and the number of birds lost without policy intervention.

With regard to the sequencing effect (the same good has different values when it is the first, second or tenth good to be valued) and the sub-additivity effect (WTP to a group of goods is less than sum of WTPs for each individual good), there is less debate. As Hanemann (1994) stated, these effects can be explained in terms of substitution effects and diminishing marginal rates of substitution.

It can be seen that the fundamental difference between the opinions of proponents and opponents of CV method is on what derives individual's utility from environmental amenities. Opponents of CV claim that individual's utility should merely depend on the level of resources, but not the action of preserving or destroying the resources, because "preferences over acts do not provide the consistency that is necessary for consistent economic theory” (Diamond and Hausman, 1994). They conclude the cause of lack of sensitivity to scope to be "warm glow": the responses to WTP questions represent only general support of respondents for environmental protection, which might be raised by 
altruistic motives, sense of duty or moral obligation, but not (merely) by their personal economic motives. Proponents of CV state that the standard view in economics is that decisions about what people value should be left to them (Hanemann, 1994); there is no theory saying that WTP should be more than, less than or exact proportionate to the scope or scale change of environmental amenities, though theory does tell us that WTP should be increasing with the increase of environmental amenities. They regard the insensitivity of $\mathrm{CV}$ results as caused by flaws of questionnaire design and survey implementation, especially the information about the public good given in the questionnaire. For example, Carson and Mitchell (1993) state:

The quality of the response is crucially dependent on the information provided to and perceived by the respondent, and the seriousness with which the respondent takes the survey interview.... That is, simply asking respondents for information about their WTP for a public good does not ensure that one gets a valid CV response. For that to happen, respondents must (i) clearly understand the characteristics of the good they are being asked to value; (ii) find the CV scenario elements related to the good's provision plausible; and (iii) answer the CV questions in a deliberate and meaningful manner.

This criterion proposed by Carson and Mitchell become more and more accepted as the standards of CV survey; researchers have realized the problem of insensitivity to scope or scale and make a lot effort to guarantee the validity of CV applications. In fact, Carson (1997) reviewed 35 CV studies since 1984, where 31 of them reject the scope/scale insensitivity hypothesis.

Health Risks and Near Proportionality

In the field of health risk valuation, the usual scope/scale effect problem of CV is that WTP to health risk reduction is not sensitive to the changes of the reduction of health risk probability. In health risk CV surveys, respondents are often asked to value a medicine or treatment, which could reduce health risk by a certain amount. For example, 
a split-sample survey result may have almost the same amounts of mean/median WTP for 1/1000 and 5/1000 reduction of mortality probability.

On the theoretical implication about the scope/scale sensitivity of WTP with the change of reduction of mortality risk, Hammitt (2000) derives that nearly proportionate change of WTP for the change of mortality risk reduction is implied by the expected state-dependent utility assumption. Near proportionality of WTP to reduce other health risks than mortality risk can also be derived similarly. Individual maximizes his expected state-dependent utility: $E U(p, y)=(1-p) u_{a}(y)+p u_{d}(y)$, where $p$ is the probability of dying during a defined period and $u_{a}(y)$ and $u_{d}(y)$ are his utilities as a function of income $y$ conditional on surviving and dying in that period, respectively. VSL is defined by the marginal rate of substitution between $p$ and $y$ :

$V S L=\frac{d y}{d p}=\frac{u_{a}(y)-u_{d}(y)}{(1-p) u_{a}^{\prime}(y)+p u_{d}^{\prime}(y)}$

Assuming survival is preferred to death $\left[u_{a}(y)>u_{d}(y)\right]$, and the marginal utility of income is non-negative and greater given survival than death $\left[u_{a}^{\prime}(y)>u_{d}^{\prime}(y) \geq 0\right]$, and risk aversion $\left[u_{a}^{\prime \prime}(y) \leq 0, u_{d}^{\prime \prime}(y) \leq 0\right]$, VSL increases with $p$ and $y$. The WTP for a reduction in mortality risk can be obtained by integrating VSL with respect to risk between the initial and final risk levels. As an individual buys successive incremental risk reductions, his VSL declines due to the decreases of risk and income. However, the decrease of VSL should not be substantial for small risk reductions usually valued in CV survey. The reasons are, first, the so-called "dead anyway" effect is small with small initial risk $p$. "Dead anyway" effect is the effect of risk $p$ on VSL. 
Assume $p_{2}=p_{1}+\Delta p$, where $\Delta p$ is a small change of risk. Then when income is constant, the ratio of VSL is: $\frac{V S L_{2}}{V S L_{1}}=\frac{\left(1-p_{1}\right) u_{a}^{\prime}(y)+p_{1} u_{d}^{\prime}(y)}{\left(1-p_{2}\right) u_{a}^{\prime}(y)+p_{2} u_{d}^{\prime}(y)}$. The value of this ration is between $\frac{1-p_{1}}{1-p_{2}}$ and 1 . So this ratio is near to one when $p_{1}, p_{2}$ are small risks, and the difference between $p_{1}$ and $p_{2}$ is small. The second effect is the effect of income $y$ to VSL. Whenever the product of the income elasticity and the WTP is small comparing to income, income changes would have small effect to the VSL. Many empirically estimated income elasticities of VSL are less than 1; the estimated WTP for a small health risk reduction is usually a very small portion of the average income. Thus, the income effect to VSL should also be small. Due to these two reasons, VSL should be nearly constant with respect to small risk changes of interest, and so the WTP can be approximated by initial VSL times the change in mortality probability (rectangular area below VSL function), and then WTP should be nearly proportionate to the reduction of risk. Furthermore, Hammitt (2000) pointed out that near proportionality does not depend on the expected utility maximization assumption, but only depend on local linearity of utility in probabilities, which is satisfied by most alternative theories of decision making under uncertainty. For example, rank-dependent expected (Quiggin, 1982) and cumulative prospect theory (Tversky and Kahneman, 1992). In contrast, prospect theory admitting discontinuities at thresholds where probabilities are rounded to zero and one does not guarantee near proportionality. This theory implies possibilities of both over proportionality and less proportionality, of which the former case has almost never been 
observed in empirical studies ${ }^{15}$. Another problem is that there is no theory regarding where the thresholds occur.

Hammitt and Graham (1999) reviewed 25 CV studies on health risks from 1980 to 1999. Out of them, 14 studies provided information to test the sensitivity of WTP to the magnitude of risk reduction. Among them eight studies were about fatality risks. Of those six studies show significant association between WTP and the magnitude of fatality risks. But all of these studies show less proportionate relationship, instead of near proportionality.

\section{Causes of Insensitivity}

In health risk CV surveys, respondents are often asked to value a medicine or treatment or other goods, which can reduce health risks by a certain amount. In these cases, the object valued in fact is a private good, instead of public or quasi-public good usually valued in the environmental and resource CV surveys, if the health problem or the disease is not infectious. Therefore, the so-called "warm glow" problem should not exist here. Researchers then realize that a possible reason for non-proportionality is that respondents may not be able to report WTP according to the probabilities offered in the survey. One possibility is that the meaning of small probabilities could not be understood by respondents. Another possibility is that respondents build up a subjective probability instead of taking the numbers offered in the survey, which is a case of "scenario rejection” proposed by Mitchell and Carson (1989). Respondents may not trust the baseline risk provided by investigator. Often this baseline risk is an average risk; while respondents may have a prior perception about how likely they would be in the risk of

\footnotetext{
${ }^{15}$ Except some cases of “certainty premium” which may happen when the health risk is reduced from a small number (for example, 1/10,000) to zero (Corso et al., 2001).
} 
mortality or developing a disease. Respondent may also have an estimate about the effectiveness of the stated intervention, which may not be the same as stated in the questionnaire. Combing these perceived risks, respondents will have a perceived posterior baseline risk and after intervention risk. A respondent's WTP depends on both his perceived baseline risk and perceived risk reduction. Respondents with higher perceived baseline risk may be willing to pay more than those with lower perceived baseline risk. (Although, theory implies the baseline effect should be small when the baseline risk is small). Respondents who think the intervention would be effective (meaning large reduction of health risks in this case) may be willing to pay more than those with lower perceived effectiveness of the medicine/treatment.

With regard to the first possible reason: miscommunication of probability, there are evidences that people have limited appreciation for small probabilities (Hammitt and Graham, 1999). To improve probability communication, researchers have developed a number of tools of visual aids and verbal analogies to assist respondents in comprehending the magnitude of risk reductions. Kunreuther et al. (1978) presented respondents with a table reporting the probabilities of a newborn surviving to various ages (a survival curve). Jones-Lee et al. (1985) used graph paper containing 100,000 squares with the appropriate number blacked out. Mitchell and Carson (1986) and Hammitt (1986, 1990) used “risk ladders” which present the numerical probabilities of dying from various causes on a visual scale. Smith and Desvousges (1987) used a series of pie charts. Hammitt and Graham (1999) used verbal “probability analogies” expressing numerical risks as analogous to the corresponding number of minutes in a year. Hammitt and Graham (1999) designed experiments to test the effectiveness of different analogy 
tools to improve probability communication in CV surveys about automobile risk and food-borne risk. They found that the estimated WTP for risk reduction was inadequately sensitive to the difference in probability, and the estimated sensitivity to magnitude was independent of whether respondents were exposed to probability analogies. Corso, Hammitt and Graham (2001) tested the effectiveness of visual aids to improve probability communication. They asked respondents’ WTP to reduce annual mortality risk associated with automobile crashes. Three types of visual aids: linear scale, logarithmic scale and array of dots were assigned to sub-samples of respondents. Their result showed that the estimated WTP was sensitive to the magnitude of risk reduction for independent subsamples of respondents with each of three visual aids, but not for the sub-sample presented with no visual aids. And, the estimated WTP was consistent with near proportionality to risk reduction for the sub-samples presented with a logarithmic scale or an array of 25,000 dots, but not for the sub-sample receiving a linear line. Hammitt and Zhou (2006) used the visual aid of array of 10,000 dots in their CV survey on colds, chronic bronchitis and mortality risks in three areas in China. Results showed no significant positive relationship between risk reductions and WTP. It is not surprising that a communication tool working well for respondents in one country may not work well in another country because of cultural and psychological differences among respondents from different countries. A tool may be more useful to help Chinese respondents is the ‘community analogies’ (Calman and Royston, 1997), which, for example, could compare a 1 in 10,000 risk with 100 expected death per year in a medium city with a population of 1,000,000. This analogy might be more understandable and acceptable to Chinese respondents because it is widely used in news report and other media in China. This tool 
is included into my questionnaire to improve probability communication. Respondents are also asked whether they think the description of risk by using chance (1 in 1000) or by the community analogy is easier to understand.

As to the second possible cause of scenario rejection: perceived prior health risk and posterior risk reduction, researchers could try to reveal the perceived health risk reduction. In my survey, effort is done to approach to the perceived baseline risk of respondents. The technique I use is: first, respondents are told the average risk of developing asthma in Chengdu city, and then they are asked to think about whether they are more likely, less likely or as likely as the average risk to develop asthma in Chengdu city. In the debriefing part of the survey, I ask respondents whether they believe the assumption that there were the stated treatments that would reduce the risk of asthma and mortality respectively. This question differentiates those respondents who have scenario rejection of the WTP question. By this way, we could test if the perceived baseline risk and the possible scenario rejection have significant effects to the magnitude and the scope/scale sensitivity of WTP.

Hypothesis Testing

The hypothesis on the scale/scope sensitivity of WTP to the risk reduction magnitude to test is:

Hypothesis 2: WTP is sensitive to the change of the magnitude of health risk reduction.

To test this hypothesis, one of two different amounts of risk reduction of getting asthma 1/1000 and 3/1000 from the original risk (5/1000) is provided randomly to respondents. For the mortality risk reduction, one of three different magnitudes 3/10,000, $5 / 10,000$ and 10/10,000 are provided randomly to respondents. By using the (log of) risk 
reduction amount as an independent variable, I test whether the estimated coefficient of this variable is positive and significant. If yes, hypothesis 2 is not rejected, meaning that the CV elicitation of people's valuation on asthma and mortality risks is sensitive to the magnitude change of the risk reduction. If hypothesis 2 is rejected, misunderstanding of probability, perceived prior and posterior risk and warm-glow to the public provision, may be the possible causes of the insensitivity.

\subsubsection{Scope/Scale Sensitivity of Different Provision Mechanisms}

From the discussion in the last two sections, "warm glow”, expected effectiveness of the private and public provision mechanism, perceived baseline risk and aftertreatment health risk, misunderstanding of probability are all possible causes of scope/scale insensitivity for the case of valuing health risks reductions. It is interesting to compare the results of the scope/scale sensitivity from the public provision sub-sample with the results from the private provision sub-sample. Thus, hypothesis 3 to test is: Hypothesis 3: the scope/scale sensitivities of the WTP of the private provision version and the public provision version of health risk reduction are not significantly different.

To do this test, an interaction term of the risk reduction amount and the dummy variable for the public provision is used in the regression estimating WTP. If the estimated coefficient of this variable is not significant, it suggests that hypothesis 3 cannot be rejected. If it is significantly positive (negative), it suggests that the WTP of the public provision is more (less) sensitive to the scale change of risk reduction than the WTP of the private provision. Combined to the result of Hypothesis 1, it would provide some useful information. If both Hypothesis 1 and Hypothesis 3 are not rejected, then Hypothesis 3 enforces the suggestion from Hypothesis 1 that people do not have different 
preferences for the private provision and the public provision of health risk reduction. If the scope sensitivity of the private provision sub-sample is greater than the one of the public provision sub-sample, and, at the same time, the WTP for the public provision is larger than the WTP for the private provision, it suggests the possible existence of "warm glow”, which may be the cause of the scope insensitivity. If the private provision scope sensitivity is greater than the public provision scope sensitivity, and the WTP for the public provision is smaller than the WTP for the private provision, perceived low effectiveness of government provision or distrust to the government may be the cause of the insensitivity. If the public provision scope sensitivity is larger than the private provision version, and the WTP for the public provision is greater than the WTP for the private provision, it suggests that people prefer the government provision and maybe have perception of low effectiveness or distrust to the private provision mechanism. For these possible results, I also investigate whether people’s answers to the debriefing questions on the reason of their preference to the private or public provision mechanism support these explanations.

\subsubsection{Severity of Symptoms of Asthma}

Another related test designed in the survey is on the scope/scale effect of WTP to the severity of the described symptoms of asthma. While asked the asthma WTP question, about 230 respondents are randomly assigned with a description of light symptoms of asthma (cold-like symptoms), whereas the rest of the respondents are assigned with a description of more severe symptoms of asthma. The descriptions of the mild and severe symptoms are stated in Table 3.1. 
Standard economic theory places few constraints on how WTP varies with health risks, except that WTP should increase with the magnitude of the benefit. Therefore, all the other variables being equal, WTP should increase with the severity of symptoms of asthma described in the survey.

In the literature, Jones-Lee et al. (1995) elicited WTP to reduce the probabilities of traffic fatality and six specified traffic injuries of varying severity, and elicited probabilities of fatality for a standard gamble between fatality and complete recovery that respondents view as indifferent to each specified injury. They found that the ratio of WTP to prevent injury to WTP to prevent fatality is much larger than the standard gamble probability for the corresponding injury. They suggested this finding represents insensitivity of the WTP values to injury severity, although nonlinearity between WTP and health-related quality of life (HRQL) could also contribute.

In a meta-analysis of five health-related CV studies, Johnson et al. (1997) examined WTP to avoid morbidity associated with 53 short-term health conditions. The authors assigned an estimate of HRQL to each health condition using the Quality of Well Being Scale (QWB) (Kaplan et al., 1993), and estimated a generalized value function that places a dollar value on avoiding any short-term health condition that can be assigned a QWB score. The results show that WTP increases with both severity and duration of the illness avoided, although WTP is relatively insensitive to health quality for mild illnesses.

Haninger and Hammitt (2006) designed and conducted a survey to test whether WTP to reduce risk of acute illness is proportional to the corresponding change in expected quality-adjusted life years (QALYs). They found that stated WTP of survey 
respondents to reduce the risk of food-borne illness increases with the severity of the illness and the amount of the risk reduction.

In this study, a dummy variable is used indicating the respondents receiving the severe symptoms description in the data analysis. The estimated coefficient of this variable is expected to be greater than zero and significant if respondents are sensitive to the stated severity of asthma symptoms in the questionnaire.

\subsection{Survey Instrument}

To estimate the value of health risks caused by air pollution, a CV survey is designed and implemented. This section describes the survey design.

This CV survey is designed to elicit respondent's individual WTP for treatments with different provision mechanisms to reduce health risks. The health end points we choose to value are asthma and mortality. The value of mortality risk or the value of a statistical life is the most important and significant part of value of the health risks caused by air pollution from the existing studies of US (Portnety and Stavins, 2000) and China (World Bank, 1997). Asthma is an important respiratory disease related to air pollution. To my knowledge, the health risk of asthma has not been valued in China before.

\section{WTP Question Format}

Choosing CV question format is an important step in the CV survey design because it decides what type of WTP data (continuous or discrete data) obtained, and more importantly, it relates to respondent's incentive to answer the WTP question honestly. The literature has focused primarily on variations of four types of questions: open-ended questions (OE), bidding games, payment cards and dichotomous or discrete 
choice questions (DC). Due to anchoring and starting point concerns, bidding games and payments cards have not been utilized as often as dichotomous choice and open-ended questions in applications. In 1993, the NOAA Blue Ribbon Panel set forth guidelines on the practical implementation of CV, which suggested CV questions be framed in a referendum format, in which respondents are asked to vote on contributions to a fund for the good of interest. It also has been demonstrated by many studies that dichotomous/referendum format is incentive compatible ${ }^{16}$. Thus, dichotomous choice question format is used for the health risks reduction in the survey.

To remedy the information loss by DC question, a follow-up DC question and a follow-up OE question are also asked. The follow-up DC question asks a higher bid if the respondent answered yes to the first DC question, a lower bid if the respondents answered no. If the answers of a respondent are no-no, he is then asked why he would not be willing to pay the amount, and an OE question is asked 'what is the maximum amount you would be willing to pay?' If he answers 'zero' or 'I would not pay for the treatment', he is then asked whether he would participate in the treatment if it were free. If the respondent would not participate in the treatment even it is free, he is asked why he would not. The answers to these open-ended questions asking why they would not pay for the treatment are used to analyze how respondents decide their WTP.

There are potential bias raised by using follow-up DC question and OE question. First, respondent's perception about the two bids of the double-bounded DC question affects their answers. Usually, a respondent takes the first bid as the cost or price of the good, while he/she may have several different possible perceptions to the second bid

\footnotetext{
${ }^{16}$ For example, see Guo and Haab (2003).
} 
when it is asked. Possible effects of the bias of the second WTP answer include 'cost expectation effect', 'yea-saying', 'anchoring effect', and 'frame effect' (Park, 2003). An easy way to check if the second answer is biased is to use only the first answers to estimate WTP and then use only the second answers to estimate it again and compare if the two estimates are significantly different. The use of the OE question is to differentiate respondents whose WTP is zero, and find out why they have zero WTP.

\section{Sub-Sample Design}

For the asthma WTP question, there are 3 pairs of treatments in the questionnaire design: (1) private provision versus public provision mechanism, (2) high risk reduction amount versus low risk reduction amount, (3) light symptom description versus severe symptom description. The design of these 3 pairs of treatments in the questionnaire is shown in Table 3.2. In the table, version 1, 2, 3 and 4 are corresponding to the provision mechanisms of private, public, first private plus second public, and first public plus second private. Version 1 is assigned with the high risk reduction amount (3/1000). Half of the sub-sample of version 1 is assigned with the light symptom description, while the other half was assigned with the severe symptom description. Sub-sample of version 2 is assigned with the high risk reduction amount and the severe symptom description. Subsamples of version 3 and 4 are assigned with the low risk reduction amount (1/1000) and the severe symptom description. Considering all the variation of three pairs of treatments, there are totally 5 different questionnaire designs as shown in Table 3.2. The targeted ratio of observations among these five groups is 3:3:2:2:2. Each respondent is assigned to one of these 5 groups randomly. 
For the mortality WTP question, there are two sets of treatments of the questionnaire design: (1) provision mechanism and (2) three levels of risk reduction amount 3/10,000, 5/10,000 and 10/10,000. The mortality WTP question has the same provision mechanism as for the asthma WTP question in each questionnaire. The level of risk reduction amount is assigned randomly to each respondent.

\section{Bid Design}

To design the initial bid values for the double-bounded binary WTP questions, result from Hammitt and Zhou (2006) is referred. I apply the four-point bid design targeting on $20 \%, 40 \%, 60 \%$ and $80 \%$ of the probability mass of WTP distribution. The four-point bid is designed as $(5,15,40,100)$ for $1 / 1000$ or $3 / 1000$ risk reduction of asthma and for $3 / 10,000,5 / 10,000$ or $10 / 10,000$ risk reduction of mortality. For the second round bid points, it would be half to the first bid, if the respondent answers 'No', and double of the first bid if the respondent answers 'Yes' to the first round bid.

\section{Private and Public Provision Mechanisms and the WTP Question}

To obtain people’s WTP for health risk reduction, researchers need to choose a hypothetical physical good to represent the health risk reduction, since it would be too abstract for respondents to answer their WTP for 'a 1 in 1000 reduction of probability of developing asthma'. Instead, respondents are often asked to value a proxy good, which could reduce their health risk. A criterion of choosing a candidate of the proxy good is that, ideally, respondents have no preferences to this good itself, but only to the health risk reduction, i.e., the good should be 'neutral' to respondents. In practice, it is not easy to find an appropriate and neutral good to be valued. Pill, treatment, shot and vaccination 
are widely used as proxy goods to risk reduction of diseases ${ }^{17}$. In this study, considering

"treatment" is more neutral to Chinese respondents than "pill”, we use "treatment" as the proxy good in the WTP question for the asthma and mortality risk reduction.

The asthma WTP question with the private provision mechanism is:

"Assume that you could participate in a preventive treatment that would reduce your chance of developing asthma. Nearby accredited hospitals to your home could provide this treatment. But you would have to pay to take part in it. Your health insurance would not cover it. This treatment would have no side effects. It would be for adults only; and it would be effective for one year. It would decrease your chance of developing asthma from 5 out of 1000 to 4 out 1000, which is a decrease of 1 out of 1000. In another word, Chengdu has about 4 million adult residents, in every year, about 20 thousand of them would get asthma; if all the adult residents in Chengdu take part in this treatment, there would be 4000 less people get asthma in the next year. If the cost of the treatment was X yuan, would you participate in this treatment?"

In the public provision version, the referendum format question is:

"Assume that you could participate in a preventive treatment that would reduce your chance of developing asthma. Nearby accredited hospitals to your home could provide this treatment. But you have to pay to take part in it. Your health insurance would not cover it. This treatment would have no side effects. It would be for adults only; and it would be effective for one year. It will decrease your chance of developing asthma from 5 out of 1000 to 4 out 1000, which is a decrease of 1 out of 1000. In another word, Chengdu has about 4 million adult residents, in every year, about 20 thousand of them would get asthma; if all the adult residents in Chengdu take part in this treatment, there would be 4000 less people get asthma in the next year.

Now suppose, to reduce the risk of developing asthma of residents in Chengdu, as a public health policy, the municipal government considered to ask every adult resident to participate in this treatment in nearby accredited hospitals, and ask every adult resident to pay a fee for the treatment, including you and your adult family members. If the majority of the residents would support this policy and pay the fee, the government would implement this policy. This fee would not be covered by health insurance. If the fee was $\mathrm{X}$ yuan per adult, would you be willing to pay it?"

\footnotetext{
${ }^{17}$ See example studies of Hammitt and Zhou (2006), Hammitt (2004), Viscusi et al. (1991).
} 


\section{Survey Mode}

Chinese populations are not very familiar with survey research in general.

Because CV surveys involve hypothetic scenarios that will be especially novel, the faceto-face interview in respondent's home is used as the survey mode, so that interviewers can provide context and explain the questionnaire to interviewees.

\section{Survey Questions}

The core question of the CV survey is the WTP of the respondent on a given scale of reduced health risks. The asthma WTP question is asked to every respondent who does not have asthma. If a respondent does have asthma, he/she is asked about the symptoms of his/her asthma, the severity, the related expenditure spent for asthma, and his/her WTP for a treatment that would provide him/her a symptom-free year without any side effect. Similar questions about chronic bronchitis are also asked to respondents who answered yes to the question 'do you have chronic bronchitis?' The mortality WTP question is asked to every respondent.

Socio-economic questions about the respondent, including age, gender, income, education, occupation, number of people in the household, are asked. Current health conditions of respondent are also asked in the survey. General questions on respondent's perception of environment, air pollution and health risks are also asked. Questions to test if respondents understand the survey content are asked at the end of the survey to ensure the validity of the answers.

\section{Population and Sampling}

The population of this survey is the residential population living in the urban area of Chengdu (defined by the municipal government) for at least one year. The authority- 
defined urban area of Chengdu, primarily within the "outer ring" road, has a size of about 600 square kilometers and 1,168,712 households (estimated by Research Center for Contemporary China). By the spatial sampling method implemented by Research Center for Contemporary China, the sample includes both registered and non-registered residents. The geo-spatial sampling method with aid of GPS data is used to provide a random sample with much less coverage bias than the traditional method based on resident's registration list in China (Landry and Shen, 2003).

About 1400 households were sampled by multi-stage, stratified random sampling with probabilities proportional to size. Chengdu was divided into 769 primary sampling units (PSU); each unit has the size of half minute of longitude by half minute of latitude. Forty PSUs were sampled with probabilities proportional to the estimated population density of each PSU. Each sampled PSU then was divided into 80 secondary sampling units (SSU) with the size of 90 meters by 90 meters. One SSU was sampled randomly in each chosen PSU. Investigators were sent to each chosen SSU to count and record the total addresses (households) in each SSU. The second ring road of Chengdu is traditionally considered as the boundary between the developed urban area and the underdeveloped suburban area. To include more urban residents in our sample, stratification was implemented: within the second ring road (urban), if the total number of addresses in each SSU is greater than 74 , then 74 addresses were sampled randomly from the list of addresses investigator recorded; if the total number of addresses is less than 74 , then all addresses were chosen. Outside the second ring road (suburban), the threshold number of addresses was 20 instead of 74. Interviewers visited the selected households and sampled one respondent from all qualified residents from 18 to 70 years old in each household by 
using Kish Grid. Kish Grid is a widely used simple procedure to select one adult from each dwelling randomly, considering the gender and age of each adult (Kish, 1965, pp398-400). In-person interviews of 997 respondents were conducted successfully. Survey Implementation

Two pretests were done with 25 respondents totally. Wording of the questionnaire were modified according to the pretest findings. Seventy-seven interviewers were recruited from college students of Sichuan University, with help from faculty members. Implementation was supervised by the staff with China Project, Harvard University Center for the Environment and the Research Center for Contemporary China, Peking University.

\subsection{Data Analysis and Results}

\subsubsection{Sample Descriptive Statistics}

The important characteristic variables of the sample are defined in Table 3.3. The characteristics of the sample are described as follows. The average years of age of respondents are 39 years. $46 \%$ of the respondents are male. The average number of education years is about 11 . About $57 \%$ of the respondents are covered by public health insurance, with either full or partial coverage. About $76 \%$ of the total sample is assigned with the severe symptom description of asthma. About $54 \%$ of the respondents think they are very familiar or somewhat familiar with asthma. About $21 \%$ of the respondents think their chance of developing asthma is above the average chance of 5 in 1000 . About $70 \%$ of the respondents believe that the stated scenario of the asthma-preventive treatment is realistic, whereas $59 \%$ of them think the stated scenario of the mortality risk reducing 
treatment is realistic. The average household size is 3 . The average household income is about 23,100 yuan (US\$2888 ${ }^{18}$ ) annually. 35\% of the respondents are assigned with the public provision mechanism in the first WTP question (questionnaire version 2 and 4). Among the respondents who are asked the WTP question with the public provision mechanism, $43 \%$ of them think that the government provision of the preventive treatment would be effective; this is $22 \%$ of the whole sample. These are the unweighted statistics of the sample; the weighted statistics are also reported in Table 3.3.

\subsubsection{WTP Model}

With the survey data, WTP is estimated using regression methods to characterize its relationship to respondent characteristics. WTP is modeled as the following:

$W T P\left(X_{i}, \varepsilon_{i}\right)=f\left(\beta X_{i}+\varepsilon_{i}\right)$

where $f(\cdot)$ is a functional form, usually assumed to be linear or exponential, $X_{i}$ a vector of independent variables associated with respondent $i, \varepsilon_{i}$ an independently and identically distributed error term usually with a logistic or normal distribution, $\beta$ a vector of parameters. In CV surveys, we assume that a respondent answers "yes” to a required bid price $t$ if his/her willingness to pay expressed in equation (3.1) exceeds $t$. When the functional form is exponential, the WTP is defined as

$W T P\left(X_{i}, \varepsilon_{i}\right)=\exp \left(\beta X_{i}+\varepsilon_{i}\right)$

Thus, the probability of a yes response is the probability that the WTP of the respondent exceeds $t$. It can be expressed as:

\footnotetext{
${ }^{18}$ The exchange rate used in this chapter is US\$1=8 yuan.
} 
$\operatorname{Pr}($ yes $)=\operatorname{Pr}\left(W T P>t_{i}\right)$

$=\operatorname{Pr}\left(\exp \left(\beta X_{i}+\varepsilon_{i}\right)>t_{i}\right)$

$=\operatorname{Pr}\left(\varepsilon_{i}>-\left(\beta X_{i}-\ln t_{i}\right)\right)=\operatorname{Pr}\left(\varepsilon_{i}<\beta X_{i}-\ln t_{i}\right)$

Note that the last equality of (3.3) holds only for symmetric $\varepsilon_{i}$ with zero mean. When $\varepsilon_{i}$

has a normal distribution with mean 0 and variance $\sigma^{2}$, the problem can be converted to $\operatorname{Pr}($ yes $)=\Phi\left(\frac{\beta X_{i}-\ln t_{i}}{\sigma}\right)$

This is the probit model. The parameters $\beta$ and $\sigma$ are estimated by maximum-likelihood techniques with yes-no answers coded as 1 and 0 . In the regression, independent variables are factors that are likely to influence respondents’ WTP. A consistent estimate of the expected WTP can be expressed as EWTP $=\exp \left(\beta X_{i}+\frac{1}{2} \sigma^{2}\right)$, and the median WTP as $M W T P=\exp \left(\beta X_{i}\right)$

The exponential functional form is used because it bounds the estimated WTP from zero. Implied by theory, WTP for health risk reduction of an individual should be greater than zero. However, the exponential model may estimate an unrealistically high expected WTP when the design of the bid price could not define the tails of the WTP distribution (Haab and McConnell, 2002). This problem is discussed in more details in the WTP estimation section.

Finally, dividing the WTP estimate for mortality risk reduction by the amount of the risk reduction provided to respondents yields the estimate of the value of a statistical life (VSL). The value of a statistical case of asthma can be estimated similarly. 


\subsubsection{WTP to Reduce the Current Risk of Developing Asthma}

Assuming the exponential form of WTP as in equation (3.2) with normal distributed error term, I estimate the WTP with a Binary Probit model. The dependent variable is the yes-no response to the first bid price for each respondent. Regression using the follow-up response only shows significantly different estimated coefficients and lower mean/median WTP than the results from the regression using the first round responses. This suggests that the responses of respondents to the follow-up question might be strategic. Therefore, the double-bounded WTP model is not used.

Respondents who stated that they currently had asthma are eliminated from the sample for the asthma regression. Observations with missing values of independent variables are also deleted from the sample. I also found very strong interviewer effect from two interviewers by using interviewer dummy variables. Thus, 59 respondents who were interviewed by these two interviewers are then also eliminated from the sample. It results in a sample with 726 respondents in the asthma WTP regression. The unweighted and weighted statistics of observations used in the regression are reported in Table 3.4. Table 3.5 shows the unweighted and weighted yes rate of this sample to reduce the risk of asthma.

The parameter estimates of WTP to reduce the risk of developing asthma are presented in Table 3.6. In this regression, only the first valuation question from each respondent is used, although in the version 3 and 4 of the questionnaire, each respondent was asked two sets of WTP questions with both the private provision and the public/government provision mechanisms. Regression using both of those two sets of WTP responses is also done and will be discussed later. The regression is weighted with 
the sampling weight of each respondent to represent the whole population. The result in Table 3.6 shows that the probability of the yes-response is decreasing with the logarithm of the bid price value. Respondents who believe in the stated scenario of the preventive treatment have significantly higher WTP. Education year also has a positive and significant effect to WTP. The household income is negative but insignificant. The estimated coefficient of the dummy of the public provision is positive but insignificant. The coefficient of the interaction term of household income and the public provision is negative and significant at 5\%, showing that respondents with higher household income are less likely to say yes to the public provision version of the WTP question. The dummy variable for those who are familiar with asthma and the variable of household size have positive but insignificant effects to WTP. The dummy variable for those who think that they have higher than average risk of developing asthma and the dummy variable for those who think the government provision would be effective have negative but insignificant effects to the WTP.

Scope/Scale Effect of the Asthma WTP

In Table 3.6, the estimated coefficient of the logarithm asthma risk reduction is not significant. But the estimated coefficient of the interaction term of household income and the log of the risk reduction is positive and significant at $9 \%$, which means that the scale sensitivity of respondents to the risk reduction magnitude is increasing with the household income. Since income usually increases with education quality received by individuals and capability of individuals, a possible explanation is that respondents with higher income may have better capability of understanding on the health risk probabilities described in the questionnaire, therefore, their WTP are more sensitive to the risk 
magnitude. In other words, the income could be seen as a proxy of the capability of respondents understanding the questionnaire.

To answer the question whether the change of WTP is proportionate to the change of risk reduction, we need to test whether the estimated coefficient of the logarithm of the risk reduction is equal to 1 . The scale sensitivity is increasing with household income as shown in Table 3.6, which suggests that respondents with low income have no or less than proportionate scale sensitivity, whereas respondents with high income may have proportionate or even more than proportionate WTP change to the risk reduction change. Table 3.7 reports the regression results using respondents with household income greater than 30,000 yuan only. The coefficient of the log of risk reduction is estimated as 1.19 with $1 \%$ significance. Wald test shows that this estimate is not significantly different to 1. Similarly, Table 3.8 reports the regression results using respondents with household income greater than 40,000 yuan only. The scale coefficient is 1.79 with $1 \%$ significance, where the Wald test still cannot reject that it is equal to 1. Regressions using respondents with even higher income cannot be done because of small sample size. From results in Table 3.6-3.8, we can conclude that the scale sensitivity of the WTP for the risk reduction of asthma is increasing with the household income; at certain point, the proportionality hypothesis holds. However, it is difficult to conclude whether respondents with even higher income may have WTP change more than proportionate to the risk reduction change.

In Table 3.6, the estimated coefficients of the dummy variable ASYMP is insignificant, suggesting that the scope/scale sensitivity of WTP to the description of severity of asthma might be absent. However, Table 3.7 reports an estimate as 0.67 with 
$12 \%$ significance; and Table 3.8 shows that this coefficient as 1.16 with $3 \%$ significance. Interaction term of household income and the severe symptom dummy has been used in the regression; it is positive but insignificant. The results in Table 3.6-3.8 still suggest that, similar to the scale effect of WTP to the risk magnitude, people with higher income may also be more sensitive to the symptom severity description. The reasons stated before may also hold here.

To answer the question whether the public provision mechanism would decrease the scale sensitivity of WTP to the risk reduction magnitude, an interaction term of the dummy of public provision with the log of risk reduction and an interaction term of public provision with the household income and with the log of risk reduction are added as independent variables in the model. The parameter estimates are reported in Table 3.9. The estimated coefficients of these two interaction terms are negative but insignificant, meaning that the hypothesis that the public provision mechanism has no effect to the scale sensitivity of WTP cannot be rejected.

\section{Within-group Regression on Provision Mechanisms}

In Table 3.6-3.9, the dummy variable of public provision is always positive but insignificant, so that the hypothesis that the public provision mechanism has no significant impact to people's WTP cannot be rejected. This result is a between-group comparison result, since every individual in the sample responded to either the public provision or the private provision, but not both. Referring to Table 3.2 on the sub-sample design of the questionnaire, in version 3 and 4, each respondent actually responded to both the public and the private provision WTP questions with different orders. Thus, pooling version 3 and version 4 together and using both of the two WTP responses of 
each respondent, I conduct a within-group comparison. The regression result is reported in Table 3.10. Here, the public provision dummy variable is positive and significant. Different from the between-group comparison result, this result rejects the null hypothesis. A possible reason for the difference is that when respondents are comparing the private provision with the public provision mechanisms directly, it is easier for them to see the advantages and disadvantages of each mechanism, thus, the positive effect of the public provision becomes more significant. The reason of this positive effect will be discussed in the following sections. In table 3.10, the variable 'Ordering Effect' is a dummy for the second WTP question of each respondent; there is a negative ordering effect at $6 \%$ significance.

\section{Estimated WTP and the Value of a Statistical Case of Asthma}

The mean and median WTPs for asthma risk reduction are computed from the parameter estimates reported in Table 3.6 and the weighted mean of the independent variables. The expected WTP is estimated as 475.39 yuan (US\$59), and the estimated median WTP is 27.93 yuan (US\$3.5). The expected WTP of the sub-sample of respondents provided with the high risk reduction in the survey is estimated as 468.43 yuan (US\$58.6); the estimated median WTP for this sub-group is 27.52 yuan (US\$3.44). The expected WTP of the sub-sample of respondents provided with the low risk reduction in the survey is estimated 488.55 yuan (US\$61.07); the estimated median WTP is 28.70 yuan (US\$3.59) ${ }^{19}$. The WTP estimates of the sub-sample provided with the high risk reduction is even slightly lower than the estimates of the sub-sample provided with

\footnotetext{
${ }^{19}$ The estimates of each sub-sample are computed using the estimated coefficients reported in Table 3.6 and the means of the independent variables of each sub-sample.
} 
the low risk reduction, because each sub-sample has different means of the independent variables.

The large difference between the expected WTP and the median WTP is caused by the flaw of the design of the bid prices in the questionnaire. The designed bid prices were not able to make the upper tail of the distraction of the WTP well defined. Referring to Table 3.5, 32\% answered yes to the highest bid. This undefined tail enables the expected WTP to be sensitive to the functional form assumption of the WTP (Haab and McConnell, 2002, pp106).

As Haab and McConnell (2002) states, when there are concerns about the distribution of response data, a conservative approach is to calculate the sample mean using the Turnbull lower bound, and then estimate the exponential willingness to pay function and calculate its median. The Turnbull lower bound (Haab and McConnell, 2002, pp75) of the expected WTP (weighted) is 44.55 yuan (US\$5.6). The estimated lower bound of the expected WTP for the sub-sample with the high risk reduction is 47.55 yuan (US\$5.94); the lower bound estimate for the sub-sample with the low risk reduction is 19.35 yuan (US\$2.42).

The value of a case of asthma is computed by dividing the estimated WTP by the weighted mean of the risk reduction amount. The median value of a case of asthma for the sub-sample with high risk reduction estimated by using the median WTP from the exponential model is 9173 yuan (US\$1147). The value for the sub-sample with low risk reduction is estimated as 28,702 yuan (US\$3588). The average of those two estimates is 18,940 yuan (US\$2368). The value of a statistical case of asthma estimated by using the lower bound of the expected WTP for the high risk sub-sample is 15,850 yuan 
(US\$1981). The value for the low risk sub-sample is estimated as 19,350 yuan

(US\$2419). The average of those two estimates is 17,600 yuan (US\$2200). Analysis on Why Respondents Answer No to the Asthma WTP Question

To the respondents who answered no-no to both the initial bid and the follow-up WTP question, I asked why they would not be willing to pay the bid prices and what would be the maximum amount that the respondent would be willing to pay for the treatment. Totally 318 of 879 respondents (the original sample deleting the observations with strong interviewer effect) were asked these questions. When asked why they would not pay the bid price, 51 respondents (6\%) answered that their income was too low or the bid price was too high for them; 197 respondents (20\%) answered that they did not think the treatment was necessary for them, because they were in very good health condition, or with no specific reasons; 19 respondents (2\%) answered they did not want to take time or effort to participate in this treatment; 17 respondents (2\%) answered that they exercised, or had health insurance, or had other ways to protect themselves; 12 respondents (1\%) stated that the treatment should not be paid by themselves but the government; 10 respondents (1\%) answered that they had suspicion or distrust to the stated treatment; other respondents had other miscellaneous reasons or missing value.

When asked on the maximum WTP, 289 of 318 respondents (33\%) answered 'zero' or 'I would not pay for the treatment'; 27 respondents answered greater-than-zero WTP from 2 to 30 yuan. Then, the 289 respondents who answered zero were asked whether they would participate in the treatment if it were free for them. Among them, 182 respondents said yes, while 107 answered no. These 107 respondents (12\% of all respondents) were asked why they would not participate in this asthma preventive 
treatment even if it were free. 13 of them (1\%) answered that they did not believe that the hypothetical treatment was effective to prevent asthma. These $1 \%$ respondents obviously had scenario rejection to the WTP question. 59 respondents (7\%) answered that they thought it was not necessary for them to participate in this treatment, because they were in very good health, or they perceived that they would have very low chance of developing asthma, or with no specific reason; 24 respondents (3\%) answered that it would be time consuming or troublesome to participate in the treatment; 4 respondents $(0.5 \%)$ answered that they had health insurance or other methods to prevent the disease; these $10.5 \%$ respondents may also have various levels of scenario rejection, but expressed it in an indirect way. Other respondents had other miscellaneous reasons or missing value. It can be seen from these statistics that the major reason for respondents answering no is that they think the treatment is not necessary for them.

\section{Analysis on the Stated Preference of Respondents to Different Provision Mechanisms}

In the version 3 and 4 of the questionnaire, respondents were asked their WTP for the health risks reductions with both the private provision and the public/government provision mechanisms. They were also asked directly on which mechanism they preferred if the cost is the same and why. Table 3.11 reports the number and percentage of respondents with different preferences to the private provision and the public/government provision mechanisms. There are $42.27 \%$ respondents stated that they preferred government provision, whereas $23.71 \%$ stated they preferred private provision, and $31.96 \%$ stated that the two provision mechanisms were indifferent to them. The percentage that prefers public/government provision is significantly greater than the 
percentage that prefers private provision. This is consistent with the estimated coefficient of the public provision dummy variable in the within-group regression in Table 3.10.

When asked why they prefer the public/government provision, 82 of the total 291 respondents (28\%) answered that the government provision would be more trustworthy or more effective; 8 respondents (2.7\%) answered that they would have more incentive to participate in the treatment if the government would provide the health risk reduction; 4 (1.4\%) respondents thought that they would be subsidized by the government or their employer if the treatment were provided by the government. On the other side, among those who prefer the private provision, 29 respondents (10\%) answered that they had distrust to the government; 40 respondents (14\%) answered that they would have more freedom to choose hospitals or date to participate in the treatment if it were privately provided. It can be seen that there are more respondents who trust the government than those who distrust the government. It also can be seen that people prefer the government provision mechanism mainly because they had trust to the government or perceived high effectiveness of the government. There is no strong evidence of altruistic incentive of respondents.

\subsubsection{WTP to Reduce the Risk of Mortality}

Similarly to the asthma WTP model, probit regressions have been done to estimate the WTP to reduce the risk of mortality. The unweighted and weighted descriptive statistics of the observations used in the regression are reported in Table 3.12. Table 3.13 shows the unweighted and weighted yes rate of the sample to reduce the risk of mortality. 
The parameter estimates are shown in Table 3.14. These results show that, similar to the asthma results, respondents who believed in the stated treatment have significantly higher WTP. Different from the asthma case, the coefficient of the public provision dummy is negative and significant, suggesting that the public provision yields lower WTP for the mortality risk reduction. A possible reason is that for the respondents, it is relatively easy to understand that the government could supply public health service to prevent certain disease like asthma, but the government provision of mortality risk reduction might be too abstract to respondents. Answering to a debriefing question in the questionnaire, 59\% of the respondents thought that it was possible that the government would provide the public health service to prevent asthma, whereas $54 \%$ of the respondents thought it was possible for the mortality risk reduction. Respondents may thus answer "no" to the public provision WTP question because they thought that the government was less likely to supply this treatment to reduce mortality risk.

In Table 3.14, the perceived government effectiveness is positive and significant. The interaction term of the dummy of the rural registration status with the public provision is negative and significant, meaning that the respondents with rural registration status are more likely to answer no to the public provision mechanism. The reason is that residents with the rural registration are generally not covered in any public health insurance system in China currently, thus respondents with rural registration may perceive that they would not be covered in the public provision mechanism either.

The public health insurance dummy and the household size are positive but insignificant; the household income has a negative but insignificant coefficient. The 
interaction term of household income with public provision kept in the asthma regressions is deleted from the mortality regression, since it was not significant. Scope/Scale Effect of the Mortality WTP

The estimated coefficient of the log of the risk reduction shows that the scope/scale sensitivity of WTP to the magnitude of risk is not significant. Different from the asthma results, the interaction term of the household income with the log of the mortality risk reduction is positive but not significant, indicating that the scale sensitivity of WTP is not significantly increasing with income. A possible cause of the lack of sensitivity is that the magnitude of the mortality baseline risk and the risk reduction is even smaller than that of asthma, expressed as chances in 10,000. It may be more difficult for respondents to appreciate the smaller magnitude. Another possible reason is that researchers could not measure very well the perceived baseline risk and the perceived effectiveness of the treatment of respondents. If respondents decide their WTP based on their perceived risk and effectiveness, but not on the stated average risk and the stated risk reduction, we would not observe significant scope/scale effect of WTP to the stated risk reduction amount.

To answer the question whether public provision affects the scale sensitivity of WTP, the interaction term of public provision with the log of risk reduction is added into the regression ${ }^{20}$. As reported in Table 3.15, this interaction term is negative but insignificant, suggesting that the hypothesis that public provision has no impact to the scale sensitivity of WTP cannot by rejected.

\footnotetext{
${ }^{20}$ The interaction term of household income and log of risk reduction, and the interaction term of public provision and household income are deleted from the regression since they are not significant. 
Within-group Regression on the Provision Mechanisms

The within-group regression results are reported in Table 3.16. Different from the between-group results in Table 3.14, the dummy of public provision is positive but insignificant here. If we add the interaction of the public provision with the log of risk reduction into the regression, the estimated coefficient of this term is positive but insignificant. It is similar to the asthma case: when respondents compare the private provision with the public/government provision directly, they are less likely to say no to the public/government provision than when they are offered with the public/government provision only.

Estimated WTP for mortality risk reduction and VSL

Parameter estimates in Table 3.14 are used for the WTP computation, with the weighted means of the independent variables. The estimated mean of WTP is 18,555 yuan (US\$2319), and the estimated median WTP is 102 yuan (US\$12.75). As stated in the asthma WTP section, the flaw of design of bid prices leads to the expected WTP overestimated. The Turnbull lower bound of the mean of WTP (weighted) is estimated as 51.50 yuan (US\$6.4). Dividing the WTP estimates by the weighted mean of the risk reduction amount yields the estimated median VSL as 189,960 yuan (US\$23,745). The Turnbull estimate of VSL is 95,903 yuan (US\$11,988). Analysis on Why Respondents Answer No to the Mortality WTP Question

To the respondents who answered no-no to both the initial and the follow-up bids, I asked why they would not be willing to pay the bid prices and what would be the maximum amount that the respondent would be willing to pay for the treatment. Totally, 280 of 901 respondents (31\%) were asked those questions. When asked why they would 
not pay the bid price, 42 respondents (3.7\%) answered that their income was too low or the bid price was too high for them; 111 respondents (12.3\%) answered that they did not think the treatment was necessary for them, because they were in very good health condition, or with no specific reasons; 18 respondents (2.0\%) answered that they did not want to take time or effort to participate in this treatment; 17 respondents (1.89\%) answered that they had health insurance or other ways to protect themselves; 7 respondents $(0.8 \%)$ thought that the treatment should be paid by the government, but not themselves; 35 respondents (3.9\%) answered that they had suspicion to the stated treatment; 5 respondents $(0.55 \%)$ answered that they had distrust to the government; 1 respondent (0.1\%) answered that the risk reduction amount was too small; other respondents had other miscellaneous reasons or missing value.

When asked on the maximum WTP, 256 respondents (28.4\%) answered 'zero' or 'I would not pay for the treatment'; 16 of them answered greater-than-zero WTP from 1 to 50 yuan. The 256 respondents who answered zero were asked whether they would participate in the treatment if it were free. Among them, 164 respondents said yes, while 92 answered no. These 92 respondents were asked why they would not participate in the treatment even if it were free. 18 of them (2\%) answered that they did not believe that the stated hypothetical treatment would be effective. These respondents obviously had scenario rejection to the WTP question. 35 respondents (3.9\%) answered that they thought it was not necessary for them to participate in this treatment, because they were in very good health condition, or with no specific reason. 18 (2\%) respondents answered that it would be time consuming or troublesome to participate in the treatment; 3 respondents $(0.7 \%)$ answered that they had health insurance or other methods that would 
be helpful to prevent the disease; these $8.6 \%$ respondents may also have various levels of scenario rejection, but expressed it in an indirect way. 2 respondents (0.2\%) expressed that they had distrust to the government. Other respondents had other miscellaneous reasons. The percentages of respondents with different reasons are very similar to the percentages of the asthma case.

Analysis the Stated Preference of Respondents to Different Provision Mechanisms

Similar to Table 3.11 for the analysis on asthma, Table 3.17 reports the numbers and percentages of respondents with different preferences to the private and public provision mechanisms in the mortality case. There are $43.53 \%$ of the respondents stated that they prefer the government provision, whereas $24.29 \%$ stated they prefer the private provision, and 30.91\% stated that the two provision mechanisms are indifferent to them. The percentage that prefers the public/government provision is significantly greater than the percentage that prefers the private provision. But the sum of the percentages of who prefer the private provision and who are indifferent is greater than the percentage of who prefer the public/government provision. This is probably why the result in Table 3.16 shows that the coefficient of public provision is positive but insignificant.

When asked why they preferred the public/government provision, 95 of 317 respondents (30\%) answered that public/government provision would be more trustworthy or more effective; 13 respondents (4\%) answered that public/government provision would induce themselves or others more incentive to participate in the treatment; 6 respondents (2\%) thought that they would be subsidized by the government or their employer if the treatment was provided by the government. On the other hand, among those who preferred the private provision, 25 respondents (8\%) answered that 
they had distrust to the government; 47 respondents (15\%) answered that they would have more freedom to choose the hospitals or the date to participate in the treatment if it was privately provided. Similar to the asthma case, respondents preferred the government provision mainly because they trusted to the government or perceived high effectiveness of the government provision. The main reasons that respondents preferred the private provision are the distrust to the government and the perceived freedom of choices of hospitals and treatment time. The between-group regression and the within-group regression yield different estimates of the public provision dummy variable. Again, it seems that when respondents compare the private provision with the public/government provision directly, they are less likely to say no to the public/government provision than when they are offered with the public/government provision only.

\subsection{Analysis on Respondents Who Have Asthma or Chronic Bronchitis}

22 respondents (about $2 \%$ of the whole sample) and 50 respondents (5\%) reported that they had asthma and chronic bronchitis, respectively. Among these respondents, 12 reported that they had both asthma and chronic bronchitis, which shows that some respondents may not be able to differentiate asthma from chronic bronchitis.

Among the 22 respondents reporting asthma, 80\% reported that they had at least one attack during the last year; among those who had at least one attack, the average number of attacks during the last year is $2.6 .75 \%$ of the respondents with asthma reported a positive cost for treating asthma with an average of cost as 732 yuan (US\$91.5) in the previous year. 4 respondents among those who paid for treating asthma reported part or all of these cost paid by health insurance. Minus the cost paid by insurance, the 
average out-of-pocket cost of who had positive cost is 543 yuan (US\$67.9). After those who claimed both asthma and chronic bronchitis are eliminated from the sample, the average cost among the positive costs decreases to 597 yuan (US\$74.6), and the out-ofpocket cost is still 597 yuan.

The value of a statistical case of asthma is the willingness-to-pay of a group of people to prevent one certain case of asthma developing among them during a period of time. From economics theory, this WTP measure should be close to the total cost that an individual suffers if he/she has asthma. This total cost includes the total medical cost for treating the disease, the total income loss caused by the disease, and the cost of discomfort caused by the disease. Therefore, the WTP should be greater than the total medical cost. If the patient has to pay the medical cost for 10 years for asthma treatment, the total medical cost would be about US\$750. The estimated WTP to prevent a case of asthma is about US\$2200, which is greater than the total medical cost.

Among the 50 respondents reporting chronic bronchitis, 76\% reported that they had at least one symptom-day during the last year. Among those who had at least one symptom-day, the average number of symptom-days during the last year was $29.68 \%$ of the respondents with chronic bronchitis reported a positive cost for treating chronic bronchitis with an average of 400 yuan (US\$50) in the previous year. 8 respondents among those who paid for treating asthma reported that part or all of these cost were paid by health insurance. After the cost paid by insurance is subtracted, the average out-ofpocket cost of who had positive cost is 318 yuan (US\$39.75). After the respondents who claimed that they have both asthma and chronic bronchitis are eliminated from the 
sample, the average cost of who have positive cost for treating chronic bronchitis is 356 yuan (US\$44.5), and the out-of-pocket cost is 335 yuan (US\$41.9).

\subsection{Conclusion}

To summarize this chapter, a contingent valuation study is conducted in China to value the health risks of asthma and mortality by using in-person interviews. The private and public/government provision mechanisms are tested for their effects to respondents' WTP. Scope/scale effects of WTP to the magnitude of health risk reduction and the description of severity of asthma are also tested.

Using a probit model, the median of the value of a statistical case of asthma is estimated as about US\$2400. The between-group regression result cannot reject the hypothesis that the public provision has no significant effect to WTP. The scope/scale effects of WTP to the risk reduction amount and the severity of description of asthma symptoms are increasing with the household income of respondents. A possible reason is that people with higher income may have better understanding on the questionnaire and the small risk probabilities, since the income is usually increasing with education level and capability. The within-group regression shows that the public provision mechanism has a positive and significant impact to the asthma WTP. This suggests that when comparing the private provision and the public/government provision mechanisms directly, respondents are more likely to say 'yes' to the public provision mechanism. From people's responses on why they preferred the public/government provision, it can be seen that their trust to the government and their perceived high effectiveness of the government provision are the main reasons. No significant altruistic incentive is found. 
Peng and Tian (2003) surveyed 356 inpatients with respiratory diseases on their total willingness-to-pay to cure asthma if they had asthma in Shanghai, China. They estimated that the average WTP per person for cure of asthma as 21,739 yuan (US\$2717). One obvious reason why this estimate is higher than our estimate is the difference of the survey samples: we surveyed the general population, whereas they surveyed inpatients with respiratory diseases.

Similarly, the median of the value of a statistical life (VSL) is estimated as about US $\$ 24,000$. This result is close to the median VSL of Beijing residents estimated by Hammitt and Zhou (2006) as US\$16,900. No significant scale effect of WTP to the magnitude of mortality risk is found. A possible reason is that the magnitude of the mortality risk is even smaller than the asthma risk, which makes it even more difficult to understand for the respondents. Another possible reason is the unknown perceived risks of respondents. The between-group regression shows that public/government provision has a significantly negative effect to people's WTP. A possible explanation is that the respondents answered no to the WTP question with the public provision since they thought that it was not very possible for the government to provide the treatment to reduce the mortality risk. In the within-group regression, the estimated coefficient of the public provision is positive but insignificant. Similar to the asthma case, this may suggest that when comparing the private provision mechanism with the public/government provision mechanism directly, respondents value the advantages of the public provision more than, or value its disadvantages less than the case when respondents were offered with the public provision mechanism only. 


\begin{tabular}{c|c|l}
\hline Mild & N & \multicolumn{1}{c}{ Description } \\
\hline Severe & 757 & $\begin{array}{l}\text { Asthma is a lung disease that you can develop at any age. The } \\
\text { symptoms of asthma, called an asthma attack, occur suddenly and } \\
\text { unpredictably. Asthma is not contagious. An asthma attack } \\
\text { happens when the airways in your lungs become suddenly } \\
\text { inflamed and swollen. Once you develop asthma, asthma attacks } \\
\text { can be triggered by indoor and outdoor air pollution such as } \\
\text { smoke, dust, automobile emission on street and so on. During an } \\
\text { asthma attack, you could experience shortness of breath, wheezing } \\
\text { or coughing after exercise and cold-like symptoms including } \\
\text { sneezing, runny nose, congestion, sore throat and headache. }\end{array}$ \\
\hline $\begin{array}{l}\text { Asthma is a lung disease that you can develop at any age. The } \\
\text { symptoms of asthma, called an asthma attack, occur suddenly and } \\
\text { unpredictably. Asthma is not contagious. An asthma attack } \\
\text { happens when the airways in your lungs become suddenly } \\
\text { inflamed and swollen. Once you develop asthma, asthma attacks } \\
\text { can be triggered by indoor and outdoor air pollution such as } \\
\text { smoke, dust, automobile emission on street and so on. During an } \\
\text { asthma attack, you could experience severe wheezing, coughing } \\
\text { that won't stop, very rapid breathing, inability to catch your breath, } \\
\text { chest pains or pressure, tightened neck and chest muscles and } \\
\text { difficulty talking. }\end{array}$ \\
\hline
\end{tabular}

Table 3.1: Description of Mild and Severe Symptoms of Asthma 


\begin{tabular}{c|l|l|l|l|l}
\hline Group & Version & Provision & Symptom & Risk reduction & $\begin{array}{l}\text { Number of } \\
\text { observations }\end{array}$ \\
\hline 1 & 1 & Private & Light & $3 / 1000$ & 237 \\
2 & 1 & Private & Severe & $3 / 1000$ & 246 \\
3 & 2 & Public & Severe & $3 / 1000$ & 172 \\
4 & 3 & Private and public & Severe & $1 / 1000$ & 163 \\
5 & 4 & Public and private & Severe & $1 / 1000$ & 176 \\
\hline
\end{tabular}

Table 3.2: Sub-Sample Design of the Asthma WTP Question 


\begin{tabular}{|c|c|c|c|c|}
\hline \multirow[t]{2}{*}{ Variables } & \multirow[t]{2}{*}{ Definition } & \multirow[b]{2}{*}{$\begin{array}{c}\text { Sample } \\
\text { Size }\end{array}$} & \multicolumn{2}{|c|}{$\begin{array}{c}\text { Mean } \\
\text { (Std. Deviation) }\end{array}$} \\
\hline & & & Unweighted & Weighted \\
\hline Age & Age in years & 962 & $\begin{array}{c}38.66 \\
(13.77)\end{array}$ & $\begin{array}{c}37.04 \\
(12.25)\end{array}$ \\
\hline Gender & Dummy variable equal to 1 if male & 962 & $\begin{array}{c}0.46 \\
(0.50)\end{array}$ & $\begin{array}{c}0.49 \\
(0.50)\end{array}$ \\
\hline $\begin{array}{l}\text { Education } \\
\text { Years }\end{array}$ & Education years received by respondent & 960 & $\begin{array}{l}10.79 \\
(3.95)\end{array}$ & $\begin{array}{l}10.88 \\
(4.09)\end{array}$ \\
\hline Health & $\begin{array}{l}\text { Respondent's perception of own current } \\
\text { health on a scale between } 1 \text { (excellent) } \\
\text { and } 5 \text { (bad) }\end{array}$ & 962 & $\begin{array}{c}2.80 \\
(0.91)\end{array}$ & $\begin{array}{c}2.76 \\
(0.93)\end{array}$ \\
\hline Exercise & Average exercise hours per week & 952 & $\begin{array}{c}3.51 \\
(4.94)\end{array}$ & $\begin{array}{c}3.20 \\
(4.71)\end{array}$ \\
\hline Smoke & Dummy variable equal to 1 if smoke & 962 & $\begin{array}{c}0.30 \\
(0.46)\end{array}$ & $\begin{array}{c}0.27 \\
(0.44)\end{array}$ \\
\hline $\begin{array}{c}\text { Public } \\
\text { Insurance }\end{array}$ & $\begin{array}{l}\text { Dummy variable equal to } 1 \text { if the } \\
\text { respondent has some form of public } \\
\text { health insurance }\end{array}$ & 953 & $\begin{array}{c}0.57 \\
(0.50)\end{array}$ & $\begin{array}{c}0.62 \\
(0.49)\end{array}$ \\
\hline $\begin{array}{l}\text { Asthma } \\
\text { Symptom }\end{array}$ & $\begin{array}{l}\text { Dummy variable equal to } 1 \text { if respondent } \\
\text { was randomized into the group in which } \\
\text { severe symptom descriptions of asthma } \\
\text { were provided }\end{array}$ & 940 & $\begin{array}{c}0.76 \\
(0.43)\end{array}$ & $\begin{array}{c}0.77 \\
(0.42)\end{array}$ \\
\hline Familiar & $\begin{array}{l}\text { Dummy variable equal to } 1 \text { if the } \\
\text { respondent perceives that he/she is } \\
\text { familiar with asthma }\end{array}$ & 940 & $\begin{array}{c}0.54 \\
(0.50)\end{array}$ & $\begin{array}{c}0.56 \\
(0.50)\end{array}$ \\
\hline Large Risk & $\begin{array}{l}\text { Dummy variable equal to } 1 \text { if the } \\
\text { respondent believes own chance of } \\
\text { developing asthma is higher than the } \\
\text { average }\end{array}$ & 940 & $\begin{array}{c}0.21 \\
(0.41)\end{array}$ & $\begin{array}{c}0.19 \\
(0.39)\end{array}$ \\
\hline $\begin{array}{c}\text { Log Asthma } \\
\text { Risk Reduction }\end{array}$ & $\begin{array}{l}\text { Natural log of the asthma risk reduction } \\
\text { amount per } 1000 \text { offered to each } \\
\text { respondent, i.e., } \log (1) \text { or } \log (3)\end{array}$ & 940 & $\begin{array}{c}0.73 \\
(0.52)\end{array}$ & $\begin{array}{c}0.71 \\
(0.52)\end{array}$ \\
\hline $\begin{array}{l}\text { Log Mortality } \\
\text { Risk Reduction }\end{array}$ & $\begin{array}{l}\text { Natural log of the mortality risk reduction } \\
\text { amount per } 10,000 \text { offered to each } \\
\text { respondent, i.e., } \log (3), \log (5) \text { or } \log (10)\end{array}$ & 962 & $\begin{array}{c}1.67 \\
(0.49)\end{array}$ & $\begin{array}{l}1.65 \\
(0.47)\end{array}$ \\
\hline Asthma Believe & $\begin{array}{l}\text { Dummy variable equal to } 1 \text { if respondent } \\
\text { believes the stated scenario of asthma risk } \\
\text { reduction is realistic }\end{array}$ & 940 & $\begin{array}{c}0.70 \\
(0.46)\end{array}$ & $\begin{array}{c}0.69 \\
(0.46)\end{array}$ \\
\hline
\end{tabular}

Table 3.3: Variable Definitions and Statistics 
Table 3.3 Continued

\begin{tabular}{|c|c|c|c|c|}
\hline $\begin{array}{l}\text { Mortality } \\
\text { Believe }\end{array}$ & $\begin{array}{l}\text { Dummy variable equal to } 1 \text { if respondent } \\
\text { believes the stated scenario of mortality } \\
\text { risk reduction is realistic }\end{array}$ & 962 & $\begin{array}{c}0.59 \\
(0.49)\end{array}$ & $\begin{array}{c}0.55 \\
(0.50)\end{array}$ \\
\hline Household Size & $\begin{array}{l}\text { Number of people living in the } \\
\text { household }\end{array}$ & 912 & $\begin{array}{c}3.00 \\
(1.16)\end{array}$ & $\begin{array}{c}3.27 \\
(1.16)\end{array}$ \\
\hline $\begin{array}{l}\text { Household } \\
\text { Income }\end{array}$ & $\begin{array}{l}\text { Annual household income divided by } \\
10000 \text { (yuan) }\end{array}$ & 843 & $\begin{array}{c}2.31 \\
(2.72)\end{array}$ & $\begin{array}{c}3.15 \\
(4.37)\end{array}$ \\
\hline Rural Reg & $\begin{array}{l}\text { Dummy variable equal to } 1 \text { if the } \\
\text { respondent is registered as a rural } \\
\text { resident }\end{array}$ & 962 & $\begin{array}{c}0.29 \\
(0.46)\end{array}$ & $\begin{array}{c}0.30 \\
(0.46)\end{array}$ \\
\hline $\begin{array}{l}\text { Public } \\
\text { Provision }\end{array}$ & $\begin{array}{l}\text { Dummy variable equal to } 1 \text { if respondent } \\
\text { was randomized into the group in which } \\
\text { public provision scenario was provided } \\
\text { in the first WTP question (version } 2 \text { and } \\
\text { 4) }\end{array}$ & 962 & $\begin{array}{c}0.35 \\
(0.48)\end{array}$ & $\begin{array}{c}0.38 \\
(0.49)\end{array}$ \\
\hline $\begin{array}{l}\text { Government } \\
\text { Effectiveness }\end{array}$ & $\begin{array}{l}\text { Dummy variable equal to } 1 \text { if } \\
\text { respondent of version } 2 \text { and } 4 \text { thinks that } \\
\text { the public provision of treatments by } \\
\text { government would be efficient }\end{array}$ & 962 & $\begin{array}{c}0.22 \\
(0.41)\end{array}$ & $\begin{array}{c}0.27 \\
(0.44)\end{array}$ \\
\hline
\end{tabular}




\begin{tabular}{|c|c|c|c|}
\hline \multirow[t]{2}{*}{ Variables } & \multirow[t]{2}{*}{ Definition } & \multicolumn{2}{|c|}{$\begin{array}{c}\text { Mean } \\
\text { (Std. Deviation) }\end{array}$} \\
\hline & & Unweighted & Weighted \\
\hline $\begin{array}{l}\text { Log of Bid } \\
\text { Price }\end{array}$ & $\begin{array}{l}\text { Natural log of the bid price assigned to each } \\
\text { respondent }\end{array}$ & $\begin{array}{c}3.17 \\
(1.11)\end{array}$ & $\begin{array}{c}3.22 \\
(1.15)\end{array}$ \\
\hline $\begin{array}{l}\text { Education } \\
\text { Years }\end{array}$ & Education years received by respondent & $\begin{array}{l}10.97 \\
(3.83)\end{array}$ & $\begin{array}{l}11.28 \\
(3.99)\end{array}$ \\
\hline Public & Dummy variable equal to 1 if the respondent & 0.60 & 0.67 \\
\hline Insurance & has some form of public health insurance & $(0.49)$ & $(0.47)$ \\
\hline Asthma & Dummy variable equal to 1 if respondent was & 0.76 & 0.77 \\
\hline Symptom & $\begin{array}{l}\text { randomized into the group in which severe } \\
\text { symptom descriptions of asthma were } \\
\text { provided }\end{array}$ & $(0.42)$ & $(0.42)$ \\
\hline Familiar & $\begin{array}{l}\text { Dummy variable equal to } 1 \text { if the respondent } \\
\text { perceives that he/she is familiar with asthma }\end{array}$ & $\begin{array}{c}0.56 \\
(0.50)\end{array}$ & $\begin{array}{c}0.57 \\
(0.50)\end{array}$ \\
\hline Large Risk & $\begin{array}{l}\text { Dummy variable equal to } 1 \text { if the respondent } \\
\text { believes own chance of developing asthma is } \\
\text { higher than the average }\end{array}$ & $\begin{array}{c}0.21 \\
(0.41)\end{array}$ & $\begin{array}{c}0.20 \\
(0.40)\end{array}$ \\
\hline $\begin{array}{l}\text { Log Asthma } \\
\text { Risk Reduction }\end{array}$ & $\begin{array}{l}\text { Natural log of the asthma risk reduction } \\
\text { amount per } 1000 \text { offered to each respondent, } \\
\text { i.e., } \log (1) \text { or } \log (3)\end{array}$ & $\begin{array}{c}0.74 \\
(0.52)\end{array}$ & $\begin{array}{c}0.71 \\
(0.52)\end{array}$ \\
\hline Asthma Believe & $\begin{array}{l}\text { Dummy variable equal to } 1 \text { if respondent } \\
\text { believes the stated scenario of asthma risk } \\
\text { reduction is realistic }\end{array}$ & $\begin{array}{c}0.72 \\
(0.45)\end{array}$ & $\begin{array}{c}0.74 \\
(0.44)\end{array}$ \\
\hline Household Size & Number of people living in the household & $\begin{array}{c}2.95 \\
(1.15)\end{array}$ & $\begin{array}{c}3.23 \\
(66.10)\end{array}$ \\
\hline $\begin{array}{l}\text { Household } \\
\text { Income }\end{array}$ & $\begin{array}{l}\text { Annual household income divided by } 10000 \\
\text { (yuan) }\end{array}$ & $\begin{array}{c}2.38 \\
(2.86)\end{array}$ & $\begin{array}{c}3.39 \\
(4.68)\end{array}$ \\
\hline $\begin{array}{l}\text { Public } \\
\text { Provision }\end{array}$ & $\begin{array}{l}\text { Dummy variable equal to } 1 \text { if respondent was } \\
\text { randomized into the group in which public } \\
\text { provision scenario was provided in the first } \\
\text { WTP question (version } 2 \text { and } 4 \text { ) }\end{array}$ & $\begin{array}{c}0.36 \\
(0.48)\end{array}$ & $\begin{array}{c}0.40 \\
(0.49)\end{array}$ \\
\hline $\begin{array}{l}\text { Government } \\
\text { Effectiveness }\end{array}$ & $\begin{array}{l}\text { Dummy variable equal to } 1 \text { if respondent of } \\
\text { version } 2 \text { and } 4 \text { thinks that the public provision } \\
\text { of treatments by government would be } \\
\text { efficient }\end{array}$ & $\begin{array}{c}0.23 \\
(0.42)\end{array}$ & $\begin{array}{c}0.30 \\
(0.46)\end{array}$ \\
\hline $\begin{array}{c}\text { Household } \\
\text { Income } \times \text { LARR }\end{array}$ & $\begin{array}{l}\text { Household income multiplied by the log of the } \\
\text { asthma risk reduction amount per } 1000\end{array}$ & $\begin{array}{c}1.81 \\
(3.12)\end{array}$ & $\begin{array}{c}2.75 \\
(5.32)\end{array}$ \\
\hline Household & Household income multiplied by the dummy & 0.90 & 1.71 \\
\hline $\begin{array}{l}\text { Income } \times \text { Public } \\
\text { Provision }\end{array}$ & variable of public provision & $(2.20)$ & (4.65) \\
\hline $\mathbf{N}$ & Sample size & 726 & 726 \\
\hline
\end{tabular}

Table 3.4: Statistics of the Independent Variables in the Asthma WTP Model 


\begin{tabular}{c|c|c|c}
\hline \multirow{2}{*}{ Bid price (yuan) } & \multicolumn{2}{|c|}{ Yes Rate } & \multirow{2}{*}{ N } \\
\cline { 2 - 3 } & Unweighted & Weighted & \\
\hline 5 & $72.07 \%$ & $69.12 \%$ & 179 \\
15 & $61.85 \%$ & $70.63 \%$ & 173 \\
40 & $46.67 \%$ & $39.77 \%$ & 195 \\
100 & $32.40 \%$ & $40.14 \%$ & 179 \\
\hline
\end{tabular}

Table 3.5: Bid Vectors and Percentage of People Saying 'yes' to the Bid for Stated Risk Reduction of Asthma

\begin{tabular}{l|c|c}
\hline \multicolumn{1}{c|}{ Independent Variables } & Coefficient & Prob>ChiSq \\
\hline Intercept & 0.50 & 0.41 \\
Log of Bid Price & $-0.42^{* * *}$ & 0.00 \\
Education Years & $0.074 * * *$ & 0.00 \\
Public Insurance & -0.14 & 0.44 \\
Asthma Symptom & -0.074 & 0.76 \\
Log of Risk Reduction & -0.41 & 0.22 \\
Asthma Believe & $0.71^{* * *}$ & 0.00 \\
Public Provision & 0.42 & 0.26 \\
Household income & -0.20 & 0.13 \\
Familiar & 0.13 & 0.42 \\
Larger Risk & -0.10 & 0.63 \\
Government Effectiveness & -0.41 & 0.28 \\
Household Income $\times$ Log of Risk & $0.20 *$ & 0.09 \\
Reduction & $-0.12^{* *}$ & 0.05 \\
Household Income $\times$ Public Provision & 0.083 & 0.25 \\
Household Size & N=726, -2LL=2535836, LLR=633131.47, Wald=82.41 \\
\hline *,** *** indicate $p$-values <0.1, 0.05, and 0.01, respectively.
\end{tabular}

Table 3.6: Coefficient Estimates for Asthma 


\begin{tabular}{l|c|c}
\hline \multicolumn{1}{c|}{ Independent Variables } & Coefficient & Prob>ChiSq \\
\hline Intercept & -0.72 & 0.58 \\
Log of Bid Price & $-0.47^{* * *}$ & 0.00 \\
Education Years & 0.049 & 0.43 \\
Public Insurance & -0.34 & 0.38 \\
Asthma Symptom & 0.67 & 0.12 \\
Log of Risk Reduction & $1.19^{* * *}$ & 0.01 \\
Asthma Believe & $1.16^{* * *}$ & 0.01 \\
Public Provision & 0.86 & 0.21 \\
Household income & -0.052 & 0.36 \\
Familiar & -0.064 & 0.86 \\
Larger Risk & 0.60 & 0.18 \\
Government Effectiveness & -0.73 & 0.23 \\
Household Income $\times$ Public Provision & -0.11 & 0.11 \\
Household Size & 0.00045 & 1.00 \\
\hline N=159, -2LL=568201.28, LLR=384902.60 , Wald=51.57 \\
*,**,*** indicate $p$-values <0.1, 0.05, and 0.01, respectively.
\end{tabular}

Table 3.7: Coefficient Estimates for Asthma (Household Income >30,000) 


\begin{tabular}{l|c|c}
\hline \multicolumn{1}{c|}{ Independent Variables } & Coefficient & Prob>ChiSq \\
\hline Intercept & -2.08 & 0.31 \\
Log of Bid Price & $-0.58^{* *}$ & 0.03 \\
Education Years & 0.16 & 0.12 \\
Public Insurance & $-1.23^{*}$ & 0.06 \\
Asthma Symptom & $1.16^{* *}$ & 0.03 \\
Log of Risk Reduction & $1.79^{* * *}$ & 0.00 \\
Asthma Believe & $1.50^{* * *}$ & 0.01 \\
Public Provision & 1.41 & 0.19 \\
Household income & 0.0079 & 0.89 \\
Familiar & 0.28 & 0.67 \\
Larger Risk & 0.27 & 0.63 \\
Government Effectiveness & -0.17 & 0.88 \\
Household Income $\times$ Public Provision & $-0.20 * *$ & 0.05 \\
Household Size & -0.27 & 0.39 \\
\hline N=98 , -2LL=323275.80, LLR=439408.30, Wald=59.90 \\
*,**,*** indicate $p$-values <0.1, 0.05, and 0.01, respectively.
\end{tabular}

Table 3.8: Coefficient Estimates for Asthma (Household Income $\mathbf{4 0 , 0 0 0 )}$ 


\begin{tabular}{|c|c|c|}
\hline Independent Variables & Coefficient & Prob $>$ ChiSq \\
\hline Intercept & 0.23 & 0.72 \\
\hline Log of Bid Price & $-0.43 * * *$ & 0.00 \\
\hline Education Years & $0.073 * * *$ & 0.00 \\
\hline Public Insurance & 0.04 & 0.88 \\
\hline Asthma Symptom & -0.019 & 0.94 \\
\hline Log of Risk Reduction & -0.07 & 0.84 \\
\hline Asthma Believe & $0.73 * * *$ & 0.00 \\
\hline Public Provision & 0.74 & 0.30 \\
\hline Household income & -0.19 & 0.22 \\
\hline Familiar & 0.10 & 0.53 \\
\hline Larger Risk & -0.09 & 0.62 \\
\hline Government Effectiveness & -0.41 & 0.25 \\
\hline Household Income $\times$ Log of Risk & 0.19 & 0.19 \\
\hline Reduction & & \\
\hline Household Income $\times$ Public Provision & -0.099 & 0.64 \\
\hline Household Size & 0.077 & 0.30 \\
\hline Public Provision $\times$ Log of Risk & -0.57 & 0.35 \\
\hline Reduction & & \\
\hline Public Provision × Household & -0.017 & 0.93 \\
\hline Income $\times$ Log of Risk Reduction & & \\
\hline \multicolumn{3}{|c|}{$\mathrm{N}=726,-2 \mathrm{LL}=2512614.6, \mathrm{LLR}=656352.63, \mathrm{Wald}=80.67$} \\
\hline
\end{tabular}

$*, * *, * * *$ indicate $p$-values $<0.1,0.05$, and 0.01 , respectively.

Table 3.9: Coefficient Estimates for Asthma 


\begin{tabular}{l|c|c}
\hline \multicolumn{1}{c|}{ Independent Variables } & Coefficient & Prob>ChiSq \\
\hline Intercept & $1.31^{* * *}$ & 0.01 \\
Log of Bid Price & $-0.63^{* * *}$ & 0.00 \\
Education Years & $0.057^{*}$ & 0.07 \\
Public Insurance & $-0.36^{*}$ & 0.09 \\
Asthma Believe & $0.56^{* *}$ & 0.03 \\
Public Provision & $1.19^{* * *}$ & 0.01 \\
Household income & -0.03 & 0.72 \\
Familiar & -0.30 & 0.12 \\
Larger Risk & 0.014 & 0.96 \\
Government Effectiveness & -0.50 & 0.18 \\
Household Income $\times$ Public Provision & -0.12 & 0.27 \\
Household Size & -0.021 & 0.81 \\
Ordering Effect & $-0.41^{*}$ & 0.06 \\
\hline N=478, -2LL=1611396, LLR=601470.48, Wald=90.38 \\
*, **, *** indicate $p$-values <0.1, 0.05, and 0.01, respectively.
\end{tabular}

Table 3.10: Within-Group Regression Estimates for Asthma

\begin{tabular}{l|c|c}
\hline Stated Preference of Provision Mechanism & $\begin{array}{c}\text { Number of } \\
\text { Respondents }\end{array}$ & $\begin{array}{c}\text { Percentage } \\
\text { \% }\end{array}$ \\
\hline Public/Government Provision & 123 & 42.27 \\
Private Provision & 69 & 23.71 \\
Indifference & 93 & 31.96 \\
Don't know and Missing Value & 6 & 2.06 \\
\hline Total Number of Respondents Asked & 291 & \\
\hline
\end{tabular}

Table 3.11: Provision Preference for Asthma 


\begin{tabular}{|c|c|c|c|}
\hline \multirow[t]{2}{*}{ Variables } & \multirow[t]{2}{*}{ Definition } & \multicolumn{2}{|c|}{$\begin{array}{c}\text { Mean } \\
\text { (Std. Deviation) }\end{array}$} \\
\hline & & Unweighted & Weighted \\
\hline Log of Bid Price & $\begin{array}{l}\text { Natural log of the bid price assigned } \\
\text { to each respondent }\end{array}$ & $\begin{array}{c}3.18 \\
(1.12)\end{array}$ & $\begin{array}{c}3.24 \\
(1.16)\end{array}$ \\
\hline Education & Education years received by & 10.96 & 11.26 \\
\hline Years & respondent & $(3.84)$ & (3.99) \\
\hline Public & Dummy variable equal to 1 if the & 0.60 & 0.67 \\
\hline Insurance & $\begin{array}{l}\text { respondent has some form of public } \\
\text { health insurance }\end{array}$ & $(0.49)$ & $(0.47)$ \\
\hline Log Mortality & Natural log of the mortality risk & 1.69 & 1.68 \\
\hline Risk Reduction & $\begin{array}{l}\text { reduction amount per } 10,000 \text { offered } \\
\text { to each respondent, i.e., } \log (3), \log (5) \\
\text { or } \log (10)\end{array}$ & $(0.49)$ & $(0.46)$ \\
\hline $\begin{array}{l}\text { Mortality } \\
\text { Believe }\end{array}$ & $\begin{array}{l}\text { Dummy variable equal to } 1 \text { if } \\
\text { respondent believes the stated } \\
\text { scenario of mortality risk reduction is } \\
\text { realistic }\end{array}$ & $\begin{array}{c}0.61 \\
(0.49)\end{array}$ & $\begin{array}{c}0.57 \\
(0.50)\end{array}$ \\
\hline Household Size & $\begin{array}{l}\text { Number of people living in the } \\
\text { household }\end{array}$ & $\begin{array}{c}2.96 \\
(1.14)\end{array}$ & $\begin{array}{c}3.22 \\
(1.17)\end{array}$ \\
\hline $\begin{array}{l}\text { Household } \\
\text { Income }\end{array}$ & $\begin{array}{l}\text { Annual household income divided by } \\
10000 \text { (yuan) }\end{array}$ & $\begin{array}{l}2.23 \\
(2.80)\end{array}$ & $\begin{array}{c}3.31 \\
(4.63)\end{array}$ \\
\hline Public Provision & $\begin{array}{l}\text { Dummy variable equal to } 1 \text { if } \\
\text { respondent was randomized into the } \\
\text { group in which public provision } \\
\text { scenario was provided in the first } \\
\text { WTP question (version } 2 \text { and } 4 \text { ) }\end{array}$ & $\begin{array}{c}0.36 \\
(0.48)\end{array}$ & $\begin{array}{c}0.40 \\
(0.49)\end{array}$ \\
\hline $\begin{array}{l}\text { Government } \\
\text { Effectiveness }\end{array}$ & $\begin{array}{l}\text { Dummy variable equal to } 1 \text { if } \\
\text { respondent of version } 2 \text { and } 4 \text { thinks } \\
\text { that the public provision of treatments } \\
\text { by government would be efficient }\end{array}$ & $\begin{array}{c}0.23 \\
(0.42)\end{array}$ & $\begin{array}{c}0.29 \\
(0.45)\end{array}$ \\
\hline $\begin{array}{c}\text { Household } \\
\text { Income } \times \text { LMRR }\end{array}$ & $\begin{array}{l}\text { Household income multiplied by the } \\
\text { log of the mortality risk reduction } \\
\text { amount per } 10,000\end{array}$ & $\begin{array}{l}3.87 \\
(4.50)\end{array}$ & $\begin{array}{c}5.25 \\
(6.04)\end{array}$ \\
\hline $\begin{array}{l}\text { Household } \\
\text { Income } \times \text { Public } \\
\text { Provision }\end{array}$ & $\begin{array}{l}\text { Household income multiplied by the } \\
\text { dummy variable of public provision }\end{array}$ & $\begin{array}{c}0.85 \\
(2.12)\end{array}$ & $\begin{array}{c}1.65 \\
(4.59)\end{array}$ \\
\hline $\mathbf{N}$ & Sample Size & 741 & 741 \\
\hline
\end{tabular}

Table 3.12: Independent Variable Statistics for the Mortality Model 


\begin{tabular}{c|c|c|c}
\hline \multirow{2}{*}{ Bid price (yuan) } & \multicolumn{2}{|c|}{ Yes Rate } & \multirow{2}{*}{ N } \\
\cline { 2 - 3 } & Unweighted & Weighted & \\
\hline 5 & $77.78 \%$ & $84.11 \%$ & 189 \\
15 & $65.84 \%$ & $58.67 \%$ & 161 \\
40 & $57.14 \%$ & $49.21 \%$ & 203 \\
100 & $40.43 \%$ & $48.52 \%$ & 188 \\
\hline
\end{tabular}

Table 3.13: Bid Vectors and Percentage of People Saying “yes” to the Bid for Stated Risk Reduction of Mortality

\begin{tabular}{|c|c|c|}
\hline Independent Variables & Coefficient & Prob $>$ ChiSq \\
\hline Intercept & $1.22 * *$ & 0.03 \\
\hline Log of Bid Price & $-0.35 * * *$ & 0.00 \\
\hline Education Years & -0.0066 & 0.81 \\
\hline Public Insurance & 0.18 & 0.35 \\
\hline Log of Risk Reduction & -0.32 & 0.22 \\
\hline Mortality Believe & $1.02 * * *$ & 0.00 \\
\hline Public Provision & $-0.40 *$ & 0.08 \\
\hline Household Income & -0.063 & 0.52 \\
\hline Government Effectiveness & $0.54 *$ & 0.07 \\
\hline Household Income $\times$ Log of Risk & 0.069 & 0.39 \\
\hline Reduction & & \\
\hline Household Size & 0.00077 & 0.99 \\
\hline Rural registration & 0.30 & 0.21 \\
\hline Rural registration $\times$ Public Provision & $-1.02 * *$ & 0.02 \\
\hline \multicolumn{3}{|c|}{$\mathrm{N}=741,-2 \mathrm{LL}=2434102.80, \mathrm{LLR}=729174.11, \mathrm{Wald}=87.53$} \\
\hline
\end{tabular}

Table 3.14: Coefficient Estimates for Mortality 


\begin{tabular}{l|c|c}
\hline \multicolumn{1}{c|}{ Independent Variables } & Coefficient & Prob>ChiSq \\
\hline Intercept & 0.79 & 0.17 \\
Log of Bid Price & $-0.33^{* * *}$ & 0.00 \\
Education Years & -0.00048 & 0.99 \\
Public Insurance & 0.19 & 0.33 \\
Log of Risk Reduction & -0.11 & 0.66 \\
Mortality Believe & $1.03^{* * *}$ & 0.00 \\
Public Provision & -0.13 & 0.84 \\
Household income & 0.039 & 0.33 \\
Government Effectiveness & $0.51^{*}$ & 0.09 \\
Household Size & 0.0037 & 0.96 \\
Public Provision $\times$ Log of Risk Reduction & -0.17 & 0.66 \\
Rural Registration & 0.28 & 0.23 \\
Rural registration $\times$ Public Provision & $-0.98 * *$ & 0.02 \\
\hline N=741, -2LL=2442146.10, LLR=721130.90, Wald=82.94
\end{tabular}

$\mathrm{N}=741,-2 \mathrm{LL}=2442146.10, \mathrm{LLR}=721130.90$, Wald=82.94

$*, * *, * * *$ indicate $p$-values $<0.1,0.05$, and 0.01 , respectively.

Table 3.15: Coefficient Estimates for Mortality 


\begin{tabular}{l|c|c}
\hline \multicolumn{1}{c|}{ Independent Variables } & Coefficient & Prob>ChiSq \\
\hline Intercept & $1.35^{* *}$ & 0.03 \\
Log of Bid Price & $-0.49^{* * *}$ & 0.00 \\
Education Years & 0.033 & 0.23 \\
Public Insurance & $-0.48^{* *}$ & 0.05 \\
Log of Risk Reduction & 0.27 & 0.30 \\
Mortality Believe & $0.70^{* * *}$ & 0.00 \\
Public Provision & 0.18 & 0.41 \\
Household income & 0.018 & 0.81 \\
Government Effectiveness & $0.52^{*}$ & 0.07 \\
Household Size & $-0.23^{* * *}$ & 0.00 \\
Ordering Effect & 0.085 & 0.71 \\
Rural Registration & $-0.57^{*}$ & 0.09 \\
Rural registration $\times$ Public Provision & -0.81 & 0.16 \\
\hline N-498, -2LL=1547126.90, LLR=398940.13, Wald=69.82
\end{tabular}

$\mathrm{N}=498,-2 \mathrm{LL}=1547126.90, \mathrm{LLR}=398940.13$, Wald=69.82

$*$, **, $* * *$ indicate $p$-values $<0.1,0.05$, and 0.01 , respectively.

Table 3.16: Within-Group Regression Estimates for Mortality

\begin{tabular}{l|c|c}
\hline Stated Preference of Provision Mechanism & $\begin{array}{c}\text { Number of } \\
\text { Respondents }\end{array}$ & $\begin{array}{c}\text { Percentage } \\
\text { \% }\end{array}$ \\
\hline Public/Government Provision & 138 & 43.53 \\
Private Provision & 77 & 24.29 \\
Indifference & 98 & 30.91 \\
Don't know and Missing Value & 4 & 1.26 \\
\hline Total Number of Respondents Asked & 317 & \\
\hline
\end{tabular}

Table 3.17: Provision Preference for Mortality 


\section{CHAPTER 4}

\section{CONCLUSIONS, IMPLICATIONS AND EXTENSIONS}

The purpose of this dissertation is to value the air-pollution-related health risks in China. Utilizing the compensating wage differential method and the contingent valuation method, I estimate the value of a statistical case of asthma and the value of a statistical life (VSL) in China. The median value of a statistical case of asthma estimated by the CV method is about 18,940 yuan (US\$2368). The VSL estimated by the CWD method in 1995 varies from about 12,000 to 120,000 US dollars. The median VSL estimated by the CV method is 189,960 yuan (US\$23,745). The lower bound of the CWD study is close to the estimate of the CV study.

Four possible reasons of the discrepancy of the estimated VSL of the CWD and CV studies are: (1) the fatality statistics reported by Chinese authority may understate the real fatality rates, so that the VSL from the wage study is over-estimated. (2) The jobrelated fatality happens mainly for some classes of the workers (e.g., unskilled workers or skilled plus unskilled workers). In this case, the by-industry fatality rate calculated by using the total number of fatality and the total number of workers in each industry understates the true fatality rate of the affected workers. (3) The survey data used in the wage differential study did not contain migrants from rural area to cities who might be 
more risk-taking than permanent urban residents, whereas my CV survey contains migrants in the sample. (4) There may be protest zeros and scenario rejections, which could not be differentiated from the survey sample, therefore the VSL from the CV study could be under-estimated. To detect and solve these potential problems, future study is needed.

Comparing to my results, World Bank (1997) reported a VSL of US\$60,000 in urban area of China transformed from contingent valuation result of U.S. Hammitt and Zhou (2006) reported an estimated mean VSL of US\$45,500 and median VSL of US\$16,300 estimated from the WTP responses in Beijing, and mean VSL of US\$29,400 and median VSL of US\$4,220 in Anqing, by a contingent valuation study in 1999. Comparing these results to my results, it seems that the interval from 20,000 to 60,000 US dollars is credible and might be used by researchers and policy makers.

We can compare the estimated VSL for China with the VSL for U.S. and other countries. Viscusi and Aldy (2003) provided a comprehensive review of the wage differential method with more than 60 studies from ten countries. It shows that most estimated VSL from US data fall from 1 to 10 millions US dollars. Some studies based on non-US labor market data provide estimates as the following: UK, from 4 to 70 millions dollars; Canada, from 4 to 20 millions dollars; India, from 1 to 4 millions dollars; Japan, about 10 millions dollars; South Korea, about 0.8 million dollars; Taiwan, from 0.2 to 0.9 million dollars. Table 4.1 summarizes the estimated VSL and annual per capita income of China, Taiwan and US. The per capita income of Taiwan is about 13 times of China's, and the per capita income of U.S. is about 32 times of China's. The VSL estimate of Taiwan is about 10-13 times of the estimates of China; the VSL of US is 
about 45-150 times of the VSL of China. The income elasticity between China and Taiwan seems around 1, but the income elasticities between China and US and between Taiwan and US seem much larger. This suggests that the income elasticity between countries might not stay constant with the increasing income level. The difference of income elasticity may also be caused by different cultural backgrounds.

Besides the empirical estimates of the economic value of health risks, there are other important contributions of this dissertation to the literature of economic valuation of health risks and environment. First, the compensating wage study in this dissertation considers the limitation of the labor mobility in China and uses the province level unemployment rates as a negative proxy of opportunities workers facing. The result suggests that the trade-off between the on-the-job fatality risk and worker's wage is convexly decreasing with the unemployment rate. This result is consistent with the economic intuition that workers facing fewer opportunities or choices of jobs receive lower compensation for job-related risks.

Secondly, in the CV survey, I empirically test the hypothesis that public/government provision of health risk reduction would yield the same WTP as private provision does. This hypothesis is important both theoretically and practically. Previous literature states that people would have altruistic or 'warm glow' incentive while valuing a public good or a publicly provided good. If this incentive leads to a higher WTP for the public provision than for the private provision of the same good, it implies that different provision mechanisms of a good may change the result of the costbenefit analysis. I conclude that the public/government provision mechanism has no effect to the WTP for the asthma risk reduction; however it has a negative effect to the 
WTP for the mortality risk reduction; and altruistic or warm glow incentive is not a major factor affecting respondents' WTP to the publicly provided health risk reduction. The major factors are trust and the perceived effectiveness of respondents to the provision mechanisms.

To improve the economic valuation of health risks and environment in China, the following issues are important for researchers in this field. First, the availability of more accurate work-related fatality and injury statistics from the Chinese authority is critically important to the VSL estimate by the compensating wage differential method. Secondly, future studies using the compensating wage differential method should consider the possible effect of the imperfect labor market in China. Further theoretical studies on compensating wage in the imperfect labor market should also be done. Thirdly, using the contingent valuation method, future studies should make effort onto improving respondents understanding of the health risk probabilities. In-depth interview could be used to test the understanding and the effects of different tools (including visual aids, oral analogies and others) aiming to improve the understanding. 


\begin{tabular}{l|ll}
\hline Country or Region & $\begin{array}{l}\text { Income (annual per capita } \\
\text { 2002) }\end{array}$ & VSL \\
\hline China & $\begin{array}{l}\text { US } \$ 960 \text { (Urban Resident, } \\
\text { disposable) }\end{array}$ & US $\$ 20,000-60,000$ \\
Taiwan & US\$14,000 & US $\$ 0.2-0.9$ million \\
U S & US\$30,906 & US\$1-10 million \\
\hline
\end{tabular}

Table 4.1: Comparison of VSL and Per Capita Income 


\section{BIBLIOGRAPHY}

Alberini A., M. Cropper, T. Fu, A. Krupnick, J. Liu, D. Shaw and W. Harrington (1997). "Valuing Health Effects of Air Pollution in Developing Countries: the Case of Taiwan", Journal of Environmental Economics and Management, 34, 107-126.

Andreoni, J. (1988). "Privately Provided Public Goods in a Large Economy: the Limits of Altruism”, Journal of Public Economics, 35:57-73.

Andreoni, J. (1990). "Impure Altruism and Donations to Public Goods: a Theory of Warm-Glow Giving”, The Economic Journal, 100, 464-477.

Andreoni, J. and Miller, J. (2002). "Giving According to GARP: An Experimental Test for the Consistency of Preferences for Altruism”, Econometrica, v70, iss. 2, 737-53.

Arrow, K., R. Solow, P. R. Portney, E. E. Leamer, R. Radner and H. Schuman (1993). "Report of the NOAA Panel on Contingent Valuation”, Federal Register, 58, 4601-14.

Bai, M and Z. Zhang (2002). “Analysis on WTP of Residents in Beijing for Air Pollution”, unpublished paper.

Baron, J. (1997). “Confusion of Relative and Absolute Risk in Valuation”, Journal of Risk and Uncertainty, 14:301-309.

Becker, G., M. DeGroot, and J. Marschak (1964). "Measuring utility by a single-response sequential method,” Behavioral Science 8: 41-55.

Boyle K. J., M. P. Welsh and R. C. Bishop (1993). "The Role of Question Order and Respondent Experience in Contingent Valuation Studies", Journal of Environmental Economics and Management 25, S-80-S-99.

Brookshire D. S., M. A. Thayer, W. D. Schulze and R. C. d'Arge (1982). "Valuing Public Goods: a Comparison of Survey and Hedonic Approaches”, The American Economic Review, Vol. 72, No. 1, 165-177.

Calman, K. C. and G. H. D. Royston. (1997). "Risk Language and Dialects,” British Medical Journal 315, 939-942.

Carson, R. T. (1997). "Contingent Valuation: Theoretical Advances and Empirical Tests since the NOAA Panel”, American Journal of Agricultural Economics, 79(5): 1501-07. 
Carson, R. T. (2004). Contingent Valuation: A Comprehensive Bibliography and History, Edward Elgar Publishers, Cheltenham, UK.

Carson, R. T., T. Groves and M. Machina (2000). "Incentive and Informational Properties of Preference Questions,” University of California, San Diego, Department of Economics Working Paper.

Carson R.T., R. C. Mitchell, M. Hanemann, R. Kopp, S. Presser and P. A. Ruud (2003). "Contingent Valuation and Lost Passive Use: Damages from the Exxon Valdez Oil Spill”, Environmental and Resource Economics 25: 257-286.

Carson R. T, M. C. Robert (1993). “The Value of Scope in Contingent Valuation Studies”, American Journal of Agricultural Economics, 75, 1993.

Carson R. T, N. E. Flores and N. F. Meade (2000). “Contingent Valuation: Controversies and Evidence”, Discussion paper 96-36R, University of California, San Diego, 2000.

Carson R. T. and R. C. Mitchell (1993). “The Value of Clean Water: the Public’s Willingness to Pay for Boatable, Fishable and Swimmable Quality Water”, Water Resources Research, Vol. 29, No. 7, 2445-2454, July 1993.

Carson R. T. and R. C. Mitchell (1993).’'The Issue of Scope in Contingent Valuation Studies, New Work on the Benefits of Environmental Regulation” (Albert McGartland, USEPA, presiding), American Journal of Agricultural Economics 75: 1263-1267, 1993.

Clarke, E. H. (1971). “Multipart Pricing of Public Goods”, Public Choice, 11:17-33.

Cornes, R. (1993). "Dyke Maintenance and Other Stories: Some Neglected Types of Public Goods”, The Quarterly Journal of Economics, Vol. 108, No.1, 259-271, 1993.

Corso, P., J. K. Hammitt, J. Graham (2001). "Valuing Mortality-Risk Reduction: Using Visual Aids to Improve the Validity of Contingent Valuation”, Journal of risk and uncertainty, 23:2, 165-184.

Crenson, M. A. (1971). The Un-Politics of Air Pollution: A Study of Non-decisonmaking in the Cities, Baltimore, The Johns Hopkins University Press.

Cummings, R. G., L. A. Cox, A. M. Freeman (1986). "General Methods for Benefits Assessment”, Benefits Assessment: The State of the Art, pp. 161-191. Technology, Risk and Society: An International Series in Risk Analysis Dordrecht; Boston; Lancaster and Tokyo: Kluwer Academic, Reidel.

Curtis, J. A. and K. E. McConnell (2002). “The Citizen versus Consumer Hypothesis: Evidence from a Contingent Valuation Survey”, The Australian Journal of Agricultural and Resource Economics 46:1, 69-83. 
Davis, J., D. Bercheva, K. Komives and D. Whittington (1996). "Household Water Supply Conditions and Willingness to Pay for Improved Services in Odessa, Ukraine (with Implications for Serving the Poor)”. A Report to the World Bank. October, 74 pp.

Delucchi, M. A., J. J. Murphy and D. R. McCubbin (2002). "The Health and Visibility Cost of Air Pollution: A Comparison of Estimation Methods”, Journal of Environmental Management 64, 139-152.

Desvousges, W. H. (1993). "Measuring Natural Resource Damages with Contingent Valuation: Tests of Validity and Reliability”, Contingent valuation: A critical Assessment, pp. 91-159, Contributions to Economic Analysis, vol. 220. Amsterdam; London and Tokyo: North-Holland; distributed in the U.S. and Canada by Elsevier Science, New York.

Diamond P. and Hausman J. (1994). “Contingent Valuation: Is Some Number Better Than No Number?” Journal of Economic Perspectives 8, 45-64.

Diamond, P. (1996). “Testing the Internal Consistency of Contingent Valuation Surveys”, Journal of Environmental Economics and Management 30, 337-347.

Diener, A., B. O’Brien and A. Gafni (1998). "Health Care Contingent Valuation Studies: A Review and Classification of the Literature”, Health Economics 7:313-326.

Dorsey, S. (1983). "Employment Hazards and Fringe Benefits: Further Tests for Compensating Differentials.” In J.D. Worrall (ed.), Safety and the Workforce: Incentives and Disincentives in Workers’ Compensation. Ithaca, NY: ILR Press, pp. 87-102.

Dorman, P. (1996). Markets and Mortality: Economics, Dangerous Work and the Value of Human Life. Cambridge: New York and Melbourne: Cambridge University Press.

Gibbard, A. (1973). "Manipulation of Voting Schemes: A General Result,” Econometrica, 41(4): 587-601.

Giles, J., A. Park and J. Zhang (2005). "What is China's True Unemployment Rate?” China Economic Review, 16 (2005), 149-170.

Green, D., K. Jacowitz, D. Kahnemann, and D. McFadden (1998). "Referendum contingent valuation, anchoring and willingness to pay for public goods,” Resource and Energy Economics, 20: 85-116.

Groothuis, P. A. and G. Miller (1997). "The Role of Social Distrust in Risk-Benefit Analysis”, Journal of Risk and Uncertainty 15: 241-57.

Groves, T. (1973). “Incentives in Teams”, Econometrica, 41(4):617-31. 
Groves, T. and J. O. Ledyard (1977). "Optimal Allocation of Public Goods: A Solution to the ‘Free Rider’ Problem”, Econometrica, 45(4): 783-809.

Groves, T. and M. Loeb (1975). "Incentives and Public Inputs”, Journal of Public Economics, 4(3): 211-26.

Guo X. and T. C. Haab (2003). "Incentive Compatibility of Referendum and Open-Ended Value Elicitation Surveys”, working paper.

Haab, T. C. and K. E. McConnell (2002). Valuing Environmental and Natural Resources: The Econometrics of Non-Market Valuation, Edward Elgar.

Haab, T. C. (1999). "Nonparticipation or Misspecification? The Impacts of Nonparticipation on Dichotomous Choice Contingent Valuation”, Environmental and Resource Economics, 14(4): 443-61.

Haab, T. C., J-C Huang, and J. C. Whitehead (1999). “Are Hypothetical Referenda Incentive Compatible? A Comment,” Journal of Political Economy, 107(1): 186-96.

Haab, T. C. and K. E. McConnell (1998). "Referendum Models and Economic Values: Theoretical, Intuitive, and Practical Bounds on Willingness to Pay,” Land Economics, 74(2): 216-29.

Hakes, J. and W. K. Viscusi (1997). "Mortality Risk Perceptions: A Bayesian Reassessment”, Journal of Risk and Uncertainty, 15:135-150.

Hanemann, M. (1994). "Valuing the Environment through Contingent Valuation”, Journal of Economic Perspectives 8, 19-43.

Hammitt, J. K. (1986). Estimating Consumer Willingness to Pay to Reduce Food-Borne Risk, R-3447-EPA, Santa Monica, CA: RAND Corporation.

Hammitt, J. K. (1990). "Risk Perceptions and Food Choice: An Exploratory Analysis of Organic- Versus Conventional-Produce Buyers,” Risk Analysis 10, 367-374.

Hammitt, J. K. (2000). "Evaluating Contingent Valuation of Environmental Health Risks: the Proportionality Test", Association of Environmental and Resource Economists Newsletter 20(1):14-19, May 2000.

Hammitt, J. K. and J. Graham (1999). "Willingness to Pay for Health Protection: Inadequate Sensitivity to Probability?”, Journal of Risk and Uncertainty, 8:33-62.

Hammitt, J. K., J-T Liu and J-L Liu (2000). "Survival is a Luxury Good: The Increasing Value of a Statistical Life”, working paper. 
Hammitt, J. K. and Y. Zhou (2006). “The Economic Value of Air-Pollution-Related Health Risks in China: A Contingent Valuation Study”, Environmental and Resource Economics (2006) 33: 399-423.

Haninger, K. and J. K. Hammitt (2006). "Willingness to Pay for Quality-Adjusted Life Years: Empirical Inconsistency between Cost-Effectiveness Analysis and Economic Welfare Theory”, working paper.

Hidano, N. (2002). "The Economic Valuation of the Environment and Public Policy: A Hedonic Approach”, Edward Elgar.

Hirshleifer, J. (1983). "From Weakest-Link to Best-Shot: the Voluntary Provision of Public Goods”, Public Choice 41:371-386.

Hoehn, J. P. and A. Randall (1987). “A Satisfactory Benefit Cost Indicator from Contingent Valuation”, Journal of Environmental Economics and Management 14, 22647.

Hudson J. and P. Jones (1995). “The Importance of the 'Ethical Voter': An Estimate of 'Altruism”, The Economics of Altruism, pp.196-205, Elgar Reference Collection. International Library of Critical Writings in Economics, vol. 48. Aldershot, U.K.: Elgar; distributed in the U.S. by Ashgate, Brookfield, Vt.

Isaac R. and J. M. Walker (1988). "Communication and Free-Riding Behavior: The Voluntary Contribution Mechanism”, Economic Inquiry, 26(4):585-608.

Isaac R. and J. M. Walker (1988). "Group Size Effects in Public Goods Provision: The Voluntary Contributions Mechanism”, Quarterly Journal of Economics, 103(1): 197-99.

Johansson, O. (1997). “Optimal Pigovian Taxes under Altruism”, Land Economics 73: 297-308.

Johnson F. R., E. E. Fries, and H. S. Banzhaf (1997). "Valuing Morbidity: An Integration of the Willingness-to-Pay and Health-Status Index Literatures," Journal of Health Economics, 16:641-665.

Jones-Lee M. W., M. Hammerton and P. R. Philips (1985). "The Value of Safety: Results of National Sample Survey”, The Economic Journal, 95, 49-72, 1985.

Kahneman, D. and J. L. Knetsch (1992). "Valuing Public Goods: The Purchase of Moral Satisfaction”, Journal of Environmental Economics and Management 22, 57-70.

Kahneman, D., and A. Tversky (1979). "Prospect Theory: an Analysis of Decision under Risk”, Econometrica. Vol 47, No. 2, 263-292. 
Kaplan, R. M., J. P. Anderson, and T. G. Ganiats (1993). “The Quality of Well-Being Scale: Rationale for a Single Quality of Life Index,” in Walker, S. R. and R. M. Rosser (eds.), Quality of Life Assessment: Key Issues in the 1990s, Kluwer, Dordrecht.

Kenkel, D., M. Berger and G. Blomquist (1995). “Contingent Valuation of Health”, in Tolley, G., D. Kenkel and R. Fabian (eds.), Valuing Health for Policy (1994), The University of Chicago Press, Chicago and London.

Kish, L. (1965). Survey Sampling, John Wiley and Sons, Inc.

Kunreuther, H., R. Ginsberg, L. Miller, P. Sagi, P. Slovic, B. Borkan, and N. Katz, (1978). Disaster Insurance Protection: Public Policy Lessons. New York: John Wiley and Sons.

Landry, R and M. Shen. (2003). "Reaching Migrants in Survey Research: The Use of the Global Positioning System to reduce coverage bias in China”, Working Paper.

Lauria, D. T., D. Whittington and K. Choe (1999). "Household Demand for Improved Sanitation Services: A Case Study of Calamba, Philippines”, in Ken Willis and Ian Bateman, (eds.), Valuing Environmental Preferences: Theory and Practice of the Contingent Valuation Method in the US, EU and Developing Countries. Oxford University Press, pp. 540-581.

Leigh, J. P. (1995). “Compensating Wage, Value of a Statistical Life, and Inter-industry Differentials”, Journal of Environmental Economics and Management, v28: 83-97.

Lipton, D. W., K Wellman, Isobel C. S. and R. F. Weiher. "Economic Valuation of Natural Resources: A Guidebook for Costal Resources Policymakers”, NOAA Coastal Ocean Program Decision Analysis Series No. 5.

Loehman, E. T., S. V. Berg, A. A. Arroyo, R. A. Hedinger, J. M. Schwartz, M. E., Shaw, R. W., Fahien, V. H. De, R. P. Fishe, D. E. Rio, W. R. Rossley and A. E. Green (1979). "Distributional Analysis of Regional Benefits and Cost of Air Quality Control”, Journal of Environmental Economics and Management 6: 222-43.

Liu, J-T, J. K. Hammitt and J-L Liu (1997). "Estimated Hedonic Wage Function and Value of Life in a Developing Country”, Economics Letters 57: 353-358.

Liu, J-T and J. K. Hammitt (1999). "Perceived Risk and Value of Workplace Safety in a Developing Country”, Journal of Risk Research 2(3): 263-275.

Marwell, G. and R. E. Ames (1979). "Experiments on the Provision of Public Goods, I. Resources, Interest, Group Size, and the Free Rider Problem”, American Journal of Sociology, 84: 1335-60. 
Marwell, G. and R. E. Ames (1981). "Economists Free Ride, Does Anyone Else? Experiments on the Provision of Public Goods, IV”, Journal of Public Economics, 15(3): 295-310.

McConnell, K. E. (1997). “Does Altruism Undermine Existence Value?”, Journal of Environmental Economics and Management 32, 22-37.

Milgron, P. (1993). "Is Sympathy an Economic Value? Philosophy, Economics and the Contingent Valuation Method”, in Hausman, J. A. (eds), Contingent Valuation: A Critical Assessment, (1993), North-Holland.

Mitchell, R. C. and R. T. Carson (1986). "Valuing Drinking Water Risk Reductions Using the Contingent Valuation Method: A Methodological Study of Risks from THM and Giardia”, report to US. EPA, Washington, D. C.

Mitchell, R. C. and R. Carson (1989). Using Surveys to Value Public Goods: The Contingent Valuation Method, Resources for the Future, Washington, DC.

National Bureau of Statistics, P. R. C. (2003). China Labor Statistical Yearbook, China Statistics Press, Beijing, China.

National Bureau of Statistics, P. R. C. (2003). China Statistical Yearbook, China Statistics Press, Beijing, China.

Opschoor J. B and D. W. Pearce (1991). Persistent Pollutants: Economics and Policy, Kluwer Academic Publishers.

Pattanayak, S., D. Whittington, J. Yang and B. Kumar (2002). "Willingness to Pay for Improved Water Supply in Kathmandu Valley, Nepal. Research Traingle Institute”, Final Report to the Water and Sanitation Program for South Asia, New Dehli: World Bank, August, 2001.

Portney, P. (1994). “The Contingent Valuation Debate: Why Economists Should Care”, Journal of economic perspectives, 8, 3-17, 1994.

Park, J. H. (2003). “A test of the Answering Mechanisms of the Double-Bounded Contingent Valuation Method”, Applied Economics Letters, 2003, 10, 975-984.

Portney P. R. and R. N. Stavins (2000). Public Policies for Environmental Protection, Second Edition, Resources for the Future, Washington, DC.

Purse, K. (2004). “Work-Related Fatality Risks and Neoclassical Compensating Wage Differentials”, Cambridge Journal of Economics.2004, 28,597-617.

Quiggin, J. (1982). “A Theory of Anticipated Utility”, Journal of Economic Behavior and Organization, 3(4): 323-43. 
Quiggin, J. (1998). "Existence Value and the Contingent Valuation Method”, Australian Economic Papers (September): 312-29.

Riskin, C., R. Zhao, and S. Li (2000). CHINESE HOUSEHOLD INCOME PROJECT, 1995 [Computer file]. ICPSR version. Amherst, MA: University of Massachusetts, Political Economy Research Institute [producer], 2000. Ann Arbor, MI: Inter-university Consortium for Political and Social Research [distributor].

Rosen, S. (1974). "Hedonic Prices and Implicit Markets: Product Differentiation in Pure Competition,” Journal of Political Economy 82, 34-55.

Row, R. D. and L. G. Chestnut (1984). "Valuing Changes in Morbidity: Willingness to Pay versus Cost of Illness Measure”. Report to Energy and Resources Consultants, Boulder, CO, December.

Russell, C. S., T. B. Bjorner and C. D. Clark (2001). "Searching for Evidence of Alternative Preferences, Public as Opposed to Private”, working papers of Vanderbilt University.

Satterthwaite, M. (1975). “Strategy-Proofness and Arrow’s Conditions: Existence and Correspondence Theorems for Voting Procedures and Social Welfare Functions,” Journal of Economic Theory, 10: 187-217.

Siebert, W. S. and X. Wei (1998). "Wage Compensating for Job Risks: the Case of Hong Kong”, Asian Economic Journal, Vol. 12, No. 2, 171-181.

Schiff, J. (1990). “Charitable Giving and Government Policy: An Economic Analysis”, Contributions in Economics and Economic History no. 102, Greenwood Press.

Smil, V. (1996). "Environmental Problems in China: Estimates of Economic Costs", East-West Center Special Report NO. 5, April 1996.

Smith, A. (1776). The Wealth of Nations. Chicago: University of Chicago Press. 1976 edition.

Smith, V. K. and W. H. Desvousges (1987). “An Empirical Analysis of the Economic Value of Risk Changes,” Journal of Political Economy 95, 89-114.

Smith, V. K. and L. Osborne (1996). "Do Contingent Valuation Estimates Pass a 'Scope' Test? A Meta Analysis”, working paper, 1996.

Smith, V. K. (1980). "Experiments with a Decentralized Mechanism for Public Good Decisions” American Economic Review, 70: 584-99. 
State Administration of Work Safety and State Administration of Coal Mine Industry, P. R. C. (2000-2002). China’s Work Safety Yearbook, Coal Mine Industry Press, Beijing.

Sugden, R. (1999). "Public Goods and Contingent Valuation”, in Bateman, I. and K. G. Willis (eds.) Valuing Environmental Preferences: Theory and Practice of the Contingent Valuation Method in the US, EU and Developing Countries, Oxford University Press.

Sugden, R. (1984). "Reciprocity: the Supply of Public Goods through Voluntary Contribution”, Economic Journal, 94:772-87.

Tolley, G., D. Kenkel and R. Fabian (eds.) (1994). Valuing Health for Policy, The University of Chicago Press, Chicago and London.

Tversky A. and D. Hahneman (1992). “Advances in Prospect Theory: Cumulative Representation of Uncertainty”, Journal of Risk and Uncertainty, 5(4): 297-323.

Viscusi, W. K. (1980). "Union, Labor Market Structure, and the Welfare Implications of the Quality of Work,” Journal of Labor Research 1(1), 175-192.

Viscusi, W. K. (2003). "Racial Differences in labor Market Values of a Statistical Life," Journal of Risk and Uncertainty, 27:3; 239-256.

Viscusi, W. K. and J. A. Aldy (2003). "The Value of a Statistical Life: A Critical Review of Market Estimates Throughout the World”, Journal of Risk and Uncertainty, 27:1:5-76.

Viscusi, W. K., J. Hakes and A. Carlin (1997). “Measure of Mortality risks”, Journal of risk and Uncertainty, 14:213-233.

Viscusi, W. K., Magat W. A, and Huber, J (1991). "Pricing Environmental Health Risks: Survey Assessment of Risk-Risk and Risk-Dollar Trade-offs for Chronic Bronchitis", Journal of Environmental Economics and Management 21: 32-51.

Whitehead, J., T. C. Haab and J. Huang (1997). "Part-Whole Bias in Contingent Valuation: Will Scope Effects Be Detected with Inexpensive Survey Methods?”, working paper, 1997.

Whittington, D. (2002). "Improving the Performance of Contingent Valuation Studies in Developing Countries”, Environmental and Resource Economics 22: 323-67.

Whittington, D., O. Matsui-Santana, J. Freiberger, G. van Houtven and S. Pattanayak (2001). “Individual's Willingness to Pay for a HIV/Aids Vaccine: Evidence for Guadalajara, Mexico”, Proceedings of the XIII International AIDS Conference. Duran, South Africa.

Whittington, D., V. K. Smith, A. Okorafor, A. Okore, J. L. Liu and A. McPhail (1992). "Giving Respondents Time to Think in Contingent Valuation Studies: A Developing 
Country Application”, Journal of Environmental Economics and Management 22, 205225.

World Bank (1997). Clear Water, Blue Skies: China's Environment in the New Century, World Bank, Washington, DC. 